University of Louisville

ThinkIR: The University of Louisville's Institutional Repository

Electronic Theses and Dissertations

$12-2019$

\title{
Campus recreation inclusion for people with disabilities: a qualitative investigation of current inclusive practices.
}

Tyler C. Spencer

University of Louisville

Follow this and additional works at: https://ir.library.louisville.edu/etd

Part of the Accessibility Commons, Disability Studies Commons, Leisure Studies Commons, and the Recreation, Parks and Tourism Administration Commons

\section{Recommended Citation}

Spencer, Tyler C., "Campus recreation inclusion for people with disabilities: a qualitative investigation of current inclusive practices." (2019). Electronic Theses and Dissertations. Paper 3313.

https://doi.org/10.18297/etd/3313

This Doctoral Dissertation is brought to you for free and open access by ThinkIR: The University of Louisville's Institutional Repository. It has been accepted for inclusion in Electronic Theses and Dissertations by an authorized administrator of ThinkIR: The University of Louisville's Institutional Repository. This title appears here courtesy of the author, who has retained all other copyrights. For more information, please contact thinkir@louisville.edu. 
CAMPUS RECREATION INCLUSION FOR PEOPLE WITH DISABILITIES: A QUALITATIVE INVESTIGATION OF CURRENT INCLUSIVE PRACTICES

\author{
By \\ Tyler C. Spencer \\ B.S. Western Kentucky University, 2009 \\ M.Ed. University of South Florida, 2011 \\ A Dissertation \\ Submitted to the Faculty of the \\ College of Education and Human Development of the University of Louisville \\ in Partial Fulfillment of the Requirements \\ for the Degree of \\ Doctor of Philosophy in Educational Leadership and Organizational Development \\ Department of Leadership, Foundations, and Human Resource Education \\ University of Louisville \\ Louisville, Kentucky
}

December, 2019 
Copyright 2019 by Tyler Clayton Spencer

All rights reserved 

CAMPUS RECREATION INCLUSION FOR PEOPLE WITH DISABILITIES: A QUALITATIVE INVESTIGATION OF CURRENT INCLUSIVE PRACTICES

By

Tyler C. Spencer

B.S. Western Kentucky University, 2009

M.Ed. University of South Florida, 2011

A Dissertation Approved on

November 25, 2019

By the following Dissertation Committee:

Mary A. Hums, Chair

T. Christopher Greenwell

Mary Brydon-Miller

Anita Moorman 


\section{DEDICATION}

This dissertation is dedicated to all the people of my past who helped me reach where I am at today and the people of the future that will help me get to be where I want to be. 


\section{ACKNOWLEDGMENTS}

I want to express my deepest gratitude to all those around me who have guided me throughout my doctoral process.

Dr. Mary Hums - No one has helped me more on this dissertation project than you. Without your expertise and dedication, there is no way I would have been able to complete this project.

Dr. Mary Brydon-Miller - As I have said to you previously, discussions with you always make me feel better. You have a true gift of mentorship and I appreciate your help in the completion of this project and my degree.

Dr. Chris Greenwell - To my coach. I say coach because you were never easy on me. You continually pushed me to be a better writer and scholar. I know I have failed you in the past (Greenlings), but your constant mockery has forced me to reach your high expectations.

Professor Anita Moorman - Thank you for your expertise and calming presence. Your influence and mentorship in regards to SRLA have allowed me to expand my network and thinking.

Dr. Fred Gibson - From day one you have been a person I have strived to emulate. I appreciate all your hard work in helping me develop as a campus recreation professional and scholar. 
Dr. Sarah Williams - The one person that has opened my eyes more than anyone else. We should not be friends, but our relationship has been built upon our differences. You are my friend for life, and I would do anything for you.

Dr. Sam Schmidt - The youngest person on this list and probably one of the wisest people I know. I hate that you are so much younger than me but have helped me develop as much as you have.

Dr. Meg Hancock - You were always available to me during my time at Louisville. Without you, I do not think I would have made it.

Dr. Marion Hambrick - Thank you for pushing me to get my first publication. I will strive to follow your example of being a great scholar.

Professor Gin Presley - My road trip buddy. I truly enjoyed our relationship since my first day at Louisville. No one works harder and is more dedicated to the success of their students. I will do my best to follow the example that you have set.

Dr. Megan Shreffler - Thank you for being there and helping me along the way. I really appreciated your guidance during some challenging times.

Dr. Jeff Valentine - You challenged me more than any other professor that I have known. I truly appreciate even though the stress almost beat me.

Dr. Thomas Miller - "It Depends" Your words from law class are uttered from my mouth daily. Before I started on this doctoral journey, you were one of the first people that I reached out to. I asked you if you think I could do it and you responded: "without a doubt". Thank you for your encouragement. Dr. Shauna Sage - Working with you changed my life. My best boss ever. Thank you for helping develop into a true professional and guiding me down this path. 
Jason Krone - I replaced you at KU and later you became my boss. I will always be grateful for following in your footsteps. Thank you for your help in the early stages of this project.

Mark "The Shark" Williams - The mentor of mentors. My Professor Xavier. Thank you for your guidance over the years. I still live my life by the credo "What would Shark do". Dr. Derek Hottell - Hotel, you will forever be my first real boss. Your influence has been felt by everyone I have worked with since. Thank you for your guidance and knowledge. Dr. Terry Wilson - To this day, whenever someone asks me who my favorite teacher was, I respond without hesitation "Dr. Terry Wilson". I will try to be that to my future students.

Dr. Steve Spencer - Dad, I have followed closely in your footsteps my entire life. We disagree on some things, but I feel that you are always looking out for my best interest. Thank you for your guidance even though at times it was very frustrating. Debby Spencer - Mom, you have been my rock my entire life. You have supported every decision no matter what. I don't know what to say... just know that without you I would be nowhere.

David Oliver - Chili Dawg, you are my best friend and when I asked about living with you during my doctoral program you responded: "I cannot wait". You gave me an outlet outside of academia that was both a facilitator and a barrier to my success. I wouldn't have had it any other way.

Finally, I wanted to acknowledge the campus recreation professionals that helped me complete this study. I utilized all of my network connections to develop a list of forward- 
thinking programs that set the example on inclusion. Your dedication to your craft is truly inspiring. Keep it up! 


\title{
ABSTRACT \\ CAMPUS RECREATION INCLUSION FOR PEOPLE WITH DISABILITIES: A QUALITATIVE INVESTIGATION OF CURRENT INCLUSIVE PRACTICES
}

\author{
Tyler C. Spencer
}

November 25, 2019

This study investigated the current practices of campus recreation professionals to create inclusive campus recreation programs, services, and facilities. The researcher identified twelve campus recreation programs known by their peers and the industry to be at the forefront of providing inclusion efforts to people with disabilities. Through indepth discussions with campus recreation practitioners at the twelve identified institutions, the investigation elicited a variety of interesting results. Utilizing the frameworks of Critical Disability Theory and Universal Design, this investigation identified how campus recreation practitioners perceive the inclusiveness of their campus recreation departments and how the campus recreation practitioners developed their inclusive practices.

After interviewing the twelve campus recreation practitioners, the researcher was able to analyze how they perceived the inclusiveness of their campus recreation departments in order to address research question one. The campus recreation practitioners discussed a variety of ways in which their campus recreation departments provided inclusive facilities, services, and programming. This discussion generated the 
themes of diversity and inclusion effort, disability inclusion, and gender inclusion in response to the perceived inclusiveness of their campus recreation department. In the campus recreation practitioners' responses to research question two, the campus recreation discussed how they determined their inclusive practices and policies. The discussion led to the themes of policy source, assessments and surveys, and personnel involved. Through analyzing the campus recreation practitioners' responses to the research questions, the researcher was able to identify relationships to Critical Disability Theory, Universal Design, and the literature discussed in this study. 


\section{TABLE OF CONTENTS}

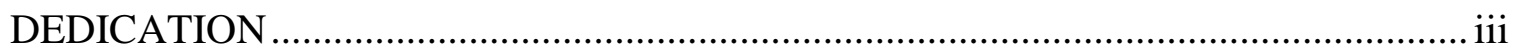

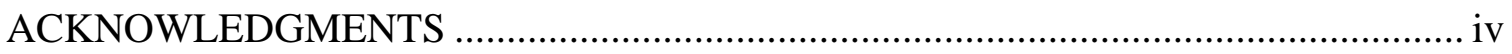

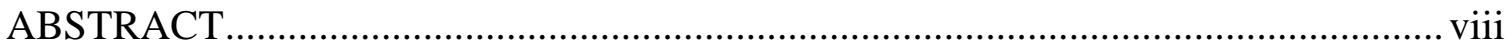

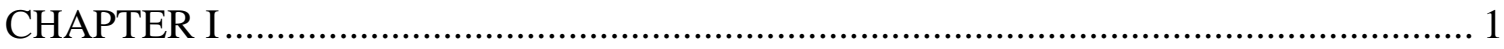

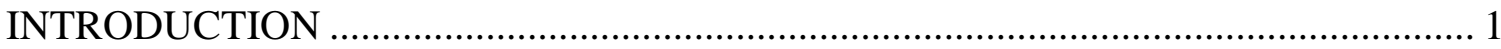

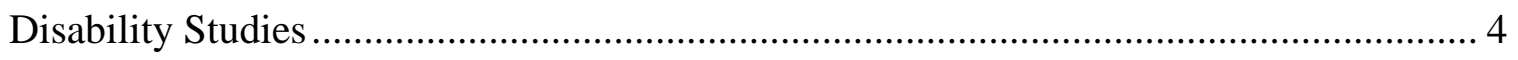

Quality of Life for People with Disabilities............................................................. 5

Recreation, Sport, and Leisure for People with Disabilities .............................................. 7

Participation by People with Disabilities in Recreation, Sport, and Leisure .................. 8

Barriers and Facilitators for People with Disabilities .................................................... 9

Legal Protection for People with Disabilities ................................................................. 11

Higher Education Inclusion for People with Disabilities .............................................. 12

Campus Recreation Inclusion ................................................................................. 13

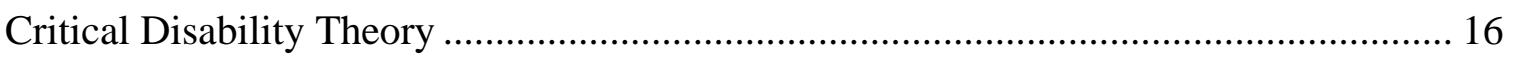

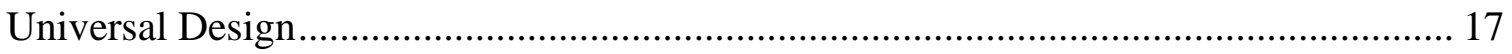

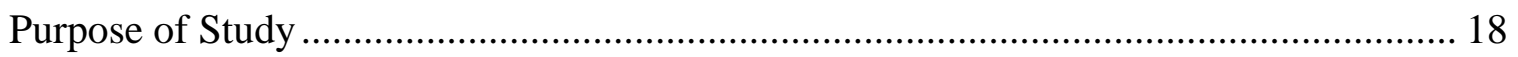

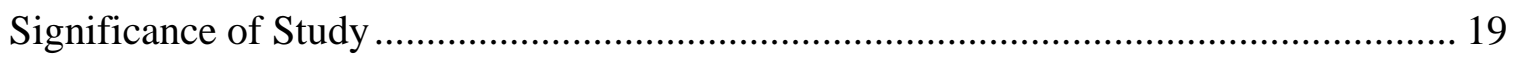

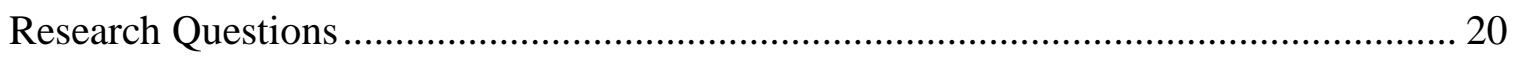

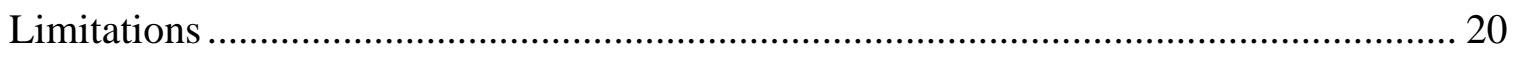

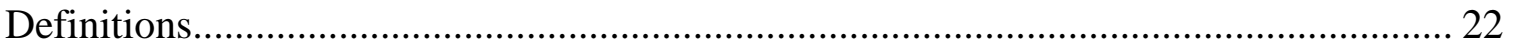

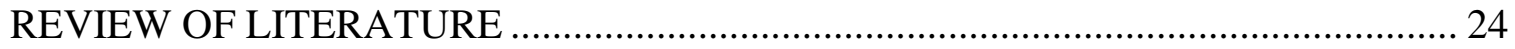

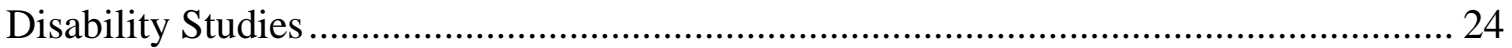

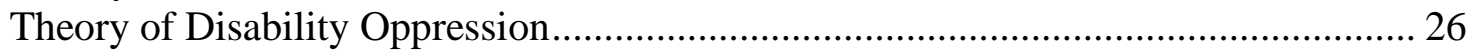

Quality of Life for People with Disabilities........................................................... 28

Recreation, Sport, and Leisure by People with Disabilities............................................... 30

Need for Recreation, Sport, and Leisure for People with Disabilities........................... 31

Benefits of Recreation, Sport, and Leisure for People with Disabilities. ...................... 31

Improving fitness levels of people with disabilities ............................................... 32

Promotes psychological health through social engagement. ……………………..... 33

Participation by People with Disabilities in Recreation, Sport, and Leisure ................ 34

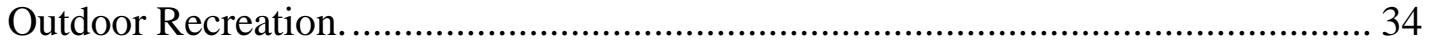




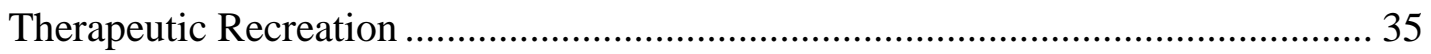

Adapted Physical Education ................................................................................ 35

Barriers and Facilitators for People with Disabilities ................................................. 36

Barriers to Recreation for People with Disabilities ................................................... 37

Physical and Environmental Barriers (Inadequate Facilities) .......................................................

Social/Attitudinal Barriers (Lack of Knowledge) ................................................................................. 38

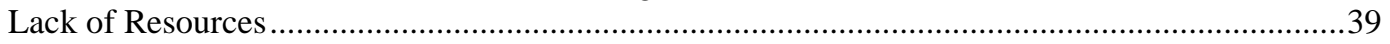

Overcoming Barriers for the People with Disabilities (Facilitators) .......................... 40

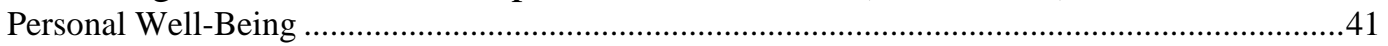

Opportunities sensitive to the needs of people with disabilities......................................................4

Legal Protection for People with Disabilities ................................................................... 43

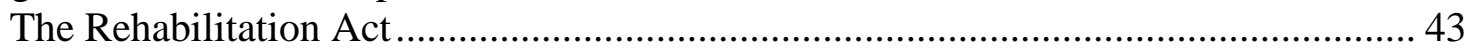

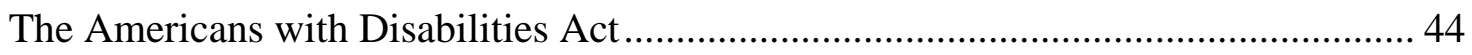

Title I: Employment …………………………………................................ 45

Title II: Public services .................................................................................. 45

Title III: Public accommodations and commercial facilities .................................... 46

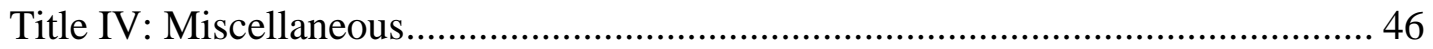

2010 ADA Standards for Accessible Design......................................................... 47

Fitness and Recreational Facilities Under the ADA................................................ 47

Higher Education Inclusion for People with Disabilities .................................................. 51

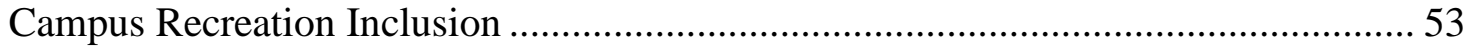

Gender inclusion in campus recreation................................................................. 54

Inclusive Campus Recreation Programming ………………................................ 59

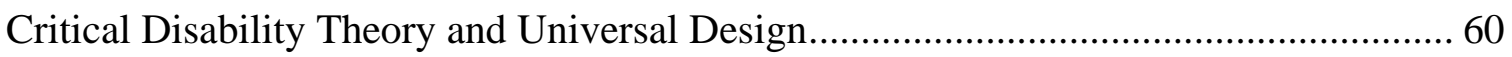

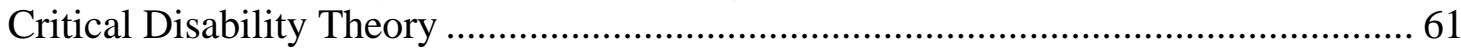

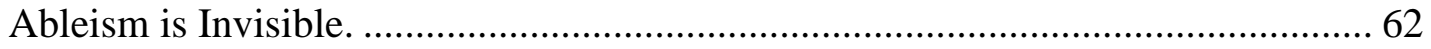

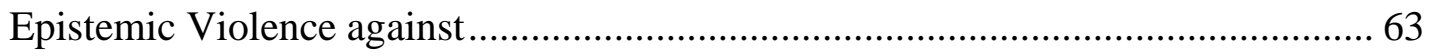

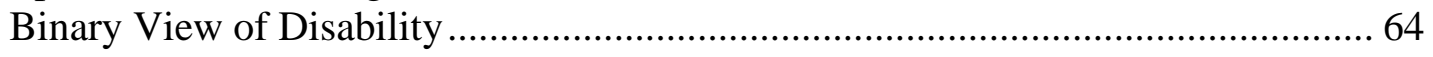

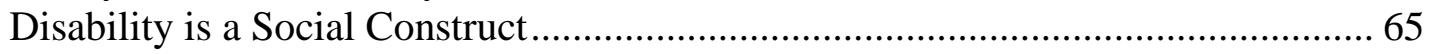

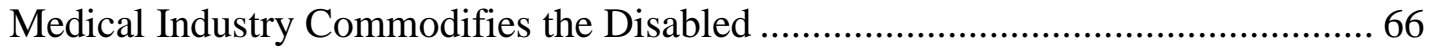

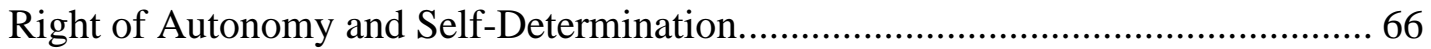

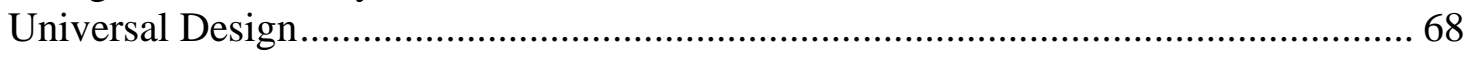

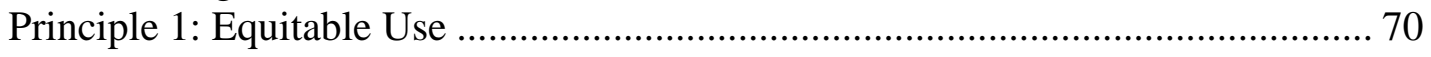

Principle 2: Flexibility in Use ............................................................................ 70

Principle 3: Simple and Intuitive Use ………………......................................... 71

Principle 4: Perceptible Information ................................................................. 71

Principle 5: Tolerance for Error ......................................................................... 71

Principle 6: Low Physical Effort............................................................................ 72

Principle 7: Size and Space for Approach and Use ………………………........... 72

Summary of the Literature ........................................................................................... 73

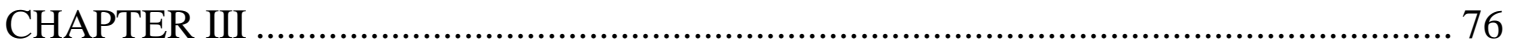

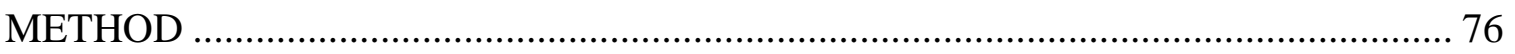

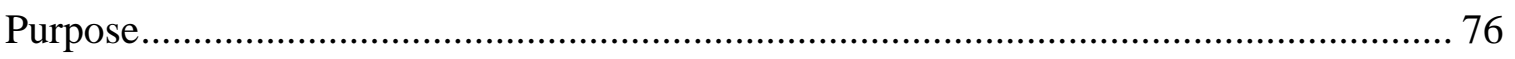

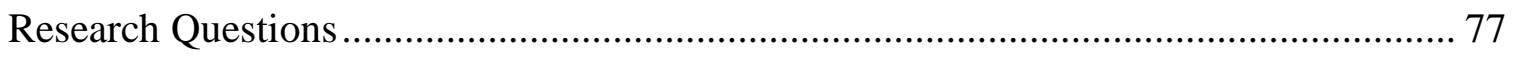




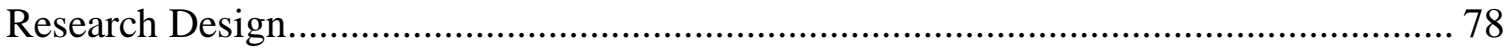

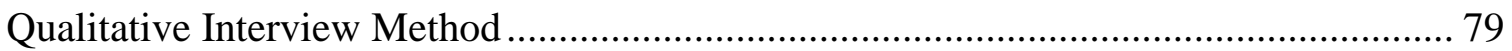

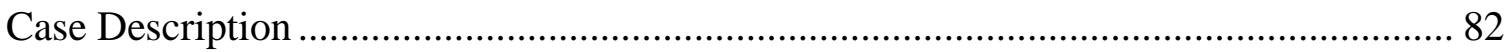

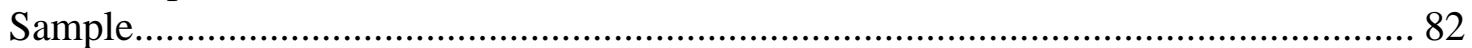

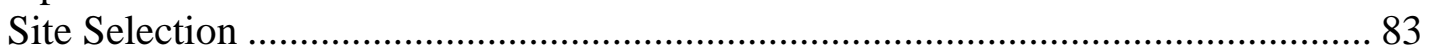

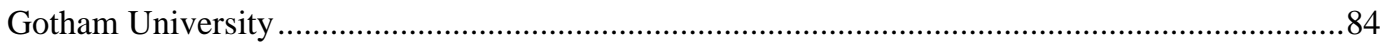

Empire State University …………………………………………………………….... 84

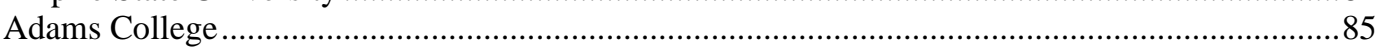

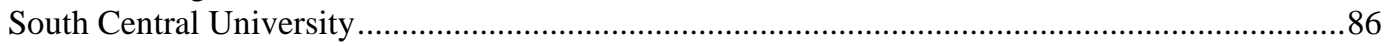

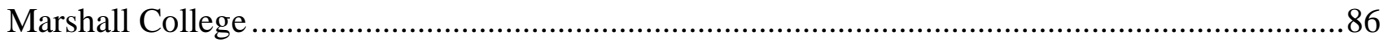

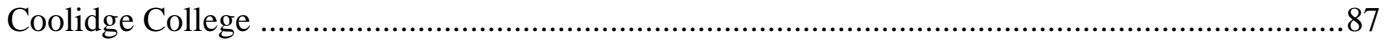

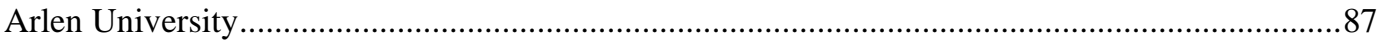

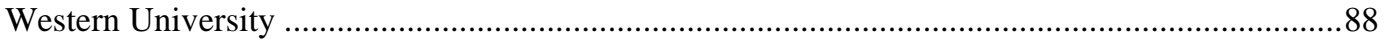

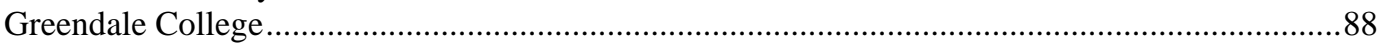

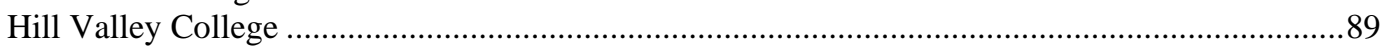

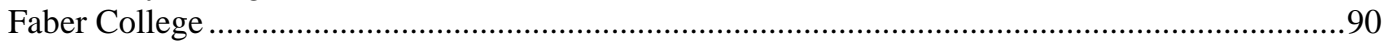

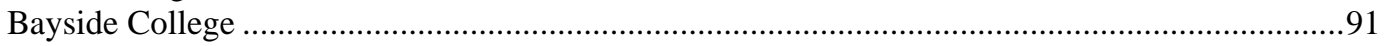

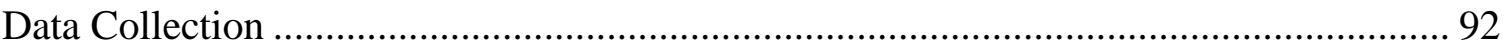

Researcher Reflexivity .......................................................................................... 93

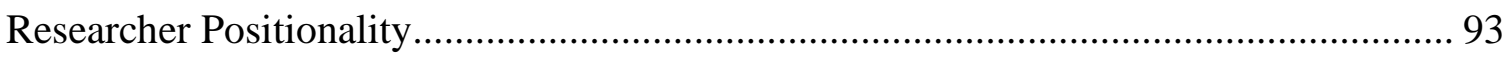

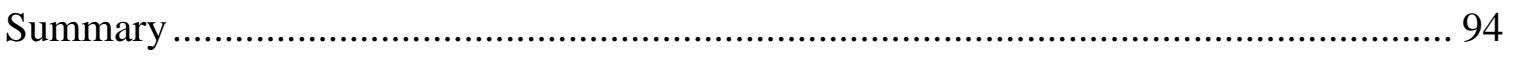

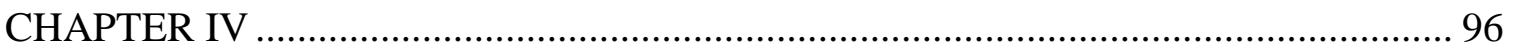

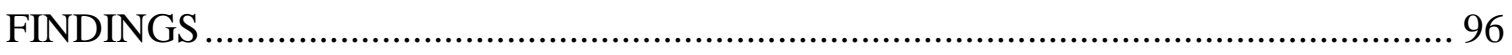

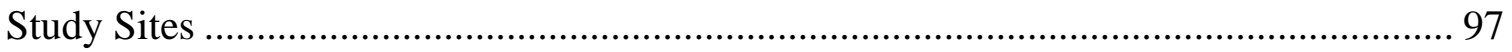

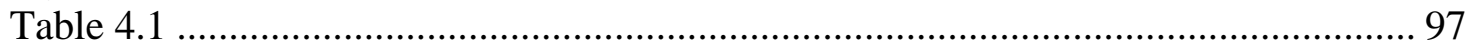

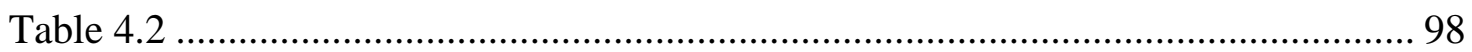

RQ1: How do campus recreation practitioners perceive the inclusiveness of their

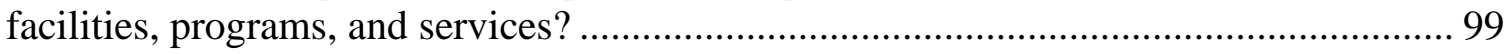

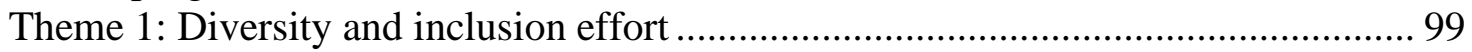

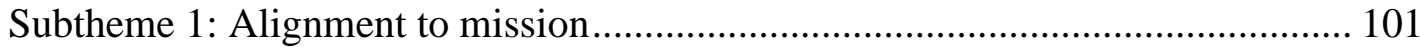

Subtheme 2: Inclusion and diversity committee .................................................. 105

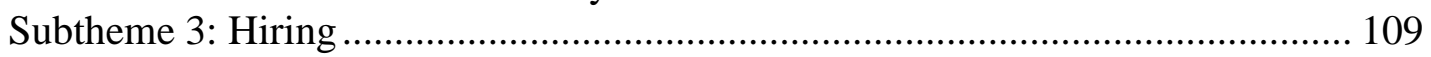

Subtheme 4: Staff training and education ........................................................... 114

Theme 2: Disability Inclusion........................................................................... 117

Subtheme 1: ADA compliance and accessibility ................................................. 117

Subtheme 2: Community partners to help inclusion.............................................. 123

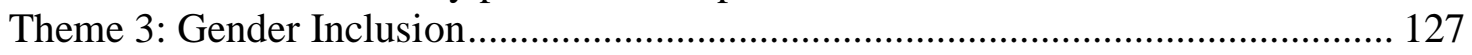

RQ2: How do campus recreation professionals determine and create their inclusive

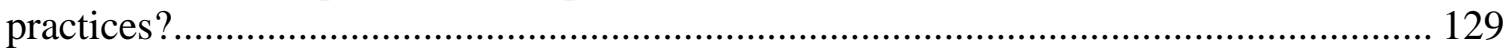

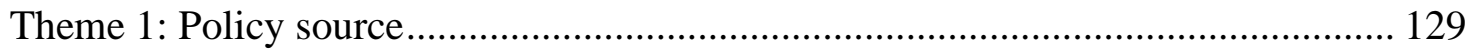

Subtheme 1: From the top down ...................................................................... 130

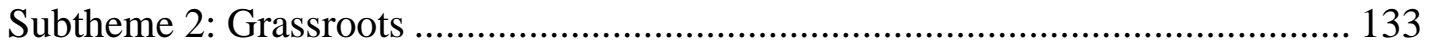

Theme 2: Assessment and Surveys........................................................................ 135

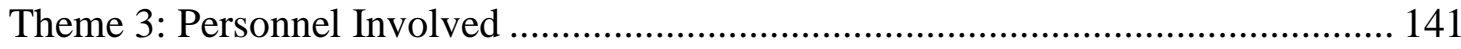


Subtheme 1: Professional staff............................................................................. 142

Subtheme 2: Campus and community partners ...................................................... 145

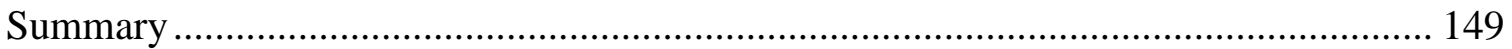

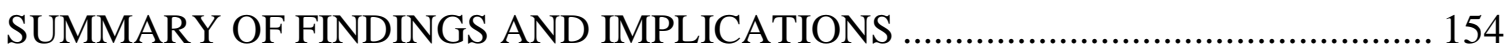

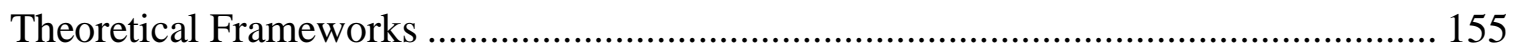

Review of Universal Design and Connections ..................................................... 156

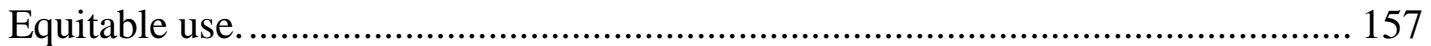

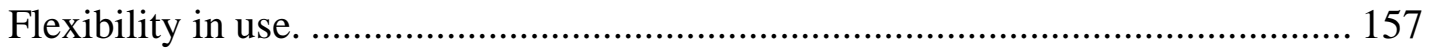

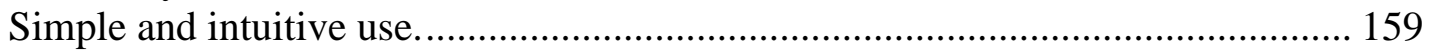

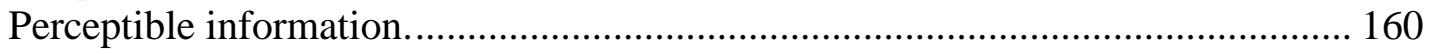

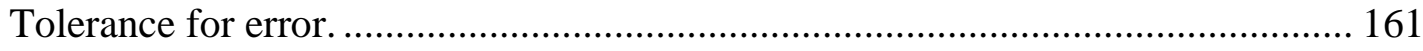

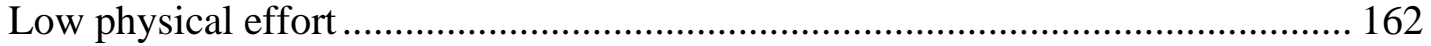

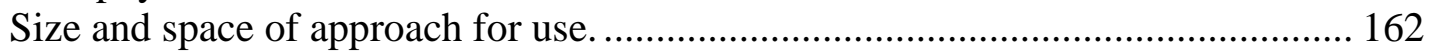

Review of Critical Disability Theory and Connections ............................................ 164

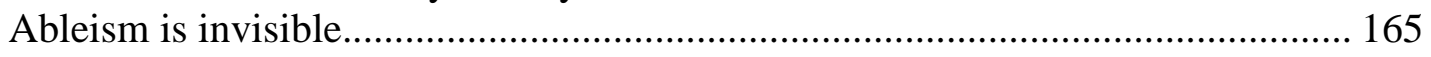

The epistemic violence against the disabled...................................................... 165

The binary view of disability instead of a continuum of human variation............. 167

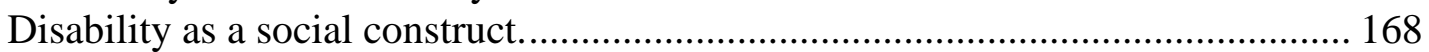

The medical industry's commodification of people with disabilities..................... 169

The right of autonomy and self-determination for people with disabilities............ 170

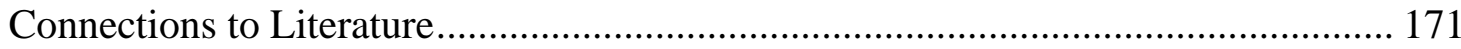

Need for recreation for people with disabilities.............................................. 172

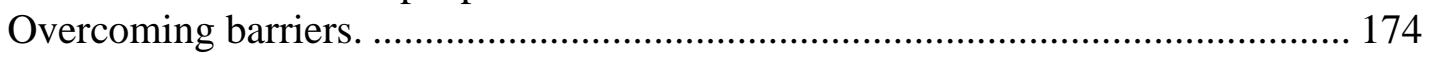

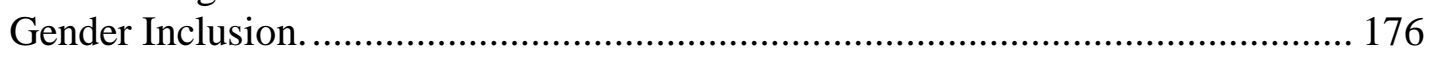

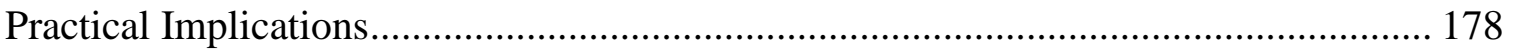

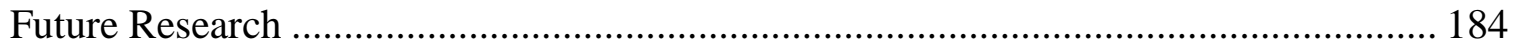

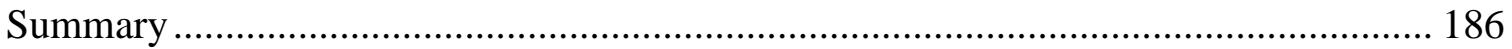

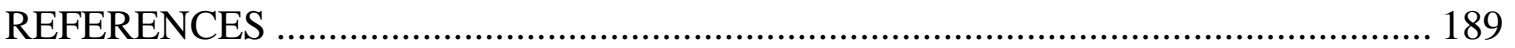

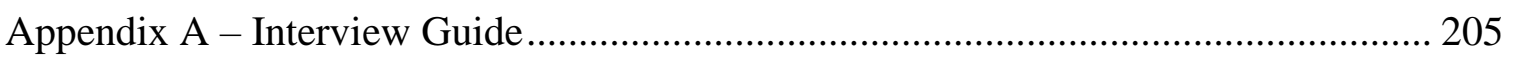

Appendix B - Question Grid .................................................................................. 206

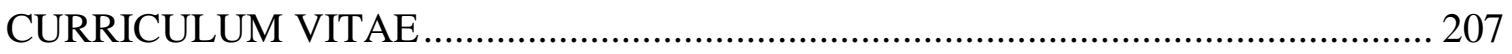




\section{CHAPTER I}

\section{INTRODUCTION}

According to the 2010 United States Census, almost 20 percent (56.7 million) of the country's population reported having a disability. Of those individuals, roughly 54 percent (30.6 million) indicated they have a mobility disability (US Census Bureau, 2012). The presence of people with disabilities is not a recent phenomenon. Disabilities have been mentioned in texts as ancient as the Bible (Rimmerman, 2013). As society began to progress and develop, the treatment of people with disabilities evolved as well.

During the Industrial Age, society viewed people with disabilities as a burden because of their perceived lesser ability to make decisions and contribute to society (Rocco, 2005). This stigma around people with disabilities created a lasting social norm resulting in discrimination against and exclusion of individuals with disabilities. Not until the civil rights movement in the 1960s was this stigma challenged (Rimmerman, 2011). Society began to see past the disability to see a person or individual defined by their abilities rather than their disabilities. One method utilized to challenge social stigmas against people with disabilities and to gain social acceptance is participation in leisure activities (Rimmer \& Rowland, 2008). 
Leisure is a fundamental right of any individual and can be described as a selfdetermination of how one should use discretionary time (Pagan, 2015; Soffer \& AlmogBar, 2016). A common mode of leisure activities is participation in sport and recreation opportunities. These activities facilitate integration into mainstream society through the development of social skills in a less inhibiting environment (Da Gama, 2000; Wright \& Titus, 2013). Additionally, participation in leisure activities provides avenues for people with disabilities to promote social cohesion, improve health, and create a more functional community (Wright \& Titus, 2013). To create leisure opportunities for people with disabilities, practitioners have continually adapted their facilities, equipment, and activities to meet the individual needs of participants. These adaptations and many other practices were catalysts to provide a more inclusive leisure environment for people with disabilities.

In order to create a more inclusive leisure environment, recreation practitioners created numerous strategies to systematically meet the needs of all individuals (Hums, Schmidt, Novak, \& Wolf, 2016). Additionally, the passage of the Americans with Disabilities Act (ADA) mandated accommodations of public offerings for people with disabilities (Americans with Disabilities Act $§ 12101,1990)$. Practitioners have utilized managerial strategies derived from Critical Disability Theory (CDT) and Universal Design (UD) to meet the legal obligations of the ADA and to develop a more inclusive environment. CDT provides a theoretical context for practitioners to gain an understanding of how people with disabilities are viewed and oppressed within society (Rocco, 2005). UD is a framework to design places, things, information, communication, and policy to meet the needs of every person (Hums et al., 2016; IHCD, 2015). 
In the higher education setting, 11.1 percent of students indicated they had a disability (NCES,2016). In order to meet the demand of this growing population, institutions of higher education created programs to meet the needs of students with disabilities. Programs were adapted and created to provide inclusion in education, transportations, and services within the campus community (Eckes \& Ochoa, 2005; Liasidou, 2014). Since leisure and recreation activities have been shown to be useful tools in creating an inclusive environment, campus administrators looked to campus recreation to facilitate inclusive initiatives (Wright \& Titus, 2013).

Campus recreation departments developed a variety of programming, services, and facilities to create a more inclusive campus environment (Young, et al., 2016). One way campus recreation departments created inclusive campus recreation was by adapting existing programs, services, and equipment for people with disabilities (Shields \& Synnot, 2016). These adaptations or modifications were developed to meet the individual needs of a user to ensure they can enjoy the same recreational experience as any other user on campus. On top of modifying existing programs and services, campus recreation departments developed new ideas and initiatives to increase the inclusion efforts of the campus community.

These inclusive practices were not always mandated by the university or legal precedence. These efforts were generally undertaken by individual departments in order to better meet the needs of an underrepresented population and to fulfil their missions (Young, et al., 2016). As the population of people with disabilities continues to grow within the higher education systems, so too must the inclusive practices. Campus recreation provides an opportunity to easily identify these inclusive practices and 
examine the impact these practices have within the community of people with disabilities. It is integral to identify the most inclusive campus recreation departments in order to continue to improve the inclusiveness of the campus recreation community. By identifying these inclusive programs, the campus recreation community can share and build upon the growing foundation laid out by these inclusive programs.

\section{Disability Studies}

Disability is a term used to describe a multitude of human conditions and a variety of impairments (Linton, 1998). Since people with disabilities have been present throughout history and remain so in today's society, scholars have developed the philosophy of Disability Studies (DS). The DS philosophy explores how individuals with a disability interact with and are treated within society (Charlton, 1998). DS theorists understand there are differences among people with and without disabilities. The significance of these differences is contingent on how they are viewed or interpreted by themselves or individuals within the society being studied (Bogdan \& Taylor, 1994). DS focuses on looking at the problems with societies rather than focusing on a "fix" for the disability. These studies aim to educate the general public on the barriers preventing people with disabilities from inclusion within a society.

Bogdan \& Taylor (1994), believe disability is a social construction which focuses on a person's lack of abilities rather than his/her abilities. Therefore, it is integral for continued efforts to study the experiences of people with disabilities. Advancements in of the field of disability studies will lead to a greater understanding society's perception of abilities. This understanding can help determine how practices can be put into place 
which will directly lead to people with disabilities having the opportunity to live a better and more fulfilling life.

\section{Quality of Life for People with Disabilities}

The well-being of an individual is a difficult construct to understand and define. Some ancient philosophers suggested the ultimate motivation of a human being is happiness (Diener, 1984). Other philosophers, such as Aristotle, believed there was a link to happiness through acts of virtuous behavior (Kesebir \& Diener, 2008). An individual's perception of a quality life is influenced by his/her position in life in regard to culture, value systems, goals, expectations, standards, and concerns (Nemcek, 2016).

Quality of life can be determined through objective and subjective features. The objective features of quality of life can easily be observed and measured in the public domain (Canha, Simoes, Gaspar Matos, \& Owens, 2016). The subjective features are more difficult to quantify because of the connection to an individual's perception of their experiences. It is difficult to understand why a person reacts positively or negatively to a life experience and if the experience makes the individual happy. Therefore, scholars developed the term subjective well-being to help measure happiness (Diener, 1984). Diener (1984) created a model which used positive emotions, negative emotions, and life satisfaction to effectively measure subjective well-being (Tove \& Diener,2008).

Subjective well-being and quality of life are important factors in the effort to be satisfied with one's life situation. Today's culture reflects the effort by individuals to lead a quality life and to be content with their own life situation (Nemcek, 2016). Pavot and Diener (1993) refer to life satisfaction as an individual's perception of his/her own aspirations and achievements in life being met. To reach the optimal level of life 
satisfaction, individuals must constantly balance goals, objectives, and experiences. Since inclusion practices have continued to expand, new opportunities are being afforded to people with disabilities on a daily basis. The ability to participate in these new opportunities could create a higher level of life satisfaction for people with disabilities.

People with disabilities have been shown to be more dissatisfied with their quality of life when compared to their nondisabled peers (Canha et al., 2016; Edwards, Patrick, \& Topolski, 2003; Sacks \& Kern, 2008; Watson \& Keith, 2002). People living with a disability face constant change and adjustment processes as they move through life. These change and adjustment periods can lead to further dissatisfaction with life (Canha et al., 2016). Dissatisfaction with life is linked to increased depression levels (Smith, Ahmad, Owe, Celikkol, Ping, Gavreliuc, Chobthamkit, Rizwan, Chen, Teh, \& Vignoles, 2016).

Scholars of life satisfaction seek to understand the positive and adaptive aspects of the human experience in order to focus on creating preferred outcomes of life satisfaction for people with disabilities (Chou, Chan, Cham, \& Phillips, 2013). This effort led scholars to identify the positive characteristics of an individual's life and deemphasize negative features (Chou et al., 2013; Dunn \& Doughty, 2005). Health promotion has been found to be closely related to or influence life satisfaction (Diener \& Chan, 2011). Health promotion is the process that enables people to improve their health (Cahna et al., 2016). This process identifies physical skills, personal resources, and social resources which have a positive influence on improved health.

Individuals have increased motivation to improve their personal health if they can easily identify how their passions can be used as a mechanism to improve health (O'Donnell, 
2009). A common passion which can be easily identified as a mechanism of improved health is participation in sport, leisure, and recreation. Leisure, sport, and recreational activities are easily identifiable mechanisms by which people with disabilities are able to improve their health and well-being (Cho, 2009; Jung, 2012; Kim \& Kim, 2009). Participation in recreation, sport, and leisure have beneficial effects which have been shown to lead to improved life satisfaction, quality of life, and well-being (Kerr et al. 2012: Rosenberg et al., 2013). Therefore, it is critical to understand why and how people with disabilities utilize recreation, sport, and leisure.

Recreation, Sport, and Leisure for People with Disabilities

Leisure is a self-determination of how one should use discretionary time (Pagan, 2015). Participation in various recreation, sport, and leisure activities is an important component to improve an individual's well-being or quality of life (Leung \& Lee, 2005; Pagan, 2015; Toepoel, 2013). The impact of participation in recreation is especially noticeable among individuals who are subject to social isolation, particularly people with disabilities. Recreation, sport, and leisure time provides people with disabilities an avenue of social acceptance otherwise unavailable to them (Rimmer \& Rowland, 2008).

Recreation, sport, and leisure not only play a large role in improving social inclusion but also improve personal health and wellness (Wright \& Titus, 2013). According to Calder, Sole, and Mulligan (2018), people with disabilities have continually indicated low levels of participation in physical activity. Compared to the general population, people with disabilities have a greater risk of living with secondary health conditions (Rimmer, Padalabalanarayanan, Malone, \& Mehta, 2015). Recreation, sport, and leisure activities provide an opportunity for individuals with a disability to maintain 
an active lifestyle, thus reducing the likelihood of these secondary conditions and positively influencing their well-being (Calder, Sole, \& Mulligan, 2018). Participation by People with Disabilities in Recreation, Sport, and Leisure As inclusion awareness continued to grow for people with disabilities, efforts to provide adapted aspects of numerous recreational, sport, and leisure grew, too.

Recreation, sport, and leisure for people with disabilities is not a new trend. For over 100 years, athletes with disabilities have competed against each other in various sports (Shapiro \& Pitts, 2014). Sports developed for people with disabilities to participate are commonly referred to as adapted or para-sports. The Paralympic Movement has helped create an awareness of the need for inclusion of individuals with disabilities in sport.

Other types of recreational, sport, and leisure opportunities for people with disabilities are outdoor recreation and therapeutic recreation. Many individuals with disabilities are drawn to outdoor recreation activities. People with disabilities regularly participate in various outdoor activities alongside able-bodied peers with the help of adapted equipment and facilities (Dorsch, Richards, Swain, \& Maxey, 2016). Recreational activities in an outdoor setting such as fishing, hunting, or kayaking amplify psychological benefits compared to activities taking place in an indoor setting (Bodin \& Hartig, 2003).

Many individuals with a disability participate in therapeutic recreation opportunities. Recreational therapy is utilized to improve or maintain physical, cognitive, social emotional, and spiritual functions (National Council for Therapeutic Recreation Certification, 2018), People with disabilities utilize recreational therapy in a variety of ways. Depending on their specific needs, they can participate in arts and crafts, sports, 
games, dance and movement, drama, music, activities with animals, and community outings.

People with disabilities engage in less physical activity and are more likely to stop participating in physical activities than people without a disability (Martin-Ginis, Latimer-Cheung, \& Rimmer, 2016). Low participation numbers and high dropout rates indicate that despite the benefits, people with disabilities face many obstacles or barriers to being physically active.

Barriers and Facilitators for People with Disabilities

People with disabilities face numerous obstacles when trying to participate in recreation, sport, and leisure opportunities. These obstacles range from physical environments (inaccessible sidewalks, trails, and facilities) to social environments (noninclusive groups, practices, and lack of education). These barriers actively exacerbate low participation rates (Rimmer et al., 2016). Studies have shown the most prevalent barriers to recreation for people with disabilities to be inadequate facilities, lack of knowledge/education, lack of resources, lack of preferences, and fear/intimidation (Calder, Sole, \& Mulligan, 2018; French \& Hainsworth, 2001; Martin-Ginis, LatimerCheung, \& Rimmer, 2016; Mulligan, Hales, Whitehead, \& Baxter, 2012; Rimmer, Chen, \& Hsieh, 2011; Rimmer \& Rowland, 2008; Rolfe, Yoshida, Renwick, Bailey, 2007).

These factors have all been shown to actively curtail participation by people with disabilities in recreation, sport, and leisure activities. Practitioners continually try to develop new strategies to overcome these barriers and reach an underserved population. Two identified facilitators to increase participation for people with disabilities are 
increased personal well-being and sensitivity to the needs of people with disabilities (Richardson, Smith, \& Papathomas, 2016).

The desire to be fit and to improve overall wellness has been shown to be the most influential facilitator for people with disabilities to participate in recreation, sport, and leisure (Richardson, Smith, \& Papathomas, 2016). People with disabilities indicated they are motivated to improve their health due to the potential benefits of improved motor function, pain reduction, aesthetic improvement, and enhanced independence (Kehn \& Kroll, 2009; Richardson, Smith, \& Papathomas, 2016).

Increased well-being can also be derived through social interaction and developing relationships (Richardson, Smith, \& Papathomas, 2016). Sharing the experiences of exercise with other individuals at a recreation center creates the feelings of belonging and acceptance. These interactions must be positive to facilitate inclusion for people with disabilities. Understanding the importance of positive interactions leads to the next facilitator of opportunity - sensitivity to the needs of people with disabilities.

Positive exercise experiences for people with disabilities occur when the recreational environment is considered welcoming. Positive social interactions with staff and other participants lead to a greater desire for individuals with disabilities to exercise (Richardson, Smith, \& Papathomas, 2016). Individuals feel more welcomed when the staff is educated and understands the challenges presented by having a disability (Shields \& Synnot, 2016).

Recreation, sport and leisure practitioners need to have an understanding that disabilities are not monolithic and what works for one individual might not work for another. Willingness to adapt equipment and modify activities to fit an individual's needs 
increases positive interactions. Asking the individual to identify his/her desires will help generate a sense of inclusion and creates a positive environment (Shields \& Synnot, 2016). Creating these inclusive modifications will increase an individual's likelihood to participate. These modifications can only be created through an understanding of the recreational, sport, and leisure opportunities for people with disabilities. Many practitioners generate their understanding out of a necessity to follow laws and legal mandates created to ensure equal treatment of people with disabilities. The following section will discuss the legal protections for people with disabilities.

\section{Legal Protection for People with Disabilities}

The movement to eliminate oppression and inequality led to The Rehabilitation Act of 1973 and later the Americans with Disabilities Act (ADA). These acts were attempts by the United States government to eradicate longstanding discrimination against people with disabilities (Wegner, 1984). Section 504 of The Rehabilitation Act states "No otherwise qualified handicapped individual shall, solely by reason of his handicap, be excluded from the participation in, be denied the benefits of, or be subjected to discrimination under any program or activity receiving Federal financial assistance" (U.S. Department of Justice, 2009, p. 34).

Extending beyond The Rehabilitation Act of 1973, the ADA is an equal opportunity law designed to guarantee people with disabilities have the same rights and opportunities as any person in a public setting (Young, Ramos, York, \& Fletcher, 2016). This law mandates the equal treatment of people with disabilities in all public accommodations, employment, public programs, and by service providers (Americans with Disabilities Act § 12101, 1990). The ADA has five sections or titles to explain the 
equal rights afforded to people with disabilities in the United States. Title I of the ADA prohibits all employers with more than 15 employees from discriminating against qualified individuals in regard to employment. Title II prohibits discrimination against people with disabilities in all programs, services, or public entities. Title III mandates private entities open to the public must allow individuals with disabilities the ability to participate equally in any goods or services offered. Title IV mandates all common communication carriers must establish interstate and intrastate telecommunication relay services at all times. Additionally, Title IV states all federally funded public service announcements provide closed captioning. Title $\mathrm{V}$ includes a variety of regulations clarifying the relationship of the ADA to any other laws or provisions to ensure people with disabilities are provided equal or greater protection of their rights (Americans with Disabilities Act $\S 12201,1990)$.

These legal protections emanated from an increased awareness of the inequalities and oppression faced by people with disabilities within society. This awareness sparked the desire to meet these legal standards in all aspects of society, including educational settings. Since higher education is included under all the titles of these laws, it was integral for institutions of higher education to provide inclusion for people with disabilities.

Higher Education Inclusion for People with Disabilities

The higher education setting has been shown to be a microcosm for society as the student population becomes more diverse (Douglas, 2005). The number of people with disabilities in the campus community is perpetually growing. According to the National Center for Education Statistics (2016), 11.1 percent of students enrolled in college during 
the 2011-2012 school year had a disability. Due to this large population, higher education administrators are becoming more focused on providing socially inclusive environments (Liasidou, 2014).

In an effort to provide a more accepting and inclusive environment, institutions have designed campus facilities, services, and programs to be accessible and usable by everyone, including those with disabilities (Stager-Wilson, Barnett, Mahoney, \& Sampson, 2012). Due to legal obligations, most college campus facilities are designed to be accessible. As the population of people with disabilities grows on collegiate campus, so too must the knowledge on how to better serve this population. College campuses aim to meet the needs and desires of people with disabilities through the diverse practices of inclusion in education, transportation, programs, environment, and services (Eckes \& Ochoa, 2005). One example of this effort to create a more inclusive campus experience is campus recreation.

Institutions of higher education have incorporated campus recreation programs ever since the first recognized programs were developed at The Ohio State University and University of Michigan in 1913 (Young, Ramos, York, \& Fletcher, 2016). Campus recreation programs promote the values of diversity and inclusion by creating programs and services to meet the students' needs and desires regardless of physical ability. Through this effort, the philosophy of campus recreation is to create opportunities for all students to be active and involved.

\section{Campus Recreation Inclusion}

Since the creation of campus recreation in 1913, campus recreation professionals have sought to provide programming to meet the sport participation needs of the student 
body (Young, Ramos, York, \& Fletcher, 2016). Campus recreation departments continually modify programs, services, and facilities to create a more inclusive campus climate (Young, et al., 2016). The professional organization for collegiate campus recreation is the National Intramural Recreational Sports Association (NIRSA). NIRSA values diversity, inclusion, and promotes opportunities for all students (Young, et al., 2016). NIRSA sets the standard for the entire industry to follow. For example, NIRSA works to increase inclusion for everyone by spreading information and gathering research on ways in which the campus recreation community can reach specific underserved populations. The campus recreation industry initiates specific programs to meet the individual needs of any user groups. For example, the campus recreation community is continually trying to meet the needs of all gender identities. Specific programs and terminology have been instituted to create a welcoming environment for all users regardless of their specific gender identity. These programs have enabled the campus recreation community to offer more opportunities to everyone. One of the more overarching examples of initiatives to increase participation numbers of everyone is to create a welcoming and inclusive environment.

Campus recreation departments utilize many different strategies to create inclusive environments. While campus recreation efforts for inclusion include meeting building codes and providing services for everyone, the movement starts with creating a welcoming and inclusive environment (Young, et al., 2016). Creating a welcoming environment is not a legal requirement of the ADA, however many campus recreation programs utilize it as a best practice for inclusion (Young, et al., 2016). Campus recreation signage, manuals, websites, and staff need to use positive inclusive language 
(Young, et al., 2016). Starting with a campus program's website, accessibility and inclusion information should be easy to find, access, and linked to the university's disability services page (Young, et al., 2016). Additional staff training is needed to properly educate staff on the inclusive practices offered by the campus recreation department. Proper staff training is integral to meeting the goal of having a welcoming environment. Inclusive campus recreation department directors educate their staffs on the appropriate language and information necessary to adequately meet the needs of their student population (Campus Recreational Sports, 2013). This training helps campus recreational staff identify the desires and possible programming opportunities to better meet the needs of any individual with a disability.

Campus recreational programming now routinely caters to specific needs of people with disabilities and strives to be inclusive. Intramural sports are being designed to incorporate inclusive sports into the competition calendar. Unified sports where people with and disabilities participate together are gaining popularity. Sports such as goalball, sitting volleyball, beep ball, and wheelchair basketball now have active intramural competitions among all students, not just students with disabilities. The University of Kansas hosted an Inclusive Recreation Extravaganza event in 2018 featuring a number of inclusive sports and an educational seminar (“Inclusive Recreation”, 2018). This event educated the entire campus community about the inclusive offerings afforded to all members of the university.

Campus recreation is a great resource to the campus community in the effort to create an inclusive campus environment. Campus recreation provides an opportunity to easily identify these inclusive practices and examine the impact these practices have 
within the community of people with disabilities. Therefore, creating an understanding of the current inclusive practices within the campus recreation setting will provide useful ideas about best practices to on ways to increase inclusion for people with disabilities. An additional way for campus recreation practitioners to increase inclusion is to utilize research and accepted theories to ensure their practices are truly inclusive. The next sections will discuss two theories which can be useful in determining inclusive practices within the campus recreation setting.

\section{Critical Disability Theory}

Critical Disability Theory looks at the daily life of people with disabilities and compares their everyday experiences with the actualities of social norms and values (Hosking, 2008). People with disabilities are continually left out of the decision-making processes in society, business, and education. This lack of autonomy is an example of ableism. Ableism is the belief held by a person without a disability, that is to say an ablebodied person, is the norm against which all others are compared (Procknow, Rocco \& Munn, 2017).

According to Procknow, Rocco, and Munn (2017), CDT asserts the following six core concepts: ableism is invisible, the epistemic violence against the disabled, the binary view of disability instead of a continuum of human variation, disability as a social construct, the right of autonomy and self-determination for people with disabilities, and the medical industry's commodification of people with disabilities. The core concepts of CDT identify the obstacles people with disabilities inherit due to the perceived norms of society. Living with a disability does not preclude an individual from being a productive member of society. Having access to the same opportunities afforded to all individuals, 
however, enhances the contributions an individual with a disability can make to the workforce, leadership, and society.

Progress toward inclusion is an ongoing global battle still being fought on all levels of society. Strategies are constantly being utilized to create a more inclusive environment. One strategy commonly used by practitioners to create inclusive practices is the theory of Universal Design (UD).

\section{Universal Design}

Universal Design (UD) is the intentional design of an environment to be as accessible as possible for all people, regardless of age, size, ability, or disability (National Disability Authority, 2014a). The UD concept is not regulated to benefit one specific group but to create the best design possible to benefit all potential users. UD considers the diverse needs and abilities of all possible users to create an accessible environment which is both convenient and enjoyable to utilize (National Disability Authority, 2014a).

As discussed earlier, efforts to promote inclusion and prevent discrimination were enforced through legislation. The design industry, in an effort to keep up with the new laws, created new accessible products, services, and environments. This led to the increased removal of barriers keeping people with disabilities from participation (National Disability Authority, 2014b). Accessible solutions continued to grow within the design industry, leading to further advances in products which made previously inaccessible products now accessible.

The UD concept was created by Ronald Mace and a group of architects, engineers, products designers, and environmental design researchers out of North Carolina State University (National Disability Authority, 2014c). Mace created the seven 
principles of UD in 1997 to guide the design of communications, products, and environments (National Disability Authority, 2014c). The seven principles are: equitable use, flexibility in use, simple and intuitive use, perceptible information, tolerance for error, low physical effort, and size and space for approach and use (National Disability Authority, 2014c). These principles can be utilized to assess existing designs, educate the designers, educate the consumers, and create a framework to lead the design process.

The universal design concept creates a more all-inclusive environment and society which in turn will encourage use of products and facilities by all individuals. This greater inclusion can create positive attributes which were previously denied to people with disabilities. These additional positive attributes could lead to more positive well-being. Critical Disability Theory and Universal Design can be key components in creating a more inclusive campus recreation department if utilized correctly.

\section{Purpose of Study}

The purpose of the study was to investigate the current practices of campus recreation professionals to create inclusive campus recreation programs, services, and facilities. This study employed interviews with campus recreation practitioners in order to examine their campus recreation centers' inclusion efforts for people with disabilities. Utilizing the frameworks of Critical Disability Theory and Universal Design, this investigation sought to identify how campus recreation practitioners perceived the inclusiveness of their campus recreation departments and how campus recreation practitioners develop their inclusive practices. Universal Design was utilized as a lens to understand how campus recreation practitioners, programs, facilities, and equipment served to meet the needs of all users and specifically people with disabilities. Critical 
Disability Theory was utilized to help understand the methods by which the inclusive practices are created and operationalized within the campus recreation settings.

\section{Significance of Study}

From a theoretical standpoint, this study investigated the understanding of the experiences of individuals working within the campus recreation industry and their efforts to create an inclusive campus recreation environment for people with disabilities. Specifically, the researcher examined the campus recreation setting and how inclusive practices were chosen and developed for the community of people with disabilities. Incorporating Critical Disability Theory into this investigation, the researcher was able to garner a greater understanding of the lack of autonomy people with disabilities had over inclusive services and programming afforded to them. This research also aimed to educate campus recreational practitioners on the current best practices of inclusive campus recreation departments and how to incorporate people with disabilities in the creation of inclusive practices in a collegiate setting.

The study's significance impacts the future of campus recreation and how best to meet the needs of people with disabilities. Many programs and facilities utilize the principles of Universal Design to meet the needs of any potential user. This study investigated this current practice to see if Universal Design practices were commonplace within the campus recreation setting and if they were being incorporated correctly. Campus recreation programs are intended to meet the needs of all students. Therefore, it was integral for this study to aid in the development of future practices to continue with this effort. 


\section{Research Questions}

The following research questions were aimed at understanding the purpose of this study:

RQ1: How do campus recreational practitioners perceive the inclusiveness of their facilities, programs, and services?

RQ2: How do campus recreation professionals determine and create their inclusive practices?

\section{Delimitations}

This study did not address every aspect of inclusion on college campuses or society. Specific delimitations for this study were set to maintain clear research boundaries (Glesne, 2016). This study was specific to recreation centers and programming on large public college campuses and did not incorporate any private colleges or recreation centers directly into the examination. The decision was made to specifically target large public institutions' campus recreation programs due to the demand on the campus recreation programs to meet the needs of large diverse populations. Additionally, all public institutions are required to adhere to strict federal laws and regulations to provide access and inclusion to all students in order to receive necessary federal funding (Higher Education Compliance Alliance, n.d). The findings do have the possibility of being transferable due to the similarities of the populations being served in campus programs outside of recreation, other institutions, and private business.

\section{Limitations}

There were several potential limitations of this study. The qualitative design of the study limits the results' generalizability. Access to a small subset of the population was necessary to complete the investigation but decreases generalizability. The involved 
cases will be bounded by a similar institution size and type. Institutions with varying sizes or private institutions will differ greatly from the institutions selected in this study.

Sensitivity to not being inclusive could result in the practitioners not being totally forthcoming during the investigation process (Malone, Nicholl, \& Tracey, 2014). These actions could result in reporting bias and was a potential limitation of the study. To mitigate this limitation the interviewer reassured participants that oftentimes people may disagree on how to implement inclusion, and this study was an effort to create better practices (Malone et al., 2014).

The last limitation was recall bias. The interview process relied heavily on the participants' recollection of experiences and may not always be the most accurate depictions of the experience. Therefore, recall bias can be a threat to the retrospective research. The researcher will minimize recall bias by interviewing multiple sources to triangulate unbiased information (Malone et al., 2014). 


\section{Definitions}

Ableism - Is the belief of a person without a disability, that is to say an able-bodied person, is the norm against which all others are compared (Procknow, Rocco \& Munn, 2017).

Adapted Sport - Is any sport designed to be specifically practiced by athletes or individuals with a disability (DePauw \& Gavron, 1995).

Americans with Disabilities Act (ADA) - Is a legal mandate of the equal treatment of people with disabilities in all public accommodations, employment, public programs, and service providers (Americans with Disabilities Act $\S 12101,1990$ ).

Campus Recreation/Recreation Services/Campus Rec - An on-campus program to integrate diverse activities and offerings into an institution to provide opportunities for social integration, healthy behaviors, and fun (NIRSA, 2013).

Critical Disability Theory (CDT) - A theory which investigates the experiences faced by people with disabilities and compares their everyday experiences with the actualities of social norms and values (Hosking, 2008).

Critical Legal Studies (CLS) - Is a leftist legal movement created to challenge traditional legal scholarship (Gordon, 1990).

Critical Race Theory (CRT) - A theory of how racism continues to be an issue in today's society and how the inequities faced by minority groups in the United States extend beyond class and gender (Ladson-Billings \&Tate,1995).

Critical Studies (CS) - A Philosophy of intellectually analyzing political and economic structures and practices (Burghardt, 2011). 
Disability Studies (DS)- A philosophy to explore how individuals with a disability interact and are treated within society (Charlton, 1998).

Leisure - Is a self-determination of how one should use discretionary time (Pagan, 2015). NIRSA - Formerly the National Intramural Recreational Sports Association, now known only as The NIRSA, is a network of professional and student leaders in collegiate recreation (NIRSA, 2018).

Other or Othering - A social norm process which takes place when anyone considered unlike "the norm" is precluded from involvement (Kudlick, 2005).

People with disabilities (PWD) - The ADA defines a person with a disability as "one who has a physical or mental impairment which substantially limits one or more major life activities" (Americans with Disabilities Act $§ 12102,1990$, p. 7).

Quality of Life (QOL) - Is an individual's perception of success in life which is influenced by his/her position in life in regard to culture, value systems, goals, expectations, standards, and concerns (Nemcek, 2016).

Recreation - An activity done for enjoyment when one is not working (Oxford University Press, 2018 a).

Sport - An activity involving physical exertion and skill in which an individual or team competes against another or others for entertainment (Oxford University Press, 2018 b). Subjective Well-Being (SWB) - A term to measure happiness through a quantification of positive emotions, negative emotions, and life satisfaction (Tove \& Diener,2008).

Universal Design (UD) - Is the intentional design of an environment to be as accessible as possible for all people, regardless of age, size, ability, or disability (National Disability Authority, 2014a). 


\section{CHAPTER II}

\section{REVIEW OF LITERATURE}

The following literature review is divided into seven sections; (a) disability studies, (b) recreation, sport, and leisure by people with disabilities, (c) legal protections for people with disabilities, (d) higher education inclusion for people with disabilities, (e) critical disability theory and universal design, (f) and a summary of literature. Disability studies, the first content area, discusses the field which investigates disabilities in order to gain insight into the lived experiences of people with disabilities. The second section discusses the opportunities for people with disabilities to participate in recreation, leisure, and sport activities. The third section reviews the history and the implications of the legal protections afforded to people with disabilities. The fourth section discusses the current disability inclusive practices within higher education specifically the campus recreation setting. The fifth section covers the literature and tenets of Critical Disability Theory and Universal Design. Finally, the last section covers a summary of the literature discussed and the implications to this study.

\section{Disability Studies}

Disability is a term used to describe a multitude of human conditions and a variety of impairments (Linton, 1998). Impairments limit or interfere with a person's ability to engage in certain tasks or participation in typical daily actions. These impairments, which create a disability, can be presented as physical, mental, cognitive, or developmental 
conditions (Disability, 2018). An estimated 1 billion people, around the world, live with a disability (PWD Factsheet, n.d.). In the United States (US), 56.7 million people are living with a disability (US Census Bureau, 2012). Just as the US population is growing, the demographic of people with a disability is perpetually growing. The PWD population is growing at an alarming rate due to the advances in medical science resulting in higher life expectancies (PWD Factsheet, n.d.). The current life expectancy of the US is 78.6 years of age (Solly, 2018). According to the United Nations, countries with life expectancies over 70 years of age will spend an average of 8 to 12 percent of their life living with a disability (PWD Factsheet, n.d.). Therefore, it is important to create an understanding of the lives of people with disabilities.

Understanding disabilities and people with disabilities is a continually growing area of academic inquiry known as Disability Studies (DS). DS addresses how people with disabilities are treated (Charlton, 1998). Disabilities have inherently been linked in the medical field as an impairment different from the "normal" or typical functions of a human body. This framing is sometimes referred to as the medical model of disability.

The philosophy of DS is that disability is basically a social construction. DS theorists understand there are differences among people with and without disabilities, but the significance of these differences is contingent on how they are viewed or interpreted within society (Bogdan \& Taylor, 1994). DS focuses on looking at the problem with societies rather than focusing on a "fix" for the disability. These studies aim to educate the general public on the barriers preventing people with disabilities from fuller participation in society. 
The purpose of DS is to explore how society, economics, and politics have oppressed people with disabilities throughout history. This field is linked closely to studies of race, class, and gender inequalities through the idea that people with disabilities constitute a minority group who has faced discrimination (Bogdan \& Taylor, 1994). Additionally, disability discrimination is manufactured through society's perceptions of abilities (Rocco, 2005). Understanding how society manufactured these perceptions can lead to the creation of practices to remove the negativity of any stigmas associated with disability. If the focus remains on people with disabilities' lack of abilities rather than their abilities, people with disabilities will continue to experience further oppression and increased isolation.

Theory of Disability Oppression

Scholars have applied works from a variety of fields to help understand the oppression people with disabilities face. Charlton (1998), for example, developed the theory of disability oppression. He coined this as "when individuals are systematically subjected to political, economic, cultural, or social degradation" (Charlton, 1998, p.8). This theory includes four concepts which determine superior and inferior norms related to people with disabilities. The first concept is the political economy. This is an understanding of how everyday life is partially controlled by the political environment. This environment is controlled by insiders who make the decisions which determine who survives or prospers (Charlton, 1998; Rocco, 2005). Here people with disabilities are labeled as inferior, used as surplus labor, and never allowed to produce, exchange, and distribute political economic goods and services (Charlton, 1998). 
The next concept includes culture and belief systems. This is the universal understanding of a classification system is used by society. Under it, people with disabilities are considered inferior. History, politics, economy, and social institutions reinforce the notion of inferiority which in turn legitimizes that belief system (Charlton, 1998). The third concept of Charlton's theory of oppression is false consciousness and alienation. This concept exists when people with disabilities become aware of the social norms and forces working against them. Individuals with disabilities begin to internalize this awareness and may begin to believe they are less capable. This leads people with disabilities to quit participating in society and social life without realizing what they might be capable of doing (Charlton, 1998).

The last concept is power and ideology. This concept discusses how the dominant power group maintains control over society. This is generally done through educational techniques that reinforce behaviors or norms oppressive to classes considered inferior (Charlton, 1998). This practice is evidenced by the low number of people with disabilities in leadership positions. Due to preconceived notions of inferiority, many people with disabilities may not be considered for positions of power or believe they are unqualified for leadership roles.

The dearth of people with disabilities in leadership roles is concerning. The ideology that people with disabilities are inferior to their abled bodied peers is oppressive. This assumption has created a barrier for people with disabilities must overcome in order to create a better quality of life. An individual's perception of a quality life is influenced by his/her position in life in regard to culture, value systems, goals, expectations, standards, and concerns (Nemcek, 2016).The next section will discuss the 
perception of quality of life for people with disabilities and how to improve the quality of life for people with disabilities.

Quality of Life for People with Disabilities

Research indicates people with disabilities are less satisfied with their quality of life when compared to nondisabled peers (Canha et al., 2016; Edwards, Patrick, \& Topolski, 2003; Sacks \& Kern, 2008; Watson \& Keith, 2002). People living with a disability face constant changes and adjustments as they move through life. These changes and adjustments periods can lead to further dissatisfaction with life (Canha et al., 2016). Dissatisfaction with life is linked to increased depression levels (Smith, Ahmad, Owe, Celikkol, Ping, Gavreliuc, Chobthamkit, Rizwan, Chen, Teh, \& Vignoles, 2016).

The major goal of quality of life research is to investigate and identify factors which contribute to an individual's sense of well-being (Smeddema, Cardoso, Chan, Dutta, Muller, Keegan, Ebener, \& Yaghmaian, 2015). Scholars seek to understand the positive and adaptive aspects of the human experience in order to focus on creating preferred outcomes of life satisfaction for people with disabilities (Chou, Chan, Cham, \& Phillips, 2013). There has recently been a shift in the philosophical emphasis of rehabilitation health researchers. This shift is called the positive psychology movement. Instead of focusing solely on the symptoms, deficits, and limitations of people with disabilities, scholars identify the positive characteristics of an individual's life and deemphasize negative features (Chou et al., 2013; Dunn \& Doughty, 2005). These positive characteristics are utilized to create rehabilitation practices to influence well-being, life satisfaction, and quality of life (Chou et al., 2013). 
The concepts of quality of life, life satisfaction, subjective well-being and health are closely related and in fact influence each other greatly (Diener \& Chan, 2011). Therefore, health promotion has shown to be a great rehabilitation process for people with disabilities to create a better quality of life. Health promotion is the process which enables people to improve their own health (Cahna et al., 2016).

O’Donnell (2009) explains health promotion as an art or science of enabling individuals to identify connections between core passion and health. This connection can lead to increased motivation and increased support for improving optimal health. Optimal health is a dynamic condition which changes throughout life depending on circumstances and a balance among physical emotional, social, spiritual, and intellectual health (O’Donnell, 2009). According to O’Donnell (2009), individuals will have an increased motivation to improve their personal health if they can easily identify how their passions can be used as a mechanism for better health. A common passion which can be easily identified as a mechanism of improved health is participation in sport, leisure, and recreation.

Leisure and recreational activities are avenues by which people with disabilities are able to improve their health and well-being (Cho, 2009; Jung, 2012; Kim \& Kim, 2009). Previous research has shown how leisure can lead to improved mental health, life satisfaction, quality of life, and well-being (Kerr et al., 2012; Rosenberg et al., 2013). These beneficial traits have especially been evident when people with disabilities participated in recreation activities and leisure. The next section will discuss how people with disabilities utilize leisure activities and the benefits which can be derived from participation in those activities. 
Recreation, Sport, and Leisure by People with Disabilities

Knowing the differences and similarities of recreation, sport, and leisure is integral to understand the impact they have to people with disabilities. Leisure is a selfdetermination of how one should use discretionary time (Pagan, 2015). Participation in varying leisure activities is an important component to improve an individual's wellbeing or quality of life (Leung \& Lee, 2005; Pagan, 2015; Toepoel, 2013). Participating in leisure activities has shown to drastically improve an individual's quality of life when they are already subject to social isolation such as people with disabilities. According to Pagan (2015), people with disabilities are at a disadvantage in the labor market since it can be difficult at times to secure employment. The working sector is where most people find social acceptance and people with disabilities oftentimes need to find this social acceptance elsewhere. One such place of acceptance is in recreation. Recreation and leisure time provide people with disabilities an avenue of social acceptance and other benefits (Rimmer \& Rowland, 2008).

Recreation provides a range of benefits which incorporates physical and mental health (Cantor, 2018). Understanding the needs of people with disabilities is key to developing principles to increase their participation in recreation opportunities. The following sections discuss the need for recreation for people with disabilities, recreational practices of people with disabilities, benefits of recreation for people with disabilities, barriers to recreation for people with disabilities, overcoming barriers to recreation for people with disabilities, and how recreation participation leads to higher life satisfaction. 
Need for Recreation, Sport, and Leisure for People with Disabilities

Recreation plays a large role in and strongly impacts social inclusion, health, and wellness for individuals and provides a positive psycho-social impact on the community being served (Wright $\&$ Titus, 2013). From a public health perspective, recreation provides an opportunity for individuals to maintain an active lifestyle. A large number of people with disabilities have indicated low levels of participation in physical activity (Calder, Sole, \& Mulligan, 2018). Compared to the general population, people with disabilities have a greater risk of living with secondary health conditions (Rimmer, Padalabalanarayanan, Malone, \& Mehta, 2015). For people with disabilities, physical activity can reduce the likelihood of these secondary conditions and positively influence their well-being (Calder, Sole, \& Mulligan, 2018). Previous studies have indicated that people with disabilities routinely engaged in less physical activity than people without disabilities (Altman \& Bernstein, 2008; Lezzoni, 2011; Rimmer, et al., 2015). Additionally, people with disabilities are more likely to stop or drop out of physical activities or active lifestyles (Martin-Ginis, Latimer-Cheung, \& Rimmer, 2016). These low participation numbers and the high dropout rates indicate that despite the benefits, people with disabilities face many obstacles or barriers to being physically active. Benefits of Recreation, Sport, and Leisure for People with Disabilities.

Leisure and recreation create opportunities to promote various aspects of physical, social, and psychological health (Soffer \& Almog-Bar, 2016). According to the United Nations Convention on the Rights of people with disabilities (CRPD), participation in leisure is a fundamental right of people with disabilities (Soffer \& Almog-Bar, 2016). 
Therefore, it is integral for recreation programs to promote leisure opportunities for people with disabilities.

Participation in sport, exercise, and other forms of physical activity has been proven to provide numerous health benefits for people with and without disabilities (Carroll, et al., 2014). Recreation and leisure activities allow people with disabilities to maintain a more active lifestyle. Leading an active lifestyle provides numerous benefits for people with disabilities.

Improving fitness levels of people with disabilities. The first benefit of recreation is improving the fitness levels of people with disabilities. As discussed previously, people with disabilities have a far greater risk of developing secondary health conditions due to sedentary behavior. These secondary health conditions like cardiovascular disease and diabetes are preventable with regular exercise and diet (Wilhite \& Shank, 2009). Recreation provides an opportunity for people with disabilities to foster healthy habits of maintaining an active lifestyle.

These healthy habits could lead to the development of improved dexterity, mobility, and balance. According to the World Health Organization (WHO) physical activity is important to human development and reduces the risk of cardiovascular disease, diabetes, colon cancer, and breast cancer (World Health Organization, 2006). Additionally, exercise interventions have been shown to improve physical fitness levels (Zwinkels, et al., 2018).

A daily physical fitness routine is beneficial for all people regardless of age or physical ability. According to Zwinkels et al. (2018), having people with disabilities engage in a regular fitness program positively affects their overall anaerobic 
performance, fat mass, and weight management. In addition, recreation can develop and enhance balance and motor skills, and decrease joint stiffness (Zwinkels et al., 2018). Due to the benefits of recreational activities, people with disabilities can develop autonomy due to their improved abilities and overall health. Recreation further aids in developing autonomy through social engagement with other participants.

Promotes psychological health through social engagement. Physical, recreational, and leisure activities have long been proven to improve psychological wellness for any participant (Blick, Saad, Goreczny, Roman, \& Sorensen, 2015). Recreational activities have been shown to alleviate depression, loneliness, and isolation (Fontaine, 2000). Participating in recreational activities can build and improve an individual's self-worth, self-confidence, and self-esteem (Frank \& Gustafson, 2001; Landers, 1997).

Another benefit of recreation is providing an opportunity for people with disabilities to engage with other individuals. Recreation provides a mechanism to develop relationships and social skills (Mgulwa \& Young, 2014). The skills develop as continued engagement occurs. Recreational experiences allow students, for example, to enhance their mental physical, mental, or emotional capacity to cope with the demands of a campus environment (Mgulwa \& Young, 2014).

The social engagement aspects of a student's participation in recreation opportunities helps develop communication skills. This social interaction facilitates the relationship between participants with and without disabilities (Cartner, 2018). Practices such as inclusive recreation programs can lead to a feeling of acceptance and increased social interaction for individuals with a disability (Mahar, Cobig, \& Stuart, 2013; 
Veselinova, 2013). While these benefits are numerous, people with disabilities also face numerous barriers which may keep them from participating. Participation by People with Disabilities in Recreation, Sport, and Leisure

For over 100 years, athletes with disabilities have competed against each other in various sports (Shapiro \& Pitts, 2014). As involvement by people with disabilities in sport continued to grow, efforts to provide adapted aspects of numerous sports grew, too. Disability sport is any sport designed to be specifically practiced by athletes or individuals with a disability (DePauw \& Gavron, 1995). Sports developed for people with disabilities to participate are commonly referred to as adaptive or para-sports.

The Paralympic Movement has helped develop further inclusion of individuals with disabilities in sport. The first Paralympic Games were held in Rome in 1960 and featured 400 athletes from 23 countries (International Paralympic Committee, n.d.). In 1989, the International Paralympic Committee (IPC) was formed as an advocacy movement to support the growth and development of Paralympic sports through the Paralympic Games (Blauwet \& Willick, 2012; Legg, Fay, Hums, \& Wolff, 2009). The Paralympic Movement represents one level of sport for people with disabilities. There are numerous forms of sport for people with disabilities and the next sections will address a number of them.

Outdoor Recreation. According to Bodin and Hartig (2003), when recreational activities take place in an outdoor setting the psychological benefits are amplified compared to activities in an indoor setting. Just like their able-bodied peers, many individuals with disabilities are drawn to outdoor recreation activities. People with disabilities regularly participate in various outdoor activities alongside able-bodied peers 
with the help of adapted equipment and facilities (Dorsch, Richards, Swain, \& Maxey, 2016). Today, many advocacy groups such as the National Ability Center in Utah work to provide access for people with disabilities to participate in outdoor activities.

Therapeutic Recreation. Also known as recreational therapy, therapeutic recreation "is a systematic process that utilizes recreation and other activity-based interventions to address the assessed needs of individuals with illnesses and/or disabling conditions, as a means to psychological and physical health, recovery and well-being" (National Council for Therapeutic Recreation Certification, 2018, p.1). Recreational therapy is utilized to improve or maintain physical, cognitive, social emotional, and spiritual functions (National Council for Therapeutic Recreation Certification, 2018),

People with disabilities utilize recreational therapy in a variety of ways. Specifically depending on their needs, they can participate in arts and crafts, sports, games, dance and movement, drama, music, activities with animals, and community outings. These activities, along with the aid of a recreational therapist, "treat and help maintain the physical, mental, and emotional well-being of their clients by seeking to reduce depression, stress, and anxiety; recover basic motor functioning and reasoning abilities; build confidence; and socialize effectively" (National Council for Therapeutic Recreation Certification, 2018, p.3).

Adapted Physical Education. Adapted physical education is a modified physical education program designed to meet the same needs for a person with a disability as for a person without a disability (Adapted Physical Education National Standards, 2008). Physical education programs help students develop physical abilities, motor skills, and athletic skills. Federal law mandates the adaptation of physical education programs to 
provide students with a disability the same opportunity to develop these skills (Adapted Physical Education National Standards, 2008). These programs utilize various recreational activities to develop fundamental motor skills and knowledge about socialization. Instructors develop adapted physical activities to develop these skills. These adapted physical activities can be sports, dance, aquatic sessions, exercise, group activities, and individual games (Adapted Physical Education National Standards, 2008).

All of these recreational, sport, leisure opportunities are designed specifically to meet the individual needs of the user. This practice is known as inclusion. As the number of people with disabilities continues to grow, efforts have also grown to meet their recreational needs. The next section discusses how many people are not afforded these recreational experiences. Barriers and Facilitators for People with Disabilities

As previously discussed, the benefits of participation in leisure activities by people with disabilities are integral to maintaining a holistically healthy lifestyle. Individuals with a disability are more likely to live less active lifestyles and discontinue participation in physical activities than people without a disability (Martin-Ginis, Latimer-Cheung, \& Rimmer, 2016). Despite the evidence of the benefits, people with disabilities are routinely an underrepresented demographic among recreation, sport, and leisure users. Recreation, sport, and leisure practitioners are continually striving to better engage people with disabilities. To aid practitioners, the following section outlines the common barriers people with disabilities face when trying to participate in physical activities and facilitators practitioners have utilized to overcome common barriers. 
Barriers to Recreation for People with Disabilities. People with mobility disabilities face numerous obstacles when trying to participate in healthy activities. These obstacles or barriers can range from physical environments (inaccessible sidewalks, trails, and facilities) to social environments (non-inclusive groups, practices, and lack of education). These obstacles force people with disabilities to miss out on opportunities to be physically active compared to people without disabilities (Martin-Ginis, LatimerCheung, \& Rimmer, 2016). These barriers actively exacerbate low participation rates (Rimmer et al., 2016). Studies have shown the most prevalent barriers to recreation for people with disabilities to be inadequate facilities, lack of knowledge/education, lack of resources, lack of preferences, and fear/intimidation (Calder, Sole, \& Mulligan, 2018; French \& Hainsworth, 2001; Martin-Ginis, Latimer-Cheung, \& Rimmer, 2016; Mulligan, Hales, Whitehead, \& Baxter, 2012; Rimmer, Chen, \& Hsieh, 2011; Rimmer \& Rowland, 2008; Rolfe, Yoshida, Renwick, Bailey, 2007).

Physical and Environmental Barriers (Inadequate Facilities). The primary barrier to recreation for people with disabilities is an inaccessible environment (Calder, Sole, \& Mulligan, 2018; Rimmer, Chen, \& Hsieh, 2011; Rimmer \& Rowland, 2008; Rolfe, Yoshida, Renwick, Bailey, 2007). Many of the built environments of fitness facilities present accessibility issues for people with disabilities. People with disabilities must overcome various inaccessible features in order to participate.

Fitness centers commonly have inaccessible access routes. This can lead to congestion and inability to utilize equipment or features of the facility. Additionally, a lack of space around equipment can create safety issues or prevent the transfer to and use of fitness equipment (Calder, Sole, \& Mulligan, 2018). The fitness equipment itself can 
be inherently inaccessible and most fitness centers lack adaptable equipment (Rimmer, 2005b). Lack of awareness, knowledge, and education can exacerbate the existing barriers for people with disabilities.

Social/Attitudinal Barriers (Lack of Knowledge). Oftentimes a lack of knowledge and understanding of the issues people with disabilities face can create barriers to participation (Calder, Sole, \& Mulligan, 2018). This lack of knowledge leads to people with disabilities not feeling supported by family members, friends, health professionals, and fitness center staff (Calder, Sole, \& Mulligan, 2018). These feelings and attitudes create barriers to recreation which people with disabilities struggle to overcome. Many studies have attributed this lack of understanding to insufficient training and education of fitness center staff (Calder, Sole, \& Mulligan, 2018; French \& Hainsworth, 2001; MartinGinis, Latimer-Cheung, \& Rimmer, 2016; Mulligan, Hales, Whitehead, \& Baxter, 2012). Specifically, a lack of understanding of the needs of people with disabilities by fitness center staff is the main component of this barrier. Policies, program offerings, membership costs, and inadequate staff training lead to an unwelcoming environment for people with disabilities (Calder, Sole, \& Mulligan, 2018). Studies have indicated a lack of staff training on disability issues and programming for people with disabilities (Calder, Sole, \& Mulligan, 2018; Rimmer, 2005b; Rolfe, Yoshida, Renwick, \& Bailey, 2012). This lack of training reflects poorly on the facility and further reduces the accessibility of recreational activities for all participants (Rolfe et al., 2012). Recreation programs generally fail to have enough staff trained in accessibility-related concerns such as operating adaptable equipment, offerings, or policies (Rolfe et al., 2012). 
This failure can cause people with disabilities to perceive situations as unfriendly and unwelcoming. At times the frustration from the customer and the facility staff can lead to potential negative attitudes. Employees who are not properly educated or trained in interacting with people with disabilities can intentionally or unintentionally create an unwelcoming environment (Cartner, 2018). Unfortunately, these actions become circular and are repeated over time if proper etiquette is not modelled and learned (Cartner, 2018). This lack of awareness or training can be attributed to a lack of funding or resources to adequately train personnel.

Lack of Resources. Cartner (2018) suggests the current financial environment of higher education institutions is the greatest challenge to inclusivity. Many recreation centers cater to a large array of customers with specific fitness needs. Oftentimes, facilities struggle to meet all of these needs. In the US, approximately 36,180 fitness facilities serve 55.3 million members (Rimmer et al., 2016). The large number of members causes recreation practitioners issues when developing strategies to satisfy their customers. According to Smith et. al (2011), recreation centers can attribute a lack of inclusiveness to insufficient budgets. If institutions do not prioritize inclusive practices from a budgetary perspective, creating an inclusive environment will be difficult (Cartner, 2018).

Unfortunately, due to the high volume of customers, practitioners will generally focus their efforts on meeting the needs of the majority of their customers. Since ablebodied members are more numerous than members with disabilities, the majority of resources are being utilized to meet their needs (Calder, Sole, \& Mulligan, 2018). This preference can be considered reflective of an ableist society. Exacerbating this issue is the 
higher cost for much of the adaptable equipment and accommodations. Fitness centers are rarely sufficiently funded and thus sustaining programs and adding adaptable equipment is sacrificed (Young, 2014).

Similar resource allocation issues arise when trying to accommodate multiple needs within the members of recreation centers with disabilities. Strength training and cardiovascular exercise programs are the most frequently recommended types of physical activities for people with disabilities (Calder, Sole, \& Mulligan, 2018). Therefore, recreation centers tend to focus on meeting those needs first. Practitioners believe they are offering inclusive practices, but at times can be unaware of the issues people with disabilities face.

Many administrators rely on users to voice inclusive challenges (Cartner, 2018). Once administrators are made aware of an issue, they will do what they can to alleviate the problem to provide adequate service. This frequent practice puts the onus on users with disabilities to speak up and voice concerns. This action can cause fear and intimidation for those individuals depending on how open the administrators are to change. This in itself is a barrier to participation and can quickly lead to patrons with disabilities not feeling welcomed at a fitness center (Cartner, 2018).

Overcoming Barriers for the People with Disabilities (Facilitators). Improving physical fitness for people with disabilities is of great interest for practitioners due to the potential health risks associated with the general inactivity of this underserved population (Bloemen, Van Wely, Mollema, Dallmeijer, \& De Groot, 2017). To increase participation by this population, it is necessary to identify potential facilitators of an active lifestyle. 
Personal Well-Being. The first facilitator is personal wellbeing and the desire to be fit. Studies have indicated individuals with disabilities want to improve their overall wellness which increases their motivation to utilize a recreation center (Richardson, Smith, \& Papathomas, 2016). In this study, individuals with a disability initiated a fitness routine motivated by potential to improve their physical health. The perceived improvements were associated with the desire to improve motor function, reduce pain, and enhance independence (Richardson, Smith, \& Papathomas, 2016). The aesthetic motivation of physical improvement has been shown to be a facilitator for following a healthy lifestyle - simply looking better can make a person feel better (Kehn \& Kroll, 2009). The more long-lasting healing benefits of exercise, however, are derived from encouragement by health professionals and rehabilitation specialists (Richardson, Smith, \& Papathomas, 2016).

People with disabilities view going to the gym as a social space to interact with people and develop relationships (Richardson, Smith, \& Papathomas, 2016). Sharing the experiences of exercise with other individuals at a recreation center creates the perception of belonging and acceptance. In contrast, in society generally social interactions are not as positive for people with disabilities. The feeling of belonging to a community, such as a gym, creates a personal perception of acceptance and self-worth (Richardson, Smith, \& Papathomas, 2016). This perception is only garnered from a positive gym going experience.

Opportunities sensitive to the needs of people with disabilities. Positive exercise experiences for people with disabilities occur when the recreational environment is considered welcoming. Positive social interactions with staff and other participants lead 
to a greater desire for individuals with disabilities to exercise (Richardson, Smith, \& Papathomas, 2016). Individuals feel more welcomed when the staff is educated and understand the challenges presented by having a disability (Shields \& Synnot, 2016).

The staff can help create this welcoming environment by dissemination information about the resources available to the participants with disabilities. Knowledgeable staff are willing to explain and modify activities to fit an individual's needs (Shields \& Synnot, 2016). Additionally, the willingness of peers to interact creates a feeling of acceptance. However, if the willingness to interact is not prevalent or noticeable, it could deter participation (Shields \& Synnot, 2016). Promotion of these efforts is determined from a top-down approach. Inclusive policies and procedures must be encouraged from directors and trickle down to the interacting staff to increase participation by people with disabilities (Shields \& Synnot, 2016).

Staff needs to have an understanding that disabilities are not monolithic and what works for one individual might not work for another. Willingness to adapt equipment and modify activities to fit an individual's needs increases positive interaction. Specifically asking the individual to identify his/her desires will help generate a sense of inclusion (Shields \& Synnot, 2016). Creating these inclusive modifications will increase an individual's likelihood of participation.

The largest barrier people with disabilities must overcome is the unequal treatment and oppression from society which deems them inferior to their able-bodied peers. To combat this unequal treatment, people with disabilities utilized the legal system to protect their rights as citizens. The following section examines the legal protections afforded to people with disabilities to ensure non-discrimination. 


\section{Legal Protection for People with Disabilities}

Individuals with disabilities have fought for legal protections of their equal rights for decades. In an effort to provide equal protection under the Constitution, many of the groups being discriminated against protested to ensure equal rights to all citizens of the US (Yell, Rogers, \& Rogers, 1998). These movements began with women's suffrage and continue to this day in the US. One of these movements worked to protect the rights of people with disabilities. This led to the creation of the Rehabilitation Act of 1973. The Rehabilitation Act

Indiana Representative John Brademas and West Virginia Senator Randolph Jennings introduced The Rehabilitation Act of 1973 in Congress (Wegner, 1984). President Nixon signed The Rehabilitation Act to extend civil rights to people with disabilities and prohibiting discrimination on the basis of disability (Wegner, 1984). Section 504 of The Rehabilitation Act mandates "No otherwise qualified handicapped individual shall, solely by reason of his handicap, be excluded from the participation in, be denied the benefits of, or be subjected to discrimination under any program or activity receiving Federal financial assistance” (U.S. Department of Justice, 2009, p. 34). The Rehabilitation Act was crafted to eradicate social barriers encountered by people with disabilities. The Act mandated affirmative action and nondiscrimination in employment by federal agencies, created the Architectural and Transportation Barriers Compliance Board, prohibited the discrimination of employment due to disability for any business with federal contracts, prohibited discrimination in the basis of disability to programs receiving funds, and created access to communication and technology (U.S. Department of Justice, 2009). 
The Rehabilitation Act was later amended in 1978, 1986, and 1992 to clarify additional services and rights afforded to people with disabilities. Additionally, The Rehabilitation Act did not protect people with disabilities from discrimination in the private sector or in public accommodations (Mid-Atlantic ADA Center, 2018). Therefore, new legislation was required to ensure equal rights to people with disabilities as mandated by the US constitution to all US citizens. This new legislation was titled the Americans with Disabilities Act.

The Americans with Disabilities Act

Due to advancements in the field of disability studies, people with disabilities are now being seen through different lenses. In the United States, significant changes have occurred in the values and attitudes toward people with disabilities (Rimmerman, 2011). As discussed previously, due to the civil rights movement of the 1960s, people with disabilities in the US have been encouraged to organize and advocate for fair and equal treatment (Rimmerman, 2011). Additionally, the equality concept has transcended from theory into practices which impact society. Today, disabilities are classified, defined, and protected through governmental and legal systems. The guiding legislation in the US is the Americans with Disabilities Act (ADA). The ADA defines a person with a disability as "one who has a physical or mental impairment which substantially limits one or more major life activities" (Americans with Disabilities Act § 12102, 1990, p. 7). The ADA prohibits discrimination against anyone meeting the definition of a person with a disability. This law mandates the equal treatment of people with disabilities in all public accommodations, employment, public programs, and service providers (Americans with 
Disabilities Act $\S 12101,1990)$. The ADA has five sections or titles to explain the equal rights afforded to people with disabilities in the United States.

Title I: Employment. Title I of the ADA prohibits all employers with more than 15 employees from discriminating against qualified individuals in regard to employment. A qualified individual is any person who can perform the essential functions of the employment position. This Title requires all private employers, state and local government, employment agencies, and labor unions to adhere to this policy during all employment processes (Americans with Disabilities Act $\S 12101,1990)$. This includes applications, hiring, firing, advancement, compensation, training, and privileges of employment. Title I is mandated unless the accommodation presents an undue hardship to the employer. An undue hardship is an action requiring significant difficulty or expense (Americans with Disabilities Act $§ 12101,1990)$.

Title II: Public services. Title II of the ADA prohibits discrimination against people with disabilities in all programs, services, or public entities. Public entities are defined as any state and local government agencies. This includes transportation services such as the public bus system. Title II mandates that all people with disabilities shall not be excluded due to their disability from participation in or denied the benefits of services by a public entity (Americans with Disabilities Act $\S 12101,1990$ ).

Title II covers all public transportation service such as bus systems, public transit, and public rail systems (U.S. Department of Justice, 2009). All public services must comply with the mandated requirements Title II (Americans with Disabilities Act $\S$ 12101, 1990). 
Title III: Public accommodations and commercial facilities. Title III of the ADA mandates:

Private entities open to the public must allow individuals with disabilities the ability to participate equally in any goods or services offered. Private entities include restaurants, stores, shops, hotels, and any other public commercial entity. This title requires these entities to remove all access barriers for people with disabilities. Additionally, all policies, practices, and procedures should be altered to accommodate the needs of people with disabilities (Americans with Disabilities Act $\S 12181,1990$, p. 30).

Title III requires all public accommodations to prohibit exclusion, segregation, and unequal treatment (U.S. Department of Justice, 2009). Additional requirements include mandates to provide access to people with disabilities for any new or altered buildings. Access requirements include barrier removal, modification policies and procedures, and effective communication efforts. All new and altered facilities must comply with the ADA's architectural standards or face litigation by the Department of Justice or private lawsuits (U.S. Department of Justice, 2009).

Title IV: Miscellaneous. Title IV of the ADA includes a variety of regulations clarifying the relationship of the ADA to any other laws or provisions. This Title specifically ties itself to the Civil Rights Act and its amendments (Rimmerman, 2011). This ensures people with disabilities are provided equal or greater protection of their rights (Americans with Disabilities Act $§ 12201,1990$ ). The miscellaneous regulations are construction, state immunity, prohibition against retaliation and coercion, regulation by Architectural and Transportation Barriers Compliance Board, attorney's fees, 
technical assistance, federal wilderness areas, transvestites, instrumentalities of Congress, illegal use of drugs, and telecommunications.

Title IV specifically addresses telephone and television access for people with disabilities (U.S. Department of Justice, 2009). All common carriers must establish interstate and intrastate telecommunication relay services at all times. These services enable callers with hearing or speech disabilities to communicate with each other through a third-party communications assistant. Additionally, Title IV mandates all federally funded public service announcements provide closed captioning (U.S. Department of Justice, 2009).

2010 ADA Standards for Accessible Design. In 2010, the United States Department of Justice published revised regulations for Titles II and III of the ADA (United States Department of Justice, 2010). The revised regulations are consistent with the guidelines published by the U.S. Architectural and Transportation Barriers Compliance Board in the Architectural Barriers Act (ABA) of 2004. To alleviate any compliance issues, the $\mathrm{ADA}$ and the $\mathrm{ABA}$ harmonized their guidelines to mirror each other. This harmonization led to changes specifically to address recreation facilities, play areas, and state and local government facilities (United States Department of Justice, 2010.

Fitness and Recreational Facilities Under the ADA. Fitness facilities open to the public or at educational institutions are covered under Title II (Public Services) and Title III (Public Accommodations and Commercial Facilities) of the ADA (Leuchovious, 2003). These Titles mandate all facilities meet the minimum standards for accessible paths, heights of countertops, heights of fixtures, signage, bathrooms fixtures, railings, 
and flooring selection (Broadhag, 2012). As a result of the new 2010 standards, additional requirements of fitness centers must have been met before March $15^{\text {th }}, 2012$ and applied to any future facilities. Failure to comply with these requirements could result in civil penalties up to $\$ 55,000$ for each offense and the ability for the individual sue the business for discrimination (Broadhag, 2012).

Fitness facilities are required to have at least one of each type of exercise equipment accessible to people with disabilities ("Fact Sheet", 2010). The requirement is fairly easy to adhere to as long as the facility has enough space to move equipment around. The designated equipment needs a minimum of 30 inches by 48 inches of open space for people with disabilities to access the equipment (Broadhag, 2012). An additional 60-inch diameter is needed to be able to make a full turn in a wheelchair (Piletic, Judge, \& Petersen, 2014). The reason for the clear floor space mandate is to allow a people with disabilities the ability to utilize the machine. Should a person need to transfer from a wheelchair to use the machine, adequate space is needed. This designated piece of equipment must be connected to an accessible route ("Exercise Equipment", n.d.). The access route is different than clear floor space. Clear floor space is where patrons will park their mobility device (wheelchair, scooter, walker, brace, etc.) (Piletic, et al., 2014). If clear space is part of an access route, the mobility device will block access for other patrons (Piletic, et al., 2014).

The ADA now requires at least one piece of strength training equipment and cardiovascular equipment meet the required space standard described previously and located on the accessible path. All must comply with the requirements of the ADA, unless they serve an identical purpose in the workouts. An example of this would be a 
treadmill made by Life Fitness and a treadmill made by Cybex. Both of these treadmills do the same exercise, therefore only one would need to meet the space requirement.

Campus recreation staff members have the important task of equipment selection and allocation. Practitioners utilize programming objectives, facility philosophies, benchmarking, trends, and target populations when deciding on equipment needs (Piletic, et al., 2014). Strength training utilizes a variety of different pieces of equipment to work targeted muscle groups. Multi-station wheelchair accessible machines must be provided (Piletic, et al., 2014). This type of fitness equipment will feature wide seats (which can be adjusted or moved out of the way), wheelchair tie downs, and storage units to hold braces or water bottles (Judge, 2013). Weight racks or pulley system machines should also be provided (Piletic, et al., 2014). These machines do not have a standard fixed seat, which allows a person to perform the desired exercise from their wheelchair (Judge, 2013). These machines are very versatile and can have numerous height adjustment features.

Practitioners are continually trying to assess the accessibility of their recreation and fitness centers. Many of their efforts require machines to have removable seats at least 18 inches wide and ideally have back support (Rimmer \& Riley, 2006). Equipment and free weights should have low weight settings starting at less than five pounds. Other selectorized machines, to increase accessibility, allow patrons to work out while standing or in a wheelchair without having to transfer to a seat (Rimmer \& Riley, 2006). This allows individuals to utilize the machine as independently as possible (Piletic, et al., 2014). Additionally, all reach requirements to access equipment can no longer be higher than 54 inches or lower than 9 inches ("Fact Sheet", 2010). This reach requirement comes into play in addressing components or add-ons to exercise equipment. 
Cardiovascular exercise machines have additional accessible recommendations. It is recommended that treadmills have a start setting of less than one mile per hour (Rimmer \& Riley, 2006). All cardio machines should have auditory signals and raised control buttons (Piletic, et al., 2014). Stationary bikes come in multiple different types (uprights, spin, recumbent, etc.) in order to meet a variety of specific needs (Piletic, et al., 2014). The same seat recommendations of 18 inches wide and back support are standard (Rimmer \& Riley, 2006).

Outside of the usual cardiovascular equipment, additional equipment caters specifically to people with disabilities. The upper body ergometer (UBE) can be used by anyone but is specifically designed to be accessible to people with disabilities (Piletic, et al., 2014). An additional machine commonly seen in fitness centers is the NuStep recumbent stepper. This machine provides exercises for arms and legs while in a comfortable seated position (Piletic, et al., 2014). Adaptable cardiovascular machines are growing in popularity; however, they are expensive and hard to find.

In today's society, fitness and recreation practitioners are charged by their leadership to focus on providing socially inclusive environments which goes beyond the limits of the ADA (Liasidou, 2014). This trend transcends fitness and recreation to most service-oriented professions. One of the more forward-thinking service-oriented professions is higher education as they continue to provide opportunities for people with disabilities. This is a drastic change from the past when people with disabilities were systematically denied access to opportunities in higher education (Liasidou, 2014).

In an effort to provide a more accepting and inclusive environment, institutions have designed campuses, facilities, services, and programs to be accessible and usable by 
everyone, including those with disabilities (Stager-Wilson, Barnett, Mahoney, \& Sampson, 2012). Due to legal obligations, most college campus facilities are designed to be accessible. Programs and services also must be designed to provide an inclusive environment and meet the diverse needs of the student population (Stager-Wilson, et al., 2012). The following section will discuss how higher education strives to create an inclusive environment.

Higher Education Inclusion for People with Disabilities

According to the 2010 United States Census, almost 20 percent (56.7 million) of the country's population reported having a disability. The higher education setting has been shown to be a microcosm for society and the student population is more diverse than ever (Douglas, 2005). The number of people with disabilities in the campus community is perpetually growing just as in the rest of the world. According to the National Center for Education Statistics (2016), 11.1 percent of students enrolled in college during the 2011-2012 school year had a disability. College campuses must be aware of the desires and needs of their participants in order to meet the needs of their constituents. As the population of people with disabilities grows on collegiate campus, so too must the knowledge on how to better serve this population grow.

College campuses aim to meet the needs and desires of people with disabilities through the diverse practices of inclusion in education, transportation, programs, environment, and services (Eckes \& Ochoa, 2005). One example of this effort to create a more inclusive campus experience is campus recreation. Many colleges operate successful campus recreation departments which promote a holistic learning environment. This holistic learning experience creates an opportunity to establish lifelong 
habits of healthy living. Campus recreation centers, specifically, provide access for students to create these lifelong habits by offering diverse and inclusive programs promoting health and wellness.

Research has proven people with disabilities have an increased risk of chronic illnesses and secondary health conditions compared to the general population (Rimmer, Padalabalanarayanan, \& Malone, 2016). Campus recreation programs specifically help individuals with a disability to lead a healthier more active lifestyle. Research has shown people with disabilities are more likely to lead a sedentary lifestyle than able-bodied individuals. An estimated 56 percent of people with disabilities take part in no leisurely physical activity (Rimmer, Riley, Wang, \& Rauworth, 2005). To combat sedentary lifestyles, many campus recreation centers provide access and training for patrons with disabilities in order to create a lifestyle of wellness and healthy living. To encourage this, campus recreation centers have started to offer programs and activities for people with disabilities. For example, Eastern Kentucky University recently created an adaptive climbing program to introduce people with disabilities to new activities previously thought to be beyond their capabilities (Eastern Kentucky University, 2016). Institutions of higher education have incorporated campus recreation programs ever since the first recognized programs were developed at The Marshall College and the Coolidge College in 1913 (Young, Ramos, York, \& Fletcher, 2016). Campus recreation programs promote the values of diversity and inclusion by creating programs and services to meet the students' needs and desires regardless of physical ability. Through this effort, the philosophy of campus recreation is to create opportunities for all students to be active and involved. 


\section{Campus Recreation Inclusion}

Campus recreation professionals seek to provide programming to meet the sport participation needs of the student body (Young, Ramos, York, \& Fletcher, 2016). Campus recreation departments continually improve programs, services, and facilities to create a more inclusive campus climate (Young, et al., 2016). The professional organization for collegiate campus recreation is the National Intramural Recreational Sports Association (NIRSA). NIRSA values diversity, inclusion, and promotes opportunities for all students (Young, et al., 2016). NIRSA, as the governing body of campus recreation programs, is inherently proactive in promoting diversity and inclusion. The organization itself was created 1950 by scholars at 20 Historically Black Colleges and Universities (HBCUs) and soon added other institutions to encompass the entire intramural community (NIRSA, 2019a). The original mission of NIRSA was to support recreational sports professionals in creating communities of well-being on campuses everywhere (NIRSA, 2019a). This mission shows how NIRSA has been a leader in promoting inclusion and diversity from the very beginning. Today the mission of NIRSA reads "NIRSA is a leader in higher education and the advocate for the advancement of recreation, sport, and wellness by providing educational and developmental opportunities, generating and sharing knowledge, and promoting networking and growth for our members" (NIRSA, , 2019b, p.1). These mission statements do not directly speak to efforts of inclusion and diversity but NIRSA aims to be a powerful example in the development of leadership, sustainable communities, health and wellbeing, equity diversity and inclusion, service, and a global perspective (NIRSA, 2019b). NIRSA tries to impart these principles upon every member institution to ensure the organizations 
continue to move forward and also to set examples for other areas of higher education to follow. NIRSA helps the campus recreation industry determine practices in identifying and including underserved populations of the campus communities. Two of these historically underserved populations are gender identities other than males and people with disabilities.

Gender inclusion in campus recreation. Gender identity inclusion and equality has been an extremely important component of campus recreation since the passage of the Title IX legislation. Title IX states "No person in the United States shall, on the basis on sex, be excluded from participation in, be denied the benefits of, or be subjected to discrimination under an education program or activity receiving federal financial assistance" (Sex, 1972, para. 1). McDowell et al. (2016) discussed how the Office of Civil Rights (OCR) created a Policy Interpretation in 1979, which determined the four levels of sport: intercollegiate varsity athletics, club, intramural, and interscholastic athletics. This confirmed campus recreation fell under the umbrella of Title IX legislation. The OCR established the following three-prong test to help determine if schools were in violation of Title IX (A Policy Interpretation, 1979): Whether intercollegiate level participation opportunities for male and female students are provided in numbers substantially proportionate to their respective enrollments; or Where the members of one sex have been and are underrepresented among intercollegiate athletes, whether the institution can show a history and continuing practice of program expansion which is demonstrably responsive to the developing interests and abilities of that sex; or Where the members of one sex are underrepresented among intercollegiate athletes, and the institution cannot show a continuing practice of program expansion such as cited 
above, whether it can be demonstrated that the interests and abilities of the members of that sex have been fully and effectively accommodated by the present program.

Schools receiving federal funding must satisfy at least one of the three prongs to be compliant with Title IX legislation. Much of the research surrounding Title IX and intercollegiate athletics pertains to varsity sport. However, this legislation goes beyond athletics to ensure equal treatment of all gender identities throughout the institutions. Campus recreation departments are located within institutions receiving federal funding and therefore are mandated to provide opportunities to all gender identities throughout their facilities, programs, and services.

Fields (2006) discussed the impact of Title IX in intramural and club sports. A personal inquiry by McDowell et al. (2016) to the OCR found no cases of Title IX violations in intramural sports, club sports, and campus recreation departments from 2000 to 2014. Still, Fields (2006) warned that Title IX violations could occur in college recreational sport programs if administrators were not careful when implementing rules, regulations and policies in intramural sports. Since intramural sport contains high participation numbers, it is important that students are being provided equal opportunities.

One of the ways to increase opportunities to the underserved populations outside of the male gender is to create coeducational recreation sports (Co Rec sports). Co Rec sports, defined as sports all gender identities can integrate into, was originally a concept created to increase female participation in campus recreation (Woods, 2014). One of the first universities to initiate Co Rec sports was Illinois State University when they added rule modifications to ensure participant safety (Bohlig, 1991). The momentum for this 
change was due to the inherently violent nature of the sport of floor hockey and the low number of women's teams (Bohlig, 1991). To combat these issues, the sport changed to coed and specific rules mitigated the violence (Bohlig, 1991). This change sparked an incredible jump in participation numbers for female students, due to the change from a competitive violent atmosphere to more of a social activity (Bohlig, 1991). Due to this increase, many programs adopted rule modifications across the United States to increase female participation in intramural sports.

NIRSA published sample sets of rules to facilitate the development of successful intramural programs ("Intramural Sport Rules", 2017). These rules generally have notes and suggested variations to give the professionals the ability to modify rules to reflect unique participation groups or program requirements. NIRSA also sponsors a championship series to foster national competition across all intramural programs. NIRSA regulates these championships by rules specific to each championship sport including rule modifications for coed sport competitions ("NIRSA Championship Series", 2017).

Flag football is generally one of the most popular intramural sports on college campuses and provided a prime example of rule modifications as promoted by the NIRSA rulebooks. The main rule modifications related to male runners, male to male completions, and touchdown values (Mauer, 2015). The male runner rule stipulated that males are not allowed to advance the ball as a runner past the line of scrimmage. However, a female can advance the ball on a running play across the line of scrimmage (Mauer, 2015). The male-to-male completion rules are a bit more convoluted. Open plays are those plays that have no limitation on involvement. Males can pass to both females 
and males. If the outcome of the open play is a male-to-male pass completion, then the subsequent play must involve a female participant (Mauer, 2015). This is considered a close play. During this play, a female member of the team must either pass or receive the ball. The touchdown value rule stipulated that if a female player scores a touchdown it is valued at nine points whereas when a male scores a touchdown it is worth the normal six points (Mauer, 2015). These rule modifications are put in place by campus recreation practitioners to increase female participation numbers. The creation of Co Rec sports and the additions of the rule modifications has increased female participation numbers but also created inequalities between the genders in the sport themselves. Recently, the campus recreation community has become aware how the Co Rec sport's rule modifications exacerbated the perceptions of gender roles and created an inequality among the participants (Wood \& Garn, 2016). Even though these rules are in place to promote female inclusion, they also promoted beliefs that women needed assistance from the rules to be able to compete on the same field as men (McDowell, Deterding, Elmore, Morford, \& Morris, 2016). In other words, even though rule changes increased female participation opportunities and promoted inclusion in sport, this inequality of genders in sport could be a violation of Title IX legislation (Tharp, 1994).

This observation of the inequalities created by the rule modifications has sparked an ongoing debate among campus recreational professionals on whether these rules create opportunities or in fact just promote inequalities. In response to this debate many campus recreation departments have removed all rule modifications from their Co Rec sport leagues (University of Colorado, 2019). The University of Colorado Boulder intramural program removed all scoring bonus and open and closed play rules. Additionally, the 
program removed the designation of male and female leagues (University of Colorado, 2019). These actions addressed not only the inequalities created by the rule modification but also provided inclusion for other gender identities beyond males and females.

Providing inclusive efforts to all gender identities is a recent trend across the campus recreation landscape. In 2015, the Recreational Sports Journal, published by NIRSA, published an article discussing the current policies and practices of the campus recreation community for transgender populations (NIRSA, 2017). This article discussed how individuals outside of the male and female gender identities experience unique challenges to their participation in campus recreation (NIRSA, 2017). This study indicated that most public four-year institutions had some gender inclusive features of their facilities in the forms of non-gender specific bathrooms. However, about $80 \%$ of the respondent institutions had no policies in place to support or protect transgender participants (NIRSA, 2017). This study also indicated that only about $10 \%$ of the institutions participating in this study had specific staff training in working with the transgender population. Furthermore, only about $1 \%$ of these institutions have created programming specifically to include people identifying as being transgender (NIRSA, 2017). These findings have alerted campus recreational professionals that this marginalized population is not being included in campus recreation (NIRSA, 2017).

It is integral for campus recreation practitioners to develop practices to increase the involvement of any populations to ensure they are provided equal opportunities. Another subpopulation identified as being underserved by campus recreation was people with disabilities. The next section will discuss the inclusive efforts being made by campus recreation departments to meet the needs of people with disabilities. 
Inclusive Campus Recreation Programming. Campus recreational programming now routinely caters to specific needs of people with disabilities and strives to be inclusive. Intramural sports are being designed to incorporate inclusive sports into the competition calendar. Sports such as goalball, sitting volleyball, beep ball, and wheelchair basketball now have active intramural competitions among all students, not just students with disabilities. The University of Kansas hosted an Inclusive Recreation Extravaganza event in 2018 featuring a number of inclusive sports and an educational seminar University of Kansas, 2018). This was an effort to educate the entire student body about people with disabilities and the inclusive offerings at the university (J. Randle, personal communication, April 4, 2018).

Creating a welcoming environment is not a legal requirement of the ADA, however many campus recreation programs utilize it as a best practice for inclusion (Young, et al., 2016). These programs and services provide opportunities to get students to interact with each other while promoting a social atmosphere. Campus recreation provides opportunities for students to engage, which in turn, creates a better quality of life at the institution with the goal of increasing student retention (Forrester, 2014).

Titus, Young, Nassen, and Ownhouse (2016) did a systematic review of recreation patterns of college students with disabilities. This study was undertaken in an effort to provide recommendations to practitioners on which recreation activities college students with disabilities preferred. The findings from this study suggested students with disabilities preferred not to engage in the institution's recreational facilities due to lack of satisfaction with the facilities and program offerings (Titus et al., 2016). The students reported numerous barriers they had to overcome such as lack of adaptive equipment. 
The students identified various obstacles which prohibited their involvement and engagement in both programs and facilities. Most of these barriers were physical barriers such as poor sidewalks, steep slopes, lack of lifts, poor signage, and architecture. The barriers the students faced cause a disability led to stress and helplessness (Titus et al., 2016).

Campus recreation practitioners are continually trying to meet the needs of their students with disabilities. Numerous studies have investigated the perceived barriers for people with disabilities to participate in campus recreation. There are a few theoretical frameworks which could aid campus recreation practitioners in their efforts to better meet the needs of their students with disabilities. The following sections will discuss the theoretical frameworks of Critical Disability Theory and Universal Design. These sections will discuss how campus recreation practitioners could benefit by implementing in their efforts to better meet the needs of their constituents.

Critical Disability Theory and Universal Design

Critical theories are linked to periods in society when complex intellectual activity takes place. Origins of critical theories can be traced back to the critical philosopher Immanuel Kant and the emergence of post-enlightenment thought (Burghardt, 2011). Many of the current critical theories originate from Kant's vision of modernity in which freedom has an intrinsic and unconditional positive value (Burghardt, 2011; Guyer, 2018). These current critical theories are Critical Legal Study (CLS), Critical Race Theory (CRT), and Critical Disability Theory (CDT). CLS and CRT laid further groundwork on top of previous critical movements for similar oppressed groups outside of the majority population. People with disabilities constitute one such 
marginalized population. Given the rich history of the critical theories, there is an evident lack of discussion surrounding the critical analysis of the oppression of people with disabilities. Critical Disability Theory attempts to address this lack of inquiry.

\section{Critical Disability Theory}

The first notion of disability oppression evolved from feminist theorists discussing bodily differences by gender (Burghardt, 2011). Incorporating disability studies into critical theory can be informative about the tensions between advocating on the behalf of others and the others' battles for self-autonomy and self-determination. Critical theories are therefore essential in analyzing the oppression of people with disabilities in order to consequently formulate strategies to create a more inclusive society.

The aforementioned CRT laid the groundwork for the creation of Critical Disability Theory (CDT). The intersectionality of CRT and CDT can provide insight into creating a culture of true equality. Greater equality has been achieved through accepting any differences of people with disabilities and acknowledging these differences do not make people with disabilities any less human.

CDT looks at the daily life of people with disabilities and compares their everyday experiences with the actualities of social norms and values (Hosking, 2008). People with disabilities are continually left out of the decision-making processes in society, business, and education. Kudlick (2005) describes a social norm process called "othering." This social norm process takes place when anyone considered unlike "the norm" is precluded from involvement and regarded as "the other" (Kudlick, 2005). This 
can be seen with people with disabilities in the notion of ableism. Ableism is the belief of a person without a disability, that is to say an able-bodied person, is the norm against which all others are compared (Procknow, Rocco \& Munn, 2017). CDT, on the other hand, is an understanding of the realities people with physical and cognitive disabilities face (Procknow, et al., 2017; Rocco, 2005). According to Procknow, Rocco, and Munn (2017), CDT asserts the following six core concepts: (a) ableism is invisible, (b) the epistemic violence against the disabled, (c) the binary view of disability instead of a continuum of human variation, (d) disability as a social construct, (e) the medical industry's commodification of people with disabilities, and (f) the right of autonomy and self-determination for people with disabilities.

Ableism is Invisible. CDT's first core concept is ableism is invisible. People with disabilities are under a constant threat of discrimination which is considered a natural state in society (similar to how racism is considered a natural state in CRT). Even in progressive settings, society unconsciously reaffirms and supports ableism (Mclean, 2011; Procknow, et al., 2017; Rocco, 2005). Since ableism is a natural state, it is invisible to offenders but is a constant threat to the victims (Rocco, 2005). Ableism marginalizes and labels people with disabilities as incompetent, lazy, and dishonest about the extent or existence of their disability (Rocco \& Collins, 2017). Oftentimes, people with disabilities are questioned when asking about possible accommodations. Exceptions for people with disabilities are frequently considered costly to programs and administrators (Rocco, 2005). However, inclusive exceptions have been proven to be minimally costly to employers (Job Accommodation Network, 2017). This misconception may cause employers to not consider accommodations due to the perceived inconvenience or lack of 
resources (Rocco, 2005). The ableist view creates oppressive systems of hiring, education, unfair treatment, and promotes or sustains oppressive structures (Procknow, et al., 2017). Oftentimes when asked to provide accommodations, administrators will ask for proof of disability to ensure no one is trying to cheat the system.

Disabilities are a fundamental part of the human experience and can occur in any person, often happening with age (Procknow, et al., 2017). Due to this possibility, people with disabilities are unlike any other minorities as individuals can join this minority group at any time and instantly experience oppression and ableism (Procknow, et al., 2017). The lack of acknowledging the possibility of becoming disabled can lead to other disqualification of people with disabilities. For example, a person who has an onset disability will immediately feel oppressed as s/he no longer is treated the same as before the disability occurred.

Epistemic Violence against People with Disabilities. Epistemic violence is the understanding of ways the disqualification of groups within a society is legitimized (Liegghio, 2013; Procknow, et al., 2017). People with disabilities are under constant threat of being ignored, silenced, or rendered unintelligible (Procknow, et al., 2017). People with disabilities' personal identities are disregarded or discounted compared to the perceived "normal" populations (Procknow, et al., 2017). The views, knowledge, and understanding of people with disabilities is often overlooked or ignored due to their perceived disability (Procknow, et al., 2017). This action promotes the oppression of the disabled minority in the same ways as racism, classism, and sexism (Davis, 2001). By devaluing an individual's contribution, society demotes people with disabilities' sense of being or identity. Once an individual is labeled or identified as having a disability, all 
other aspects of the individual are looked at through a lens filtered by disability. This lens moves people with disabilities outside of the "in-group" as they are considered incapable of significant contribution according to preconceived standards of society (Procknow, et al., 2017).

Davis (2001) insists oppression against people with disabilities is similar regardless of the individual's sex, race, or class. According to the sociocultural or historical context, intersectionality of an individual's identities (gender, race, disability, ethnicity, religion, or class) should produce varying effects of experiences. However, at certain times one identity can dominate an experience and at other times multiple intersecting identities can influence the oppression a person endures (Rocco \& West, 1998; Sheared, 1999). The outcomes can be influenced by varying levels of identities which carry differing levels of sociocultural privilege (Sheared, 1999).

Binary View of Disability. Human variations are naturally occurring phenomena which manifest differently in different individuals. Disability has the possibility to transcend other human variations and an individual can become disabled at any point in his/her life (Procknow, et al., 2017). However, when a variation is identified as a disability it is often considered a problem. Society sees disability as a black and white concept of either having a disability or not.

Disability is a natural occurrence and should be viewed on a continuum of the human condition (Procknow, et al. 2017). The qualification of disability is determined by the life the individual with the variation leads and the contexts of sociocultural, political, and historical views (Procknow, et al., 2017). Recognizing this disability continuum in its 
many variations should aid in creating a refitted societal view and generate a more supportive environment for people with disabilities (Procknow, et al., 2017).

Disability is a Social Construct. Disability is viewed by society as a deficiency. Objectification of disabilities is determined by the political, social, economic, and cultural norms of the "in-group", that is, able-bodied individuals. Ableism creates obstacles for people with disabilities by labeling such individuals as disadvantaged (Procknow, et al., 2017). This view allows society to isolate people with disabilities by creating attitudes against achieving success (Procknow, et al. 2017). Barriers are created to uphold these beliefs, continuing to establish inequalities for people with disabilities. This general understanding of disability separates society into able and disabled, labeling the disabled as abnormalities and thus perpetuating the construct (Procknow, et al., 2017). People with disabilities are often objectified and portrayed as victims, leading society to create more attitudes and beliefs based upon the disability and not the individual (Linton, 1998; Oliver, 1996).

Public attitudes lead to standardization of societal norms which determine general standards for physical space, organization, policies, and procedures. The needs of the majority establish these standards (Rocco, 2005). However, since people with disabilities are outside of the majority their needs are not routinely accommodated. If the needs of people with disabilities were addressed in addition to the needs of the majority, all individuals' needs could be met (Rocco, 2005). If appropriate accommodations are considered during the planning stages, costly exceptions or changes would be alleviated (Rocco, 2005). This notion ties closely to the concept of Universal Design, which is discussed later in this review. 
Medical Industry Commodifies the Disabled. Historically, the medical profession and society have treated people with disabilities as a commodity (Rocco, 2005). Taking away the identity of self, medical professionals have long sequestered people with disabilities in treatment facilities, asylums, or group homes (Finkler \& Grant 2011; Procknow, et al., 2017). The medical profession can actually make the decision if a person with a disability is going to be a successful contributor to society or not. This determination fosters a stigmatization which may result in permanent dependence and lack of responsibility (Malhotra \& Rowe, 2014; Procknow, et al., 2017).

Right of Autonomy and Self-Determination. People with disabilities should have the same rights as all individuals for their autonomy and self-determination (Rocco, 2005). Oftentimes, disabilities are viewed as monolithic instead of being viewed as an individual anomaly (Procknow, et al., 2017). It is important to remember that the needs of one do not meet the needs of all. Self-determination is the ability to make one's own choice to determine the outcomes of one's individual actions (Rocco, 2005). People with disabilities do not need to rely on others to make decisions, but instead should be able and free to make decisions on their own behalf. Being able to exercise one's right to autonomy is true equality.

A common practice which illustrates the denial of autonomy is not involving anyone with a disability in decision-making processes that affect them. Many of these decisions are made by practitioners under the guise of what they think would best suit an individual with a disability. Creating a dialogue between decision-makers and the intended beneficiaries is integral to accurately meet the needs of potential clients with 
disabilities. This common practice is one of many which leads to further oppression of people with a disability.

The core concepts of CDT identify the obstacles people with disabilities inherit due to the perceived norms of society. Living with a disability does not preclude an individual from being a productive member of society. However, having access to the same opportunities afforded to all individuals enhances the contributions people with disabilities can make to the workforce, leadership, and society. Researchers utilize CDT to understand the exclusion of marginalized populations like people with disabilities.

Dunn, Hanes, Hardie, Lesliem, and MacDonald (2008) specifically utilized CDT in a study to develop a more thorough knowledge of practices in Canadian Schools of Social Work which lead to more equitable outcomes for students with disabilities. Dunn, et al. (2008) were able to develop a list of recommendations for college programs on how to be more equitable in their principles and practices with different student populations. This study surveyed administrators at 25 different Canadian colleges to gather information about accomplishments in disability inclusion and areas practitioners felt needed to be addressed to provide a more equitable student experience (Dunn et al., 2008). Additionally, the researchers held a one-day forum for experts in disability services which included both students and professionals to discuss the current landscape of inclusion on college campuses (Dunn et al., 2008). This study identified the following themes of best practices for inclusive campus: collaboration between the school and disability services is key, schools must advocate for social change, understanding the concept of equity, creating progressive and comprehensive inclusive policies, and creating an inclusive environment (Dunn et al., 2008). This project found many 
successful inclusive programs on college campuses. Through this investigation, the researchers gained knowledge on ways to continually create more inclusive environments on college campuses through making the environment a place where everyone is recognized, valued, and empowered (Dunn et al., 2008).

People in leadership positions continually create new practices to facilitate society's progress to become more diverse and inclusive. This can be seen in governmental laws or bills to provide access or even resources to programs to make society more accessible to all people. Progress toward inclusion is an ongoing global battle still being fought on all levels of society. One method practitioners use to create inclusive practices is the theory of universal design (UD). The next section discusses the theory of UD and how the practice can promote opportunities for all people.

\section{Universal Design}

Universal Design (UD) is the intentional design of an environment to be as accessible as possible for all people, regardless of age, size, ability, or disability (National Disability Authority, 2014a). UD is a concept related to designing environments, buildings, products, or services to meet the needs of any possible user. The UD concept is not just a benefit for a minority group but a design condition to create the best facility for all potential users. UD considers the diverse needs and abilities of possible users to create an accessible environment which is convenient and enjoyable to utilize (National Disability Authority, 2014a). Light switches are a good example of UD in practice. As opposed to older knob switches the new M-Smart jumbo switch is a highly visible flat panel anyone can easily operate (National Disability Authority, 2014b). 
As discussed earlier, the civil rights movement resulted in the development of many concepts to create equity. However, the development of the UD concept started even before the civil rights movement. The driving force behind the UD concept was the large number of disabled soldiers returning from World War II (Institute for Human Centered Design, 2015a). These soldiers fought for their country and made great sacrifices. Therefore, the US government responded with efforts to provide resources and protection for disabled veterans (National Disability Authority, 2014c). This, in turn, produced an increased amount of equal rights and anti-discrimination legislation to respond to these growing demands. The design industry, in an effort to keep up with the new laws to promote inclusion and prevent discrimination, created new accessible products, services, and environments. As this movement continued to grow, so too did the industry. This brought about the first barrier-free design concept.

This concept was an effort by the disability specific design industry to remove any barriers keeping people with disabilities from participation (National Disability Authority, 2014c). This disability-specific design industry would continue to grow to provide accessible solutions to the standard products and services in the public environment. This sparked the creation of assistive technologies to provide more specialized solutions for people with specific disabilities (National Disability Authority, 2014c). These products were created to make previously inaccessible products accessible and available to those who could benefit from their use.

The UD concept was created by Ronald Mace and a group of architects, engineers, products designers, and environmental design researchers out of North Carolina State University (National Disability Authority, 2014c). Mace created the seven 
principles of UD in 1997 to guide the design of communications, products, and environments (National Disability Authority, 2014d). These principles can be utilized to assess existing designs, educate the designers, educate the consumers, and create a framework to lead the design process.

The following are the seven principles of Universal Design (National Disability Authority, 2014d).

Principle 1: Equitable Use. The first principle of UD is the principle of equitable use. This principle mandates the design to be useful and marketable to people with diverse abilities. This principle includes four guidelines or recommendations for designers. The first guideline is to provide identical means of use to all people whenever possible and an equivalent means of use when it is not possible. The next guideline is to avoid segregating or stigmatizing the users. The third guideline is to provide equal privacy, security, and safety to all users). The last guideline of the equitable use principle is to make the design appealing to all users.

Principle 2: Flexibility in Use. The second principle of UD is the principle of flexibility in use. For this principle, the design must accommodate the preferences and abilities of a broad range of individuals. This principle has four additional guidelines for designers. The first guideline is to offer a method of choice to the users. The next guideline is to accommodate both left- and right-handed users. The third guideline is to facilitate the user's accuracy and precision. The last guideline is to provide adaptability to all users' pace. 
Principle 3: Simple and Intuitive Use. The third principle of UD is the principle of simple and intuitive use. This principle stipulates the use of the design or product be easy for the user to understand. The user should be able to utilize the product or service despite previous experience, knowledge, language, or concentration level. This principle has five guidelines for designers. The first is to eliminate any and all unnecessary complexity. The next guideline is to stay consistent with the user's intuitions and expectations. The third guideline is to accommodate various literacy or language skills of the users. The fourth guideline is to arrange any information in a consistent format by importance. The final guideline is to provide effective feedback both during the task and after the task is completed.

Principle 4: Perceptible Information. The fourth principle of UD is the principle of perceptible information. This principle discusses how important necessary information should be effectively communicated to users with any sensory ability level. This principle has five guidelines, the first of which is to utilize different modes of communicating vital information. These redundant modes can be pictorial, verbal, or tactile. The second guideline is to make the information stand out from its surroundings. The third guideline is to make the information as clear as possible for users to understand. The next guideline states instructions or directions must be described in a clear and concise manner. This is to make it easier for the user to understand directions. The last guideline is to provide compatible resources for people with sensory limitations.

Principle 5: Tolerance for Error. The fifth principle of UD is tolerance for error. This principle stipulates the design should minimize the risk and adverse consequences of unexpected actions. This principle has four guidelines. The first specifies the need to 
arrange elements in a way to minimize risks and errors. The second guideline is to provide adequate warnings of potential risks. The next guideline is to provide features to protect the users should an accident occur. The last guidelines discourage any unconscious actions which require constant supervision.

Principle 6: Low Physical Effort. The sixth principle of UD is a low physical effort. This principle discusses the design and how it should be used with minimal fatigue. The design should be able to be utilized efficiently and comfortably. The design must allow the user to maintain a neutral body position, use reasonable operating forces, minimize repetitive actions, and minimize sustained physical effort.

Principle 7: Size and Space for Approach and Use. The last principle is the size and space for approach and use. This principle mandates how the appropriate space should be provided regardless of a user's ability. All users should be able to reach, fit, manipulate or use all spaces. The first guideline for this principle is to provide a clear line of sight for important elements for all users. The second guideline is to allow for a comfortable reach to any components for all users. The next guideline is to accommodate variations as needed to fit any hand or grip sizes. The last guideline is to provide adequate space as needed for methods of assistance. This assistance could utilize devices or personal assistance.

$\mathrm{UD}$, as well as ADA compliance, is an essential component of facility design used to promote diversity and inclusion (Hums et al., 2016). Additionally, facility designers and managers who utilize UD during the design process will find ADA compliance more easily attainable. Universal design will continue to grow and practitioners embracing the concept of UD are considered leaders in inclusion (Hums et al., 2016). 
Watchorn, Larkin, Hitch, and Ang (2014) investigated the use of UD in promoting participation in social activities in Australia. The study utilized focus groups and telephone interviews to identify themes of barriers and facilitators which influence the application of UD in the built environments. This study suggests that in order to advance inclusion, educating society is imperative. Future design practitioners need to be able to argue the economic, sustainability, and equity benefits of UD built environments. Incorporating a UD approach to make buildings and communities usable by anyone results in increased social participation by everyone in a community at large (Watchorn, Larkin, Hitch, \& Ang, 2014). It is essential for practitioners to strive to create accessible facilities which meet all ADA standards and promote the UD concept.

Creating accessible facilities is integral as practitioners continually seek to meet the needs of their clientele. Another way practitioners develop strategies is to understand how their product meets the needs of the user. To understand a product, it is necessary to identify a true need of a product they are promoting. The most successful products generally create a feeling of happiness to the product's users. This understanding of happiness as a motivational factor to increase use can be difficult to define. Subjective well-being, quality of life, and life satisfaction are terms scholars have created to help quantify and define an individual's happiness.

\section{Summary of the Literature}

Campus recreation directors are continually striving to provide a better product for their participants. Research and assessment of participants and facilities to make improvements are vital components of the campus recreation industry. Many different 
policies, theories, and strategies have been implemented to improve the accessibility of campus recreation.

These policies, theories, and strategies are discussed within this literature review. The legal protections afforded to people with disabilities offer guidance for many policies to ensure an inclusive environment in public facilities. These legal protections are identified as The Rehabilitation Act and The Americans with Disabilities Act. These acts, along with further accommodating policies, help campus recreation practitioners develop an inclusive physical environment.

Critical Disability Theory and Universal Design theory help to create an even more inclusive environment by going beyond simply physical accommodations. These theories help create an understanding of the lives lived by people with disabilities and the hardships or oppressions they endure. Understanding people with disabilities is key to providing the most inclusive environment possible. This understanding can only happen with the participation and active engagement of people with disabilities.

To encourage this participation, many practitioners utilize strategies to create a more welcoming environment for people with disabilities. Utilizing the previous policies and theories, strategies can be developed to help people with disabilities overcome potential barriers to participation in physical activities. This can only be accomplished through a desire to meet the individualized needs of people with disabilities. To understand these needs, people with disabilities need to be involved in the decisionmaking process of creating inclusive environments. 
Therefore, this study will investigate the current practices of campus recreation practitioners to create inclusive campus recreation programs, services, and facilities. This study employs interviews campus recreation practitioners in order to examine their campus recreation centers inclusion efforts. A framework will be created using Critical Disability Theory, Universal Design, and the data collected to develop strategies to create a more inclusive environment for campus recreation administrators to better meet the needs and desires of patrons with disabilities. 


\section{CHAPTER III}

\section{METHOD}

The following section outlines the methodology for the study. First, the researcher reviews the purpose and the research questions which led the study. Then the researcher will provide an explanation of the qualitative methodology and provide a rationale for the methodology used in this study. This will be followed by the overview of the research design, the cases in question, and the sites investigated. Finally, the data collection and data analysis methods are outlined, and then a discussion of the strategies to ensure trustworthiness of the study.

\section{Purpose}

The purpose of the study was to investigate the current practices of campus recreation professionals to create inclusive campus recreation programs, services, and facilities. This study employed interviews with campus recreation practitioners in order to examine their campus recreation centers' inclusion efforts for people with disabilities. Utilizing the framework of Critical Disability Theory and Universal Design, this investigation sought to identify how campus recreation practitioners perceive the inclusiveness of their campus recreation departments and how campus recreation practitioners develop their inclusive practices. Universal Design was utilized as a lens to understand how campus recreation practitioners, programs, facilities, and equipment 
strive to meet the needs of all users and specifically people with disabilities. Critical Disability Theory was utilized to help understand the methods by which the inclusive practices are created and operationalized within the campus recreation settings.

\section{Research Questions}

The following research questions were aimed at understanding the purpose of this study:

RQ1: How do campus recreational practitioners perceive the inclusiveness of their facilities, programs, and services?

RQ2: How do campus recreation professionals determine and create their inclusive practices?

The questions for this study were derived from the previous literature review of Critical Disability Theory (CRT) and Universal Design (UD). The first research question examined the current inclusive practices and offerings from the perspective of a campus recreation professional. The campus recreation personnel interviewed in this study were able to elaborate on their inclusive practices for people with disabilities within their departments. This question led to an in-depth conversation of the entirety of the inclusive offerings of the campus recreation department and the perceptions of the practitioner and their knowledge and reasoning behind these offerings.

The final research question was directly guided by Critical Disability theory to create an understanding about the process by which practitioners develop and create their inclusive practices. Following the CDT framing, question two identified the amount of autonomy allowed to people with disabilities in determining the practices and policies directly influencing themselves (Rocco, 2005). This question was intended to determine 
if practitioners utilize people with disabilities to assist in the determination of the organizations inclusive practices and policies.

\section{Research Design}

This investigation utilized a qualitative research method to satisfy the purposes of the current study. Utilizing a qualitative method provides a greater understanding of another person's lived experiences and social environment by providing additional details of the intersections between actions and narratives (Glesne, 2016). Denzin and Lincoln (2011) developed a definition of qualitative research which encapsulates the intention of this study.

Qualitative research is a situated activity that locates the observer in the world. Qualitative research consists of a set of interpretive, material practices that make the world visible. These practices transform the world. They turn the world into a series of representations, including field notes, interviews, conversations, photographs, recordings, and memos to the self. At this level, qualitative research involves an interpretive, naturalistic approach to the world. This means that qualitative researchers study things in their natural settings, attempting to make sense of, or interpret, phenomena in terms of the meanings people bring to them (p. 3).

A qualitative method was necessary for this study for several reasons, the first of which was to examine a complex problem (Creswell, 2013). Understanding the current lack of inclusive offerings in campus recreation illuminates a complex problem within this industry. A qualitative method was necessary to create an understanding of the interactions and narratives surrounding the experiences lived by the campus recreation professionals who create inclusive programs. The researcher utilized qualitative semistructured interviews to empower a participant to elaborate on his/her perception of the campus recreation department and its inclusive practices. Qualitative methodology also 
allowed the researcher to garner a deep understanding from multiple points of views (Creswell, 2013).

The amount of in depth details is needed to gain an understanding to address the research question is best suited for a qualitative study. Due to the need of through understandings of the lived experiences, it would not be possible for the researcher to gain the appropriate level of understanding from a quantitative method to answer the proposed research questions (Patton, 2015). Utilizing a qualitative method allowed the research to have a more fluid structure which generated a more thorough understanding.

In sport and exercise sciences, the interview is the most widely utilized method to collect qualitative data (Smith \& Sparkes, 2016). There are numerous other forms of qualitative methodologies utilized but the main five designs are narrative, phenomenology, grounded theory, ethnography, and case studies (Creswell, 2013). It is integral for a researcher to utilize the correct research design to address the research questions of the study (Wimpenny \& Gass, 2000). Research design approaches can be utilized in creative ways to best fit the research problems and questions (Annells, 2006). Therefore, in order to best fit the research design and to answer the research questions, the qualitative method chosen for this investigation was a qualitative interview process.

Qualitative Interview Method

An interview takes place when two or more individuals engage in a discussion and share knowledge about themselves and their experiences in the social world (Smith \& Sparkes, 2016). These discussions between individuals in an interview elicit conversations of their interactions with others over time, in a certain place, and through a range of senses felt during their experiences (Sparks \& Smith, 2014). The purpose of the 
interviews in qualitative methodologies is to create conversations which invite the participants to tell a story about their perspectives, insights accounts, experiences, feelings, emotions, and behaviors in regard to the research questions (Smith \& Sparkes, 2016).

There are four typical forms of qualitative interviews. Each one differentiates itself in forms of structure and the number of participants interviewed at one time. The four types of interviews are the individual structured interview, individual semi structured interview, individual unstructured interview, and focus group (Smith \& Sparkes, 2016). An individual structured interview is a process in which all participants are asked a set of identical questions in the same order. An individual semi structured interview takes place when the researcher uses a preplanned guide of open-ended questions about a specific topic. The individual unstructured interview has little preset structure and uses a few open-ended questions to facilitate a discussion. A focus group utilizes a group of individuals at the same time to participate in the interview process (Smith \& Sparks, 2016).

A preplanned semi structured interview was utilized in this study. As a means of access, the interviews were conducted over the phone. Utilizing a telephone to conduct qualitative interviews has been shown to be a useful tool in collecting qualitative data (Smith \& Sparks, 2016). The justification for the semi structured interview process was to elicit rich in depth conversations with campus recreation practitioners not bounded by the strict question and answer format of structured interview process. Interviews are designed to encourage a conversation in which participants can share information personally meaningful to them (Smith \&sparks, 2016). The semi structured design allows 
the researcher to guide the participants to delve into unanticipated avenues in order to garner additional rich insights not available in other forms a qualitative research (Smith \& Sparks, 2016).

This process of semi structured interviews is an effective way for the researcher to gain knowledge and meaning about a topic from the participants (Smith \& Sparks, 2016). This process allows the participants to give their own personal perspectives, insights and interpretations of their experiences without being curtailed by the format of the interview. As insights are discussed it is up to the researcher to formulate additional questions to elicit more information. This process allows the researcher to gain rich knowledge to help create a better understanding of the participants' experiences and meanings. Additionally, the semi structured interview can provide a detailed and complex understanding of the participants' decisions, values, motivations, beliefs, perceptions, feelings, and emotions (Smith \& Sparks, 2016). Since the accounts or descriptions of an individual's experiences are shaped by society and culture, an interview can reveal sociocultural dynamics of human life (Smith \& Sparks, 2016).

A semi structured interview design was an appropriate choice for this study since the researcher worked directly with campus recreation practitioners to discuss their personal experiences, feelings, perceptions, values, motivations, beliefs, and emotions. The initial question underpinning this study was the understanding of how campus recreation departments practice inclusion and how these efforts were determined on their campuses. A semi structured interview was an appropriate methodology to share the learned lessons from specific campus recreation inclusion practices and the shared experiences of individuals developing these practices. This process enabled the 
researcher to elicit rich discussions into the current inclusive processes at each institution and allowed the participants the freedom to discuss their practices and how they were determined in an in-depth manner.

\section{Case Description}

As noted in the literature review section, previous studies have explored the use of Critical Disability Theory and Universal Design to improve the inclusiveness of facilities and programs. This study focused specifically on accessibility and inclusion for people with disabilities in campus recreation activities and offerings by utilizing the six concepts of Critical Disability Theory (CDT) and the seven principles of Universal Design (UD). Sample

Choosing a study sample is integral to any investigation because it is rarely practical to study whole populations (Marshall, 1996). The goal of some sampling approaches is to make the study population represent a total population or a population representing a certain characteristic, so the results are more transferable (Marshall, 1996). Random sampling provides the best opportunity for results to be generalizable but does not generate an understanding of complex issues of human behavior (Marshall, 1996).

A common method of sampling is judgement or purposeful sampling. Purposeful sampling is a procedure to select nonrandom participants to take part in a study (Cottingham, Gearity, Goldsmith, Kim, \& Walker, 2015). This non-random selection process is undertaken to generate the most productive sample to answer the research questions (Marshall, 1996). The researcher develops a framework of variables applicable to the study based upon the researcher's practical knowledge of the subject, the literature on the subject, and evidence from the study itself (Marshall, 1996). Judgement sampling 
could lead to snowball sampling if subjects recommend other potential candidates (Marshall, 1996).

This investigation utilized multiple sampling strategies to identify sites and candidates for this study. Each site was carefully chosen to represent identified inclusive campus recreation departments. The corresponding directors of campus recreation for each were selected due to their involvement in creating and facilitating inclusive practices. The following section identifies the reasoning behind each site selected for this study.

Site Selection. Twelve sites were selected for this study. The researcher previously identified the following sites based upon three criteria. The first criterion for site selection was that each school must be a member of the National Intramural Recreational Sport Association (NIRSA). NIRSA has six regions within the United States. Two schools were selected from each region based upon the following categories. The next two criteria were that each site was required to be a public institution with an enrollment of 18,000 students or more. This was in order to find a similar standard in institution sizes and offerings. The fourth criterion was based upon advanced inclusive practices. The researcher utilized industry professionals and previous studies to identify campus recreation programs offering advanced inclusive recreation practices. These criteria where chosen to aid in the possible transferability of the knowledge gained from this study. These criterions allow industry professionals to identify the peer institutions and enable them to better develop their own inclusive standards to match the standards set. The following are brief descriptions of each site and their campus recreation departments' inclusive practices. Many of these descriptions utilize research gathered 
from the institutions websites and previous research discussing their inclusive offerings. Therefore, many of the citations in the following section will also have the pseudonyms as the reference to protect their identities.

Gotham University. Gotham University (GU) enrolls 18,484 students and is a member of NIRSA Region I. The mission statement of GU is "Campus Recreation is committed to providing exceptional programs, services, and facilities that promote and encourage a balanced, healthy lifestyle. We are dedicated to creating a safe, welcoming, and inclusive environment that enhances student learning and skill development, fosters enjoyment and appreciation for recreational activities, and enriches the quality of life for the Gotham Community" (Gotham University , 2019a, p. 1).

GU offers a variety of programs and offerings to meet the needs of their entire student body. Many of their offerings are able to be modified to meet the individual needs of their patrons (Gotham University, 2019b). GU strives to create a campus recreation environment that is caring supportive, and inclusive (Gotham University, 2019a). The campus recreation department works to ensure that all participants feel welcomed, valued, and respected. Through these efforts and collaborations Gotham actively follows their mission statement and enriches the quality of life for the Gotham Community.

Empire State University. Empire State University (EU) enrolls 41,200 students and is a member of NIRSA Region I. EU campus recreation is committed to providing an inclusive environment through creating an accessible and welcoming recreation environment (Empire State University, 2019a). Programs, facilities, services, and employment opportunities are created and provided to all EU community members of any ability (Empire State University, 2019b). Programs are designed to allow participation or 
can be adapted to meet the individual needs of any user. Additionally, EU campus recreation strongly encourages people with disabilities to apply for employment (Empire State University, 2019b). EU campus recreation promotes the idea that accommodations can be made in the interview process, job training, and in the workplace to meet the needs of any potential employees (Empire State University, 2019b).

EU uses their website to promote how accessible their facilities and programs are for people with disabilities. Even going as far as making a facility access guide for any user. This part of the website discusses how accessible each individual facility is and what type of accommodations are provided within the programs or facilities (Empire State University, 2019b).

Adams College. Adams College (AC) enrolls 31,242 students and is a member of NIRSA Region II. The mission statement of AC campus recreation is "Through sport, fitness, outdoor adventure, experiential leadership development, and instructional programs, Recreational Sports inspires and empowers the AC community to commit to a lifetime of wellness" (Adams College, 2019a, p. 1).

One of the core values of AC campus recreation is inclusion (Adams College, 2019a). They strive to make sure that all individual identities are not only supported but valued. AC Campus recreation encourages this through offering fitness and recreation opportunities to engage students of various identities or backgrounds. The campus recreation department view its offerings as tools for students to interact with one another and break down barriers related to differences (Adams College, 2019a). 
South Central University. South Central University (SC) enrolls 51,862 students and is a member of NIRSA Region II. The Department of Recreational Sports' mission "is to offer experiences that enrich the lives of South Central University students through excellence in facilities, fitness, sport, adventure and play. Recreational Sport strives to be inclusive and provide a variety of accommodations for equal access to our programs and facilities" (South Central University, 2019a, p. 1). One of the core values of the department of campus recreation is to embrace diversity through inclusion.

SC encourages this core value through making accommodations for any individual. (South Central University., 2019b). They promote individuals to inquire about accommodations through their website or in person. Recreational sports also work with other departments to create as welcoming an environment as possible. Their website promotes the accessible features of their facilities and programs and show a truly well rounded inclusive campus recreation program (South Central University, 2019b).

Marshall College. Marshall College (MC) enrolls 61,170 students and is a member of NIRSA Region III. MC campus recreation encourages people with disabilities to participate in their programs and services through inclusive services (Marshall College, 2019). MC campus recreation provides inclusion support services of staff support, interpretation services, and adaptive equipment. The services fall under the oversite of the Adapted Recreational Sports (ARS) program.

Marshall College Campus Recreation use ARS to accommodate the individual needs of any user with a disability. The accommodation is available at no extra cost to the user. This programs also offers individual consultation to discuss the recreational 
opportunities to any user (Marshall College, 2019). Additionally, this program provides assistance to individuals needs transportation and any need that may arise during the recreational experience (Marshall College, 2019).

Coolidge College. Coolidge College (CC) enrolls 46,002 students and is a member of NIRSA Region III. CC Campus Recreation promotes diversity and inclusion through offering a wide variety of programs, services, and facilities to meet the health and recreational needs of all users (Coolidge College, 2019a). CC helps this effort by provided orientation to equipment and facilities for any patron.

Additionally, $\mathrm{CC}$ campus recreation provides sports and recreational opportunities to the disabled community. They offer wheelchair basketball, electronic sports, and group exercise classes (Coolidge College, 2019b). Any of their other offerings are able to be modifies to meet individual accommodations.

Arlen University. Arlen University (AU) is a large public institution enrolling 26,216 students. AU is a member of NIRSA Region IV. The researcher chose AU as a location for this study due to AU's dedication to providing an inclusive campus recreation program and services. AU campus recreation department's mission statement is "We are a community dedicated to providing opportunities for recreation and wellness that develop health and engage citizens" (Arlen University, 2018, p. 1). This statement leads AU to provide for all citizens of the AU community.

AU engages the community through utilizing Universal Design (UD) to make their environment as inclusive as possible. AU built a new recreation center in 2013 to accommodate the needs of all the potential users of the facility (Harbourne, 2016). The design of the facility involved a total campus effort with representatives from campus 
recreation, campus administration, planning and design, student government, and disability services (Harbourne, 2016). A driving force behind the design process of the recreation center was the integration of UD principles throughout the facility (Harbourne, 2016). AU hosted open forums during the design process to inform and encourage input from the campus community (Harbourne, 2016). The recreation utilized the continual feedback to create a dynamic facility to specifically meet the needs and desires of all potential users (Harbourne, 2016).

Western University. Western University (WU) enrolls 25,295 students and is a member of NIRSA Region IV. The WU campus recreation departments sponsors the program ABLE tech which is a statewide assistive technology program (Western University, 2019). This program helps to improve access and develop assistive technology for individuals with disabilities. This programs helps people to function independently in recreation as well as education, employment, and daily living activities (Western University, 2019).

Greendale College. Greendale College (GC) enrolls 33,877 students and is a member of NIRSA Region V. GC was chosen due to advanced practices and offerings for people with disabilities. The inclusion statement from this program is "Campus Recreation is dedicated to providing inclusive services, programs, and facilities to all persons, and welcomes participants and visitors reflective of all characteristics including age, culture, different ideas and perspectives, disability, ethnicity, familial status, gender identity and expression, geographical background, marital status, national origin, race, religious and spiritual beliefs, sex, sexual orientations, socioeconomic status, and veteran status" (Greendale College, 2018a, p. 1). GC created an Inclusivity Committee comprised 
of students and professional staff members to make recommendations to the department and improve the inclusive environment of the GC community (Greendale College, 2018b). This committee meets monthly to work on projects to promote new inclusive practices and offerings (Greendale College, 2018b).

The Student Recreation Center is built with a commitment to providing a welcoming environment for all users. The facility offers accessible workout areas designed to accommodate various levels of abilities and skills (Greendale College, 2018a). In addition to meeting all ADA standards, the facility offers adaptable fitness equipment, adaptable aquatic equipment, accommodations for care and assistance, and climbing wall accommodations (Greendale College, 2018b). The website offers a link to an interactive map for participants to identify all of the inclusive features of the GC Student Recreation Center.

In addition to providing inclusive facilities, GC creates adapted programs, activities, and events. All of these offerings are promoted as a part of the GC Adaptive Activity program. This program is used to indicate to people of all abilities when accommodations are possible to the programming. GC created an icon to use on all promotional and marketing materials to indicate to individuals looking for specific accommodations to meet their individualized needs (Greendale College, 2018a).

Hill Valley College. Hill Valley College (HV) enrolls 32,948 students and is a member of NIRSA Region V. Recreational services at HV provides inclusive recreation opportunities to all who wish to participate. The recreational activities help to make the HV campus a welcoming environment (Hill Valley College, 2019a). Many of the HV inclusive efforts are created by the diversity, equity, and inclusion committee within 
campus recreation. This committee works to identify opportunities of inclusion that can be implanted and expanded at the HV Campus Recreation Department (Hill Valley College, 2019b).

HV Campus Recreation currently offers a variety of adapted recreational programs. These programs range from rowing, aquatic, fitness, outdoor, tennis, and unified sport (Hill Valley College, 2019a). Additionally, they have a wide array of adapted equipment and accessible facilities to create a fully inclusive campus recreation experience (Hill Valley College, 2019a). They promote many of the adapted elements of their facilities through special events and challenges open to the entire campus community (Hill Valley College, 2019c).

Faber College. Faber College (FC) enrolls 27,229 students and is a member of NIRSA Region VI. FC was chosen as a site for this study due to their advanced culture celebrating inclusivity in the campus recreation departments. The mission statement of FC campus recreation is "Campus Rec provides an inclusive environment where recreation and wellness opportunities inspire, empower, and educate people to be positive contributors to the global community" (Faber College, 2018a, p. 1). FC specifically offers an inclusive rec program which demonstrates the campus recreation program's commitment to creating a community to welcome everyone (Faber College, 2018b).

FC offers programs for anyone looking to participate in recreation. There is an adaptive swim program which provides a lap lane for adaptive swimming at all open swim times (Faber College, 2018b). FC has equipment available for anyone to play goalball or wheelchair basketball. FC has a unified sports program where people with and without disabilities are encouraged to participate and play (Faber College, 2018b). The 
unified sports program is inspired by the principle that playing together leads to friendship and understanding (Faber College, 2018b).

The FC campus recreation center offers many different features for inclusive use. The aquatic facility has easy entry steps and lifts which provide access to the spa and the adaptive swimming lane (Faber College, 2018b). The facility offers adaptive courts with lines and specific time slots for adaptive sports such as goalball, wheelchair basketball and sit-down volleyball (Faber College, 2018b). The outdoor recreation program offers climbing, kayaking, and hiking trips each semester (Faber College, 2018b). The facility offers numerous pieces of adaptive equipment such as workout equipment, service dog hookups, accessible locker rooms, and elevated stretching mats (Faber College, 2018b).

Bayside College. Bayside College (BC) enrolls 27,932 students and is a member of NIRSA Region VI. The BC Campus Recreation department intentionally create ad diverse and inclusive environment to enhance the social, mental, and physical well-being of the university community (Bayside College, 2019). The BC campus recreation facilities is continually improving the accessibility of the programs and facilities for people with disabilities.

The facility offers equipment designed for adapted recreation and trains staff on the proper ways to assist any individuals needs in using that equipment (Bayside College, 2019). BC also provides a variety of programs to enhance the inclusiveness of the campus recreation department. These programs range from intramurals, to fitness, and even unified sports.

The researcher obtained approval from the Institutional Review Board (IRB) to conduct the investigation. Each participant was provided an informed consent form 
indicating there were no risks involved in participating in this study. The researcher informed the participants and the IRB that any benefits of this study would be related to improving awareness, education, and better practices within the campus recreation program and the campuses' disability communities. The sites and individuals participating in this study were not be provided with any financial gains to assist with the research process.

\section{Data Collection}

A pilot study was utilized to ensure effectiveness of the selection process and interview questions. This pilot study allowed the researcher to test the interview questions. This test ensured that the questions asked are both pertinent and used appropriate terminology in the data collection process. All issues brought up from the pilot study and IRB approval were addressed. Invitations were sent through email to all of the identified inclusive sites to elicit participation from the campus recreation directions or practitioners better able to address the research questions.

After the selected sites agree to participate, data was collected from campus recreation practitioners via semi-structured phone interviews by the primary researcher. Each interview was audiotaped and lasted between 30 to 60 minutes. Interviews were concluded when the researcher observed a saturation of new information (Merriam, 2009). All collected data was stored securely on a password-protected computer or a locked filed cabinet inside the research office. This ensured the security and anonymity of any personal information gathered from the participants for this study.

The recordings of each interview were transcribed verbatim through a paid transcription service. During the data analysis phase of the study, all participants and sites 
were given a pseudonym and any identifying information was changed or deleted.

Additionally, the transcriptions were sent all of the participants to review, clarify, and confirm interpretations (Glesne, 2016). This investigation will develop a rich illustration and a step-by-step approach to creating more inclusive recreation programs (Creswell, 2013).

\section{Researcher Reflexivity}

Researcher reflexivity is defined as an understanding or consciousness about the personal biases, values, and experiences which the researcher brings to the study (Creswell, 2013). Researcher reflexivity is an important component of any qualitative methodology. One method to gain this understanding of characteristics and experiences a researcher brings into a study is to utilize a peer-debriefing (Hays \& Singh, 2011). The researcher will utilize peer debriefing with multiple sport management scholars who have knowledge of Critical Disability Theory and Universal Design throughout the study. The author will discuss the findings with peers to ensure accurate themes are developed from the data.

\section{Researcher Positionality}

It is important to acknowledge my position as the lead researcher in this study. I have been a professional within the campus recreation field for over 11 years. In those 11 years, I held various role in campus recreation at multiple universities. I enter this study acknowledging that my own prior experiences would affect questioning, choices of information to collect, decisions on observations, interpretation of data, and the way the data is presented in written form. I am a White able-bodied male investigating the experiences of individuals with a disability. It is imperative that I understand and 
acknowledge how my own personal biases would affect the data. Therefore, I chose to withdraw my own voice from the narrative of this study to preserve the voices of the participants, so their experiences could be emphasized. I did this by making sure that I did not provide any additional details from my own experiences in creating inclusive campus recreation environments. This decision was made to maintain an emphasis on the campus recreation practitioners involved in this study. This allowed the practitioners to create a true dialogue about their campus recreation departments without the influence of my own personal experiences.

\section{Summary}

This investigation utilized a qualitative interview approach to investigate the current practices of campus recreation professionals to create inclusive campus recreation programs, services, and facilities. Interviews with campus recreation practitioners from corresponding inclusive campus recreation settings were the primary sources of data for this study. Additional supplemental data were gathered through a variety of sources to assist in the triangulation of the data process. Critical Disability Theory and Universal Design were utilized to determine research questions and frame the data analysis.

Overall, the use of this qualitative method was appropriate for this investigation due to the need to gain in-depth knowledge and understanding of the experiences and perceptions of the campus recreation professionals.

The proposed study is an effort to create inclusive practices of campus recreation centers to better serve people with disabilities. The current state of campus recreation inclusive practices needs to be overhauled and practitioners should be educated on how to better serve the disabled community. Results from this study will have the potential to be 
instrumental in increasing inclusion practices across the campus recreation community. Additionally, educating practitioners of campus recreation on the systematic exclusion of a specific population will lead to advanced efforts to increase awareness of previously unidentified exclusive practices. Ultimately, the proposed research will lead to providing a better campus recreation. Experience to the entire campus community. 


\section{CHAPTER IV}

\section{FINDINGS}

The purpose of the study was to investigate the current practices of campus recreation practitioners to create campus recreation programs, services, and facilities that are inclusive to people with disabilities. This study is significant because it provides an in-depth examination of some of the most disability inclusive campus recreation programs throughout the United States (US). The author utilized the National Intramural Recreational Sports Association (NIRSA) membership list to intentionally study two institutions representing each of the six US regions of NIRSA. By completing this study, the author strove to inform campus recreation practitioners of the effective strategies used by these inclusive campus recreation programs. The information gathered in this study can be utilized by campus recreation professionals to refine the inclusive practices of their facilities, programs, and services. In addition, the author utilized this study to understand how campus recreation professionals perceived the inclusiveness of their own facilities, programs, and services. This study also helped create an understanding about how the inclusive campus recreation practices are determined and created. 
The focus of this study investigated the inclusive practices of campus recreation programs, services, and facilities for people with disabilities. The study utilized the following research questions:

RQ1: How do campus recreation practitioners perceive the inclusiveness of their facilities, programs, and services?

RQ2: How do campus recreation practitioners determine and create their inclusive practices?

\section{Study Sites}

A total of twelve campus recreation departments agreed to take part in this study. Pseudonyms were utilized in order to protect the anonymity of the sites. Basic institutional demographic information was used to guide this study and aid in potential transferability to similar institutions. The campus recreation director at each site either participated in the study or assigned another campus recreation practitioner to represent the site's campus recreation department. The campus recreation director's decision to delegate the interview request was to ensure the person most familiar with the current inclusive practices was participating in the interview. The participants interviewed represented multiple campus recreation directors, associate directors, and assistant directors directly involved in the inclusion efforts within their campus recreation departments. No participant demographics were collected to protect the confidentiality of the individual and the institutions they represent.

Table 4.1

Sites of Study Demographic Information

\begin{tabular}{lll}
\hline & NIRSA & \\
Institution (Abv.) & Region & Enrollment \\
\hline Empire State University (EU) & 1 & 41,200
\end{tabular}




\begin{tabular}{lll} 
Gotham University (GU) & 1 & 19,465 \\
Adams College (AC) & 2 & 31,242 \\
South Central University (SC) & 2 & 55,862 \\
Coolidge College (CC) & 3 & 46,002 \\
Marshall College (MC) & 3 & 61,170 \\
Arlen University (AU) & 4 & 23,697 \\
Western University (WU) & 4 & 25,295 \\
Hill Valley College (HV) & 5 & 32,948 \\
Greendale College (GC) & 5 & 33,877 \\
Bayside College (BC) & 6 & 27,932 \\
Faber College (FC) & 6 & 28,241 \\
\hline
\end{tabular}

The following table outlines the guiding research questions, themes, and subthemes generated from the study. Twelve campus recreation professionals participated in the current study. In-depth, semi-structured interviews were the main source of data collection utilized in this study.

Table 4.2

Research Questions and Themes

RQ1: How do campus recreation practitioners perceive the inclusiveness of their facilities, programs, and services?

Theme 1: Diversity and inclusion effort

Subtheme 1: Alignment to mission

Subtheme 2: Inclusion and diversity committee

Subtheme 3: Hiring

Subtheme 4: Staff training and education (cultural awareness)

Theme 2: Disability inclusion

Subtheme 1. ADA compliance and accessibility

Subtheme 2. Community partners to help inclusion

Theme 3. Gender inclusion

RQ2: How do campus recreation professionals determine and create their inclusive practices?

Theme 1: Policy source

Subtheme 1: From the top down

Subtheme 2: Grassroots 
Theme 2: Assessments and surveys

Theme 3: Personnel involved

Subtheme 1: Professional staff

Subtheme 2: Campus and community partnerships

Each interview consisted of questions regarding (a) perceptions of their current campus recreation inclusive practices, (b) perceptions of their current campus recreation inclusive practices specifically for people with disabilities, (c) how their campus recreation inclusive practices were determined, and (d) how campus recreation department could improve their inclusive practices. The following sections will discuss the selected campus recreation sites of study and the emergent themes from the research questions

RQ1: How do campus recreation practitioners perceive the inclusiveness of their facilities, programs, and services?

The following section outlines the perceptions of campus recreation practitioners on the inclusiveness of their campus recreation facilities, programs, and services. During the interview portion of this study, the campus recreation practitioners discussed in great detail the inclusiveness of their campus recreation facilities, programs, and services.

From this discussion, three themes became evident. The three themes were diversity and inclusion effort, disability inclusion, and gender inclusion.

Theme 1: Diversity and inclusion effort

Diversity and inclusion effort emerged as a theme in the majority of the answers given by campus recreation practitioners. This theme indicated how many of the campus recreation departments work to meet the needs of all patrons of their facilities, programs, 
and services. For example, the campus recreation practitioner from Marshall College (MC) stated:

It's in the DNA to think about, you know, who we're serving and, and to make sure that we start with serving everyone and that we only, exclude if we are forced to for some reason, you know, which might include, health and safety reasons.

Campus recreation practitioners understand how important it is to accommodate the needs of an individual unless it creates an unsafe scenario for other participants. This practitioner made it clear that every effort is put forth to serve everyone unless there is a health or safety precaution which might prohibit involvement. This practice relates to how willing the campus recreation departments are to make changes to meet the specific needs of its users while still understanding the needs of the whole.

This statement of meeting everyone's needs illustrates the diversity and inclusion effort. The campus recreation practitioner from Western University (WU) said "We plan our activities that appeal to every user group on campus." Many of the campus recreation practitioners reiterated how they continually utilize their facilities programs and services to provide inclusive efforts to meet the diverse needs of their patrons. The campus recreation practitioner from Bayside College $(\mathrm{BC})$ stated:

Within our department we look at diversity through obviously all of our staffing, our students staffing, our full-time staffing, our programs the whole entire gamut of our, department and basically trying to offer inclusive and diverse programs that meets all the demographics we have on campus. Ranging from our aquatics program through our fitness and wellness program, outdoor programs, intramurals and club sports, and the general open recreation and our facilities here.

Many of the campus recreation practitioners listed the different groups making up their patrons at their specific universities. For example, the campus recreation practitioner from Faber College (FC) said "Not just with folks with disabilities but maybe LGBTQ community, women, international students, students with children, and different things 
like that." The practitioner from South Central University (SU) indicated a few more groups of identified participants in saying "We're really trying to cater to all students regardless of ability, regardless of color, creed, socio economic status, and every other, you know, affinity group that is out there. We want to be welcoming." The campus recreation practitioners had very broad answers to the diverse populations they strive to include. Among all 12 of the campus recreation practitioners, the following groups were identified as populations their campus recreation departments serves - individuals with physical and mental disabilities, lesbian gay bisexual and transgender individuals, individuals of different cultural backgrounds, individuals with different socioeconomic backgrounds, people of color, people of varying religious affiliations, military and veterans, gender identity populations, the student population, and university staff populations.

All of the responses from the campus recreation practitioners indicated their efforts to create inclusive campus recreation departments. Upon further analysis of the campus recreation practitioners' answers falling under the theme of diversity and inclusion effort four subthemes were identified: mission, vision, and values; inclusion and diversity committees; staff trainings and education; and hiring. The following details the subthemes found under the theme of diversity and inclusion effort.

Subtheme 1: Alignment to mission. Interviews with the campus recreation practitioners consistently indicated how inclusion and diversity were hallmarks of their organizational mission statements, vision, and values. Participants from each institution participating in this study discussed how the alignment to mission were critical in providing inclusive and diverse campus recreation departments. These campus recreation 
departmental missions, visions, and values help the department to determine program goals and objectives. They also help prioritize initiatives to create inclusive and diverse programming and services. Many of the campus recreation practitioners referenced the campus recreation departments' alignment to mission when answering the questions of this study. When answering the first question, the campus recreation practitioner from South Central University (SC) stated:

It's part of our mission, vision, and values. To make sure that we encourage wellbeing through participation, but more specifically embrace diversity through inclusion. We live and breathe that as part of our mission and everything that we do, whether that's within the facilities that we build and then operate, whether it's in the programs that we staff and service or whether it's the experiences, events that we put on.

According to Fried (2015), an organization's mission, vison, and values are the guidelines by which that organization meets its goals and objectives. Specifically, the definition of mission is the stated end results envisioned by the organization. Vision is the aspirational goal of what the organization desires to achieve.

An organization's values explain what ideals are of importance while working to achieve their mission (Fried, 2015). This notion is exemplified in the answer the campus recreation practitioner from Gotham University (GU) by stating: "I mean, it's the words though, to include a welcoming and inclusive environment is in our mission statement. And you know, a mission is important to an organization for you know, why they exist." Mission, vision, and values are at the core of every campus recreation department. They guide every decision, program, or initiative which the campus recreation department undertakes. Many times, in discussing this question with the participants, they referenced how their alignment to mission is the guiding principle to ensure they are living up to stated goals and objectives. For example, the practitioner from Adams College (AC) 
stated "it's my responsibility to make sure that the practices that are in place align with our values." For the most part, having a mission statements are a common practice since most campus recreation program proudly lists their mission statements on its website, generally under the "About Us" section. This is in an effort to communicate the underlying principles which guide the practices of the campus recreation department.

All of the practitioners interviewed discussed how inclusion and diversity were key parts of their mission. The practitioner from Faber College (FC) said "it first starts with our mission and vision statements because all the inclusive language is in there." From there, they were able to identify ways and initiatives which help the organization accomplish its intended goals of diversity and inclusion. These practices are not specific to a certain group of individuals but are aimed to make campus recreation a welcoming resource for anyone. The practitioner from GU summed it up with the following statement:

A mission is important to an organization for why they exist. But I think those are just words and making sure that we exemplify that through our staff training and letting our staff know what inclusive means, whether it's abilities, whether it's race, ethnicity, that's important to us that one of our philosophies is not just for the athletic and fit, that we want to make sure anybody has an opportunity to take advantage of health and wellbeing resources in our spaces.

The key to this statement is the last sentence which indicated that campus recreation is a resource for everyone to utilize to better themselves through healthy life choices. The campus recreation practitioners discussed how they continually tried to better the user holistically through providing resources to aid in mental, physical, and emotional health. These resources help the users to discover and practice lifelong healthy habits of exercise, recreation, relaxation, and socialization. 
The analysis of the data indicated how many practitioners ensure that inclusion and diversity were present within their mission, vision, and values. Many of these organizations have reworked their mission statements to reflect the practices which they promote. For example, the campus recreation practitioner from GU stated, "We continue to change the mission statement to what we want to reflect, having the word inclusive was important to us." Some of these organizations have been practicing inclusion for decades, while others have undertaken inclusion as a new initiative because of a perceived need. This is shown by the following statement by the practitioner from SC:

You know, we talk, our mission talks about being excellent and one of those areas to be excellent is that inclusion, embracing diversity through inclusion. Um, so it took us four or five years of really doing a lot of this programming to finally say, this is who we want to be, and this is who we are, and we need to put it into our mission. So, it took us a while to finally have it in there as a value for us. Um, but since then, it has become even more of a staple for us and now permanent for us.

As the mission, vision, and values of the campus recreation department become ingrained in the culture of the staff, the inclusion efforts become the norm. The staff just begins to understand how their programs are created to involve everyone. This is reiterated in by the campus recreation practitioner from Faber College stating:

I just saw a report from them [Campus Recreation Staff] the other day. It's like, it's really feels like our, our staff gets it all the way around you know. So, it's just again, I think who we are. That's where it started with was the mission vision and the buy in from everyone from the top down. Now everybody wants folks to be a part of it.

Campus recreation departments are historically proactive in creating inclusive practices.

As discussed in Chapter 2, inclusion is in the very roots of how campus recreation was developed from the very beginning. NIRSA works with member institutions to assist in their efforts to provide inclusive facilities, programs and services. Additionally, campus 
recreation and specifically intramural sports were originally designed to bring students together to socialize outside of the academic arena.

Since being inclusive is a part of the history of campus recreation, it makes since that the mission statement of each department has a core initiative of being inclusive. At times, this inclusion effort is not accurately stated within the campus recreation mission statement. Knowing inclusion is a core principle of NIRSA and peer institutions, many campus recreation practitioners realigned their mission, vision, and values to meet it. This process to realign the campus recreation mission statement toward inclusion typically originates from the leadership in the campus recreation program. As indicated in this study, many of the mission statements were rewritten or formulated by a committee dedicated to inclusion and diversity. This practice is part of a larger effort to make sure that the campus recreation department is continually being perceived as inclusive by their employees and the campus community. One of the ways the campus recreation department influences this perception is to dedicate a committee to continually monitor and increase their inclusion efforts.

Subtheme 2: Inclusion and diversity committee. Committees are groups of individuals within an organization purposefully selected to perform a function on behalf of a larger group (Grigsby, 2008). In the higher education setting, committees are a necessity. This is especially true within the campus recreation setting as they are charged with a variety of tasks. Committees are set up to ensure that each programmatic area within campus recreation has input into any potential outcomes. For example, representatives from intramurals, club sports, outdoor recreation, fitness, wellness, and staff development are generally selected to serve on these committees. Without this 
holistic input and from the entire department, committees and tasks tend to progress more slowly. For example, the campus recreation practitioner from GC said, "it was pretty, you know, mostly informal and passion based until, until that committee was established." With more structure, direction and buy-in from all of the campus recreation programming areas, the inclusion and diversity committees are able to accomplish their goals. For example, the practitioner from EU said "our senior staff originally created what those goals would look like for our department. And then that is when our department formed its diversity and inclusion committee." Going further the campus recreation practitioner from GC stated:

That dissonance of like just the passionate people were doing it and people weren't understanding that it's all of our jobs to be concerned about these things and creating inclusive environments. And so, um, the committee was created and has been in operation I think for the past four years now. So that is another way we're trying to create that culture is by having it be our jobs but also ensuring that the work's moving forward through accountability on that committee.

This statement just shows how invaluable it is to have a total departmental commitment involved in increasing the inclusive efforts of campus recreation. Developing committee buy in is difficult but can be managed by finding individuals dedicated to creating an inclusive campus recreation department.

The participants indicated some difficulty is in finding dedicated individuals to serve on these committees. The interviewees indicated how many campus recreation departments had set up the committees through identifying individuals passionate about the outcomes or just requiring them to serve. The campus recreation practitioner from Hill Valley College (HV) expressed the following:

We developed a committee in our department, and I got the lucky job of being the chair of that committee yeah. Voluntold, which I was okay with because I do like the topic. The committee is made up of individuals from every single program 
area within our department. So that way we're representing the entire department and really thinking inclusively about everybody.

This statement described how committees are typically formed within the campus recreation setting. In this case, the leadership charges an individual to chair the committee while forming the committee with a representative from each programming area. This same process was done at Greendale College (GC) as indicated by the following statement:

The committee was created four years ago and the people that are on it now represent everything from our leadership team. So, we actually have all three of our associate directors on it right now. And then we have people at our entry level which would be a coordinator position and then we'll have students.

GC actually went a step further by ensuring they have representatives from every level of the organization. GC even uses students to serve on this committee to ensure that their input and viewpoints are taken into consideration when practicing inclusion. This is in an effort to be sure every subgroup working within campus recreation is truly represented. Additionally, the practice of having multiple subgroups serve on a committee is beneficial because there is a representative of every facet of the campus recreation department from part-time staff, student-staff, full-time staff, and leadership.

Once formed, these committees work together to make the campus recreation department more diverse and inclusive. The data indicated that once the committee is created, they have free reign to do anything within the campus recreation department's means to increase the inclusion efforts of campus recreation, even going as far as changing the mission, vision, and values of the entire department. The Empire State University interviewee said "our department formed its diversity and inclusion committee. And so, one of our first goals was to look at how we include inclusion in our 
mission statement or our core values. We ended up redoing all of our core values." These committees work together to research and develop new values which reflect the efforts to be inclusive through every effort within their campus recreation department. This just shows how dedicated each of these programs is to make sure their program is as inclusive as possible, sometimes even fully changing the direction of their department to ensure that inclusion and diversity are focal points in the department's future.

These committees will select initiatives to undertake in order to make their campus recreation program inclusive. For example, GC said "we are now at a point where we're choosing two or three issues each year. And dividing up into teams and trying to tackle them." The groups identified where they needed to focus their efforts and created realistic goals which would make a difference in the inclusion effort of their campus recreation department. The EU individual said, "We have a department diversity inclusion committee that takes a lead on initiating. A lot of these things we kind of divide about six people in some kind of items, kind of championing which initiative at the time". These committee subgroups are assigned a specific task to undertake. Many times, this is in an effort to address an inclusion issue specific to their own expertise. For example, the committee will identify a need to increase programming in intramurals for people with disabilities, but the subgroup will do the research and develop a practice to address or mitigate the concern. This continued effort to advance inclusion is shown at multiple universities. The campus recreation practitioner from EU said:

Goals have continued to build each year. And this is our diversity inclusion committee is I'd say our most active departmental committee that we have. So constantly looking to pursue, you know, we have our goals projected for three years out for the committee. And so constantly looking to meet those goals. 
Continued advancement is a goal of each and every campus recreation department. It is how they first started creating inclusive initiatives and it will continue as more needs are identified. This is evident as said by the campus recreation practitioner from HV "we thought it would be important for our department to kind of take a bigger stance on inclusion and think about, you know, adaptability or, um, communication, you know, in our marketing. Are we communicating an inclusive place?" The Hill Valley College campus recreation department is advancing beyond the programming and facilities and moving toward more inclusive service for their patrons. How can they educate their clientele on the inclusive efforts that they have developed? This is the next stage or task for their Inclusion and Diversity Committee to undertake.

The following sections will discuss the efforts to provide an inclusive perception through the hiring practices and educating current and future campus recreation staff. The subtheme of hiring was indicated as important by five of the campus recreation practitioners in this study as hiring is the first step in a process to create the perception of a quality inclusive campus recreation program.

Subtheme 3: Hiring. It is the charge of campus recreation directors to create and maintain a high-quality campus recreation programs. One of the keyways to achieve this task is by hiring the best potential candidates for each position (Stier et al., 2006). No matter the area of specialty within campus recreation, the success of the program is fully dependent on finding the right person for the job (Strunk, 2019). The practitioner from BC discussed this by saying:

We're hiring the best people for the job, but we obviously try to make sure we have that diversity. In our staffing fulltime and student staffing, and then and have the people working in those positions and that they're going to be catering to the clientele as well. 
As indicated by this statement, this choice is made even more difficult when trying to hire individuals to create a more inclusive environment. This task can be achieved through many different practices. The following will discuss how the campus recreation departments who participated in this study utilized unique hiring practices to develop their inclusive environment. Many of the campus recreation practitioners referred to these practices as hiring with a purpose.

The inclusive hiring practices from many of these campus recreation departments originate with the job posting. All of the programs are required by their university human resources departments to post jobs in a variety of locations to create a diverse hiring pool. The participants of this study indicated that they utilized the university's website, professional networks, job posting sites, and localized publications to post jobs they are hiring for. For example, the practitioner from BC discussed this by saying:

We strategically place our job postings in certain avenues across the country through higheredjobs.com, bluefishjobs.com, obviously our HR website and so forth. But then we have those, those parameters that we try to stay within that, that that's human resources make us stay within. It makes sure we are providing that diversity on campus.

Individuals use all sorts of different sources to find job postings, it is evident that many of these programs strategically post jobs for multiple reasons. One to make sure that people are aware of the job postings, two to get the best people to apply for the job, and three to create a diverse hiring pool.

After the job posting procedures, the next step is the application process of the individuals trying to get the positions. From this study, it was indicated that even this step has initiatives to hire with a purpose. The campus recreation practitioners indicated a number of resources they utilized to promote inclusion during this step of the process. 
The first resource indicated was the use of supplemental questions. For example, the practitioner from FC said "We utilize supplemental questions about diversity and inclusion. And so even folks that are just applying for a job, know it's there and our environment." This statement indicates how part of the application process promotes the efforts of the campus recreation department to be inclusive. These supplemental questions are also used as a screening tool to find the best possible candidate for the position. The goal of these questions is to find individuals which promote a similar view of diversity as the campus recreation department. These questions can be anything from asking individuals, to define diversity, how they promote diversity, to asking about their knowledge or prior experience of serving people with disabilities. For example, the practitioner from FC said:

Our director has a vision of we want to hire a staff that's dedicated to adaptive rec. Then as far as the kind of our practices now, all of our professional staff, were involved in promoting that vision.

The statement discusses how they try to hire people who are likeminded on the importance of inclusion and diversity to continue their progression in being welcoming to everyone. As far as the purpose of demographic questions during the hiring process, many of the campus recreation departments discussed this during the interview process. For example, the practitioner from EU stated:

We currently conduct mass screening of applicants and interviews as the first round for people applying within our department. We collect some of that demographic data so that moving forward we can kind of look at what populations of people we might not be seeing, um, that are applying to work for us. And so that way in the future we can do more targeted marketing. Um, to better match the demographics of the campus community.

This statement is fascinating because the EU campus recreation department is utilizing the supplemental questions and demographics in multiple ways. First, they are using the 
data to understand which demographics are not represented in the application pool. From that data, they can identify ways to do a better job of making sure specific demographics are being notified about potential job openings. The second part of this statement is that they utilize the data to hire with a purpose. In this case, the purpose to hire individuals who are representative of the campus community. For example, the practitioner from HV reiterated this in saying "In terms of our student hiring practice, we try and represent the university and the student population". This same process was again reference by the campus recreation practitioner EU by saying:

One of the things that we've been trying to pay more attention to is in terms of hiring is something we've been thinking about in terms of really the people that we are hiring, what does that look like? For role modeling purposes.

The phrase role modeling is an interesting terminology used for this technique from both the EU practitioner and the FC practitioner. The practitioner from FC used the phrase role modeling to also discuss their effort to hire employees which represent the university demographics in saying:

I guess it goes back to role modeling and staff too. I think campus rec when you see faces, same thing with diversity with races and different things the more you see folks on your staff I think the more diverse folks you have coming into, to utilize a program.

Role modeling, in this sense, is an intentional effort to make the staff diverse and therefore more inclusive and welcoming to people who have similar appearances or identities. This role modeling technique was indicated by both the FC and EU practitioners as being a productive step in promoting an inclusive environment. This process elicits people with varying abilities, physical appearances, and diverse background to be a part of their campus recreation staff. However, many programs have 
this similar intention of hiring diverse staff, but the process is easier said than done. The statement by the practitioner from HV said:

Hiring diverse staff has been a push on campus but also a struggle for the entire campus. If I'm honest, because people want to hire the best, but we also know that there that is a priority to hire diverse individuals. To be honest, is it a challenge for some of our, our colleagues to get around because of the opinion that we want to hire the best of the best and we don't care what they look like.

The campus recreation department wants to hire diverse applicants but also the best applicants. At times, these efforts can compete against each other and at times it can be difficult to change a culture. For example, the practitioner from HV expanded on the earlier statement by saying:

We want the best of the best and so actually what I've done is I actually called a couple of my colleagues at other universities who are African American. And I asked him, you know, if we had an opening position, would you consider coming here? Because I wanted to know, like, I mean, you've seen our staff directory, I'm sure it's all White except for two people. So that's a problem. And so, I called them, and they said no, because we're HV and we are not diverse, and they would not feel comfortable there. The only exception would be if they had somebody in a higher position who they could relate to. Yeah. Which they do because our vice president is African American, so that does help.

This statement just goes to show how unwelcoming an environment can be just by appearances only. People are unwilling to go to this university because they do not see anyone similar to themselves. This just proved how hard it is to try to create a diverse and welcoming environment. Trying to build a diverse staff is not an easy task. At times, the lack of current diversity can actually be a hindrance to becoming more diverse. It is imperative that the effort to become more diverse continues in order to create a more welcoming environment for all.

One of the ways this effort can be helped is after the hiring process and through the training of the campus recreation staff. The training and education of individuals 
working at the campus recreation center can create a more welcoming environment. The next section will discuss the staff training and education that happens after the position is hired.

Subtheme 4: Staff training and education. Campus recreation departments employ some of the largest staffs on campus. Their numbers include professional staff, student staff, administrative staff, housekeeping, and volunteer staff. Once the staff is in place, it is integral to provide training and education to the staff to ensure effectiveness. Creating a truly inclusive environment is dependent on the mindset of the staff. Many programs implement trainings and continuing education courses to ensure the staff is knowledgeable about inclusion and diversity. The campus recreation practitioner from GC stated, "we're trying to do so much on the staff training side and making sure our staff is creating a welcoming environment". This practice takes place through a variety of training and education courses which develop and increase the multicultural competencies of the campus recreation staff as a whole. Staff training includes every single person who works with the campus recreation department. The EU campus recreation practitioner explained how their staff training practices were developed with the following statement:

As professional staff, we implemented a semester long training for our professional staff. It was four parts that focused on increasing our professional staff multicultural competency and capacity. Then we went through that together with who was here at that time. And now what we do is every January, all new professional staff that we've had hired over the past year goes through a similar training to that so that we're all at the starting the same kind of starting level to support our students and then all employees go through an inclusive language training as, as far as new student or a student employee orientation. And then our student supervisors actually do a semester long training focus on increasing multicultural competency and capacity as well. Kind of, it kind of mirrors some of the same things at the professional staff has gone through. 
It starts from day one for all staff working within the campus recreation setting. From the time a person is hired in the campus recreation department, they become a part of the culture. To ensure the employee accurately represents the culture of the campus recreation department, they are put through training and education on the correct methods of being inclusive within the campus recreation setting. This can include an understanding of the correct terminology, the preferred method in dealing with difficult situations, bringing in experts on diversity and inclusion to get the employees comfortable with the topic. The practitioner from SC addressed their process of educating and training their staff by stating:

It's embedded in every teaching that we have with every of our student employees, even right from our team training day, which is our kickoff event for all of our students and then all the way down into our programming trainings. So, it's embedded in who we are. It's, it's taught to our students and we try our best to make sure that we live and breathe it every day.

The goal for each of these programs is to have training to educate the staff enough so that inclusion and diversity are embedded in the very core of their department. Inclusive language, accessibility, and diversity should constantly be on the mind of any staff working the facility, services, and or programs. The practitioner from GC discussed the same premise of educating the entire staff from the moment they start working for campus recreation. The practitioner from GC said:

We also have an expectation that our staff, whether they're full timers or student staff, are being educated on this value. It's not, it's not one of our actual values where we put it on our website, but it is an unwritten value for us. And so, we have onboarding processes that results in both full time and student staff, getting some education right away from their supervisors about why this matters to us. And then we do two all staff trainings a year and in one of those, at a bare minimum, there needs to be something around equity, diversity and inclusion as a topic to ensure those are being discussed. 
To ensure that this training and education stays fresh in everyone's minds, additional classes and seminars are held to provide continuing education on inclusive topics. For example, the practitioner from EU detailed how their staff continues to grow as inclusive leaders. The practitioner from EU said:

Probably about two a semester coffee and conversations or lunch and learns, focused on diversity and inclusion. Where we create that space of professional staff to continue to kind of learn and grow with one another.

The key takeaway from this statement is how the staff continues to grow together. As new inclusive practices are discovered or new adaptive equipment is purchased, each program trains their staff accordingly. For example, the practitioner from AU said, "We get special training to our instructors on modifications--not modifications necessarily for disability, but modifications for anybody." This shows how there is a continued effort to educate all staff on any new modifications which can help individuals remove barriers from participation. Some of these barriers are removed when specific adaptable equipment is purchased. However, many of these pieces of equipment require proper training to operate. It is integral that campus recreation staffs have training of proper operations of adapted equipment. The practitioner from WU reiterated this statement by saying "And all of our staff is trained to provide equipment and orientations on those machines as well". The goal of the stated training initiatives from each of these campus recreation sites is to create a diverse and inclusive environment. Therefore, a knowledge base must be created around each specific area of the inclusion effort. The next section will discuss the inclusion efforts of the campus recreation program people with disabilities. 
Theme 2: Disability Inclusion

The efforts to create an inclusive environment were discussed in various way by the campus recreation practitioners who participated in this study. The most evident theme of these inclusion efforts was aimed at people with disabilities. Many options were put into place to create opportunities so people with disabilities could become involved in the campus recreation department's programs, services, and facilities. This was discussed previously in the creation of new mission statements, hiring practices, and employee training efforts.

This section will discuss the efforts to create opportunities for people with disabilities through developing inclusive facilities, programs, and services. The most evident subtheme of diversity inclusion efforts was the effort to be in compliance with the Americans with Disabilities Act. This legislation leads to various accommodations by the campus recreation practitioners to meet the needs of people with disabilities.

Subtheme 1: ADA compliance and accessibility. The Americans with Disabilities Act (ADA) is the guiding legislation in the US to protect the rights of people with disabilities. The legislation mandates the equitable treatment of people with disabilities relative to places of public accommodations, employment, public programs, and service providers (Americans with Disabilities Act $\S 12101,1990)$. The ADA has five sections or titles to explain the equal rights afforded to people with disabilities in the United States. In 2010, the United States Department of Justice published revised regulations for Titles II and III of the ADA (United States Department of Justice, 2010). The revised regulations are consistent with the guidelines published by the U.S. Architectural and Transportation Barriers Compliance Board in the Architectural Barriers Act (ABA) of 
2004. These revised regulations specifically discussed how recreation facilities must be designed to be accessible and usable by everyone, including people with disabilities (Stager-Wilson, Barnett, Mahoney, \& Sampson, 2012).

Compliance and adherence to the ADA was discussed by the campus recreation practitioners throughout the interview process. The interviewees discussed how they maintained compliance with the ADA in their answers to multiple questions. For example, the practitioner from Western University stated:

Accessibility obviously is our pool access. There's a machine that helps with that and everything within the department meets ADA standards in terms of facility build out. Anytime we do a renovation we have to go through our campus ADA people. We had a giant ADA ramp in the middle of our facility that we actually took out to open the space up for more equipment, new flooring, things like that. But we had to go back in and add in some accessibility pieces.

This statement was similarly repeated from other campus recreation practitioners interviewed. Many of the practitioners discussed how they maintain correct spacing between the equipment to ensure that anyone is able to access the equipment even if they are using a wheelchair. The practitioner from Gotham University even easily stated the exact dimensions needed for equipment to be accessible according to the ADA. This practitioner said, "want to have the 36-inch clearance for wheelchair accessibility." This intimate knowledge and understanding of the legal obligations campus recreation facilities must abide by is fascinating. Each one of the practitioners understood how they met the current policies set forth by this legislation and immediately were able to identify when they are not in compliance. For example, the practitioner from AC stated: "And then for ADA compliance issues, we have a circuit, a full circuit, here that you can use if you're a wheelchair user." 
Inversely, the campus recreation practitioners were quick to indicate how certain spaces within the scope of their programs were present prior to the implementation of the ADA. These spaces are not in compliance of the ADA. For example, the practitioner from Adams College said their "facilities are equipped to be as ADA accessible as we can. We do have a few spaces that are grandfathered in from the 1960s or inaccessible, but we offer what's inaccessible in those spaces in an accessible space." In this instance, one of the campus recreation facilities was built before the ADA was enacted and therefore was not required to meet the modern standards. However, they strategically program around the inaccessible space so that no one is denied access.

It is up to the facility and campus recreation staff to ensure that ADA requirements are maintained at all times. Campus recreation practitioners must be vigilant to stay up to date on the ADA compliance of their facilities and services. For example, the practitioner from GU stated:

We want to be cognizant of the law and being proactive in regard to ADA compliance and even spaces such as our free weight room when individuals move equipment at their own volition. We need to know as a staff member when you want to have the 36-inch clearance for wheelchair accessibility.

This statement indicated that the campus recreation facility must be aware of the policies set forth by the ADA and when they could potentially be in violation of the legislation.

The campus recreation practitioners understood the requirements of the ADA, but they also understood how the ADA provides a baseline set of rules or standards for accessibility. Many of the practitioners say they do their best to advance their inclusive practices in order to have the most accessible facilities and programs. The practitioner from SC exclaimed "Most people are required by law to have a lift, but we go an extra mile." In an effort to be more inclusive, practitioners are constantly trying to be proactive 
in meeting the needs of any and all participants. Many of these proactive efforts involve additional services to remove any barriers to utilizing campus recreation programs, services, and facilities. Another example of a campus recreation program going the extra mile is at Arlen University (AU). The campus recreation practitioner indicated how they had a number of students with vision impairments which resulted in having a service animal present at all times. The campus recreation practitioner was able to elaborate a little bit more on how they were able to go above and beyond the ADA to meet the needs of these students. The practitioner from AU stated:

We had two or three different students that wanted to personal train and it was just easier to personal train with just the trainer and not with the dog always in the way. So, we went and bought some collapsible kennels for the dogs.

This service is not mandated by the ADA but done by the campus recreation department of their own volition to remove a potential barrier. The campus recreation practitioner at SC indicated additional ways they go beyond the ADA with the following statement:

We go an extra mile and making sure that, that it's one that the individual can actually control themselves so that they don't have to ask someone else to help lower and lift them out of the water. We really try and reduce any barrier that would be to create a stigma on someone for whatever ability or inability that they would bring.

South Central University even has a residence hall which is designed to meet the needs of students who have extreme mobility impairments. The campus recreation practitioner stated:

We found that they wanted some more recreational spaces which is awesome. So, our fitness team went to them and now we take a yoga classes and fitness classes to them in their hall specifically cause they, they couldn't get 12 to 15 people in chairs over across campus to our rec center every day.

Many of these efforts which the inclusive practices mandated by the ADA utilize additional equipment to remove barriers and provide access. For example, the practitioner 
from EU stated, "we tried to do a variety of programming that reach a variety of populations on campus." All of these efforts are designed to not only meet the standards set forth by the ADA but to continually advance the inclusive accommodations for people with disabilities. The practitioner from SC summarizes this by saying "it's really making sure that everyone has the same access the same way." The practitioner from EU reiterated this statement by discussing the equipment they purchased to cater specifically to the needs of people with disabilities. The GU practitioner said: "We've been able to purchase adaptive equipment to allow persons with physical disabilities to participate." The practitioner from AC stated a similar opinion by saying "All of our facilities are equipped to be as ADA accessible as we can.” The goal of purchasing adaptable equipment is so that everyone has the same opportunities to utilize the facilities, programs, and services of the campus recreation department. Additionally, the campus recreation practitioner from WU stated:

We intentionally try and choose programs and equipment that meets everyone's needs. So, we are not committed to just one vendor. For example, in terms of like fitness equipment, we will literally purchase any type of fitness equipment to try and offer a variety of pieces that would meet everybody's desires in terms of their fitness experience.

This intentional purchase to meet the exact needs of an individual is a way for campus recreation practitioners to advance the mandate of the ADA to provide greater accessibility and accommodations in their facilities and programs. The practitioner from HV discusses this practice in the following statement:

We have adaptive climbing equipment, adaptive kayaking equipment and adaptive biking equipment. And so, we're able to offer those adaptations for some of our, adventure trips. And then in terms of our fitness department, group fitness, they have been working to kind of also get more adaptive equipment to allow persons with physical disabilities and to participate in classes. And so, we had one 
of the arm ergs which we recently purchased another one of those to have in our cycling studio as well.

The campus recreation practitioner from AU reiterated this by saying the following about the adaptable equipment they have:

Then we have adaptive equipment, fitness equipment too which I totally forgot about. So, we have a whole line of that where the seats pull out. And also, we changed out to free motion type stuff where you know, you know what, I may need one handled to do a workout.

There are various types of other equipment the campus recreation practitioners identified to provide opportunities for people with disabilities. The practitioner from SC said:

We host things such as goalball. We do a sitting volleyball tournament every year. We've done blind baseball (Beep Ball) before and we even did some three on three a wheelchair basketball. We are currently looking even to start a wheelchair basketball club on campus.

In these instances, the campus recreation program either bought or rented additional equipment such as balls, blindfolds, wheelchairs, and adaptable sport accessories. This equipment was all purchased to aid individuals with disabilities to participate in campus recreation programs, services, and facilities.

The campus recreation practitioners participating in this study discussed in detail how they continually met and advanced the mandates set forth by the ADA. Not only does this practice meet the requirements of the ADA but also aligned with the mission statements of their campus recreation departments. Many of the practitioners indicated how they accommodate and design facilities, services, and programs to an individual's specific physical needs. However, many of the campus recreation practitioners also discussed how they do their best to cater to the needs of people with other disabilities not 
just with physical disabilities. The practitioners from AC discusses this in the following statement:

We generally try to offer varying range of activities based on your physical limitation and or your skill limitations. And that's true whether you have a physical disability or intellectual disability. One of the evident ways of creating diversity inclusion was the connection of campus recreation to the Special Olympics.

This statement leads to the next generated subtheme of diversity inclusion which is Community partners to help inclusion. The next section will discuss how campus recreation practitioners utilize Community partners to help inclusion to promote diversity and inclusion.

Subtheme 2: Community partners to help inclusion. The first community partner which helps inclusion is Unified Sports. Unified Sports is a global initiative, in conjunction with Special Olympics, to breakdown stereotypes about people with disabilities through sports (Special Olympics, 2019). Currently about 1.4 million people worldwide participate in Unified Sports (Special Olympics, 2019). This initiative combines individuals with and without intellectual disabilities to promote social inclusion through sport (Special Olympics, 2019). NIRSA works with the Special Olympics to expand the Unified Sports program even further. Campus recreation programs have started to offer Unified Sports through their programs to promote inclusion in their collegiate setting.

The practitioner from Gotham University stated how their program was the first Unified Sports program in campus recreation. The practitioner said "we were the first university in the country that started a unified sports program with the Special Olympics, New Jersey. And so, we did that through our sports clubs' program." Many of the campus 
recreation departments offer Unified Sports to create a more inclusive environment within their department and campus. The campus recreation practitioner from Hill Valley College (HV) stated:

Unified Sports, we started that two years ago, I believe. And so, we have like football, volleyball and basketball that we offer for unified sports. And that has been huge in terms of creating an inclusive culture for individuals with disabilities to be in integrated with individuals who are able bodied.

Similarly, the Gotham University practitioner reiterated:

And it's been really great for our unified sports club that has worked with the families in the area with including the Special Olympic athletes and a lot of college students have eye opening experiences whenever they join the club and they realized the purpose and the outcomes from participation, coaching or officiating those events.

Both of these programs utilize Unified Sports to create an inclusive culture and build community relationships to increase the awareness of diversity and inclusion. Unified Sports promotes inclusion for individuals with intellectual disabilities but also show how the campus recreation departments are dedicated to promoting inclusion within the campus recreation setting. The campus recreation practitioner from AC made the following statement which reiterated this same principle:

The reason why we work with Special Olympics is the right thing to do. But we also have a program on campus for folks with autism called AFIT and they're students. And so, it, it provides those students, maybe a way to participate, that they wouldn't feel comfortable participating in a different setting.

Not only are they creating programs to fit the specific needs of an individual, but they are doing it because it is the right thing to do. Many individuals in a campus setting are just trying to fit in and feel comfortable. The campus recreation practitioners recognize this need and create programming like Unified Sports to integrate specific populations into the campus setting. 
These initiatives to create opportunities for people to become involved in the campus community go back to the creation of the campus recreation's mission, vision, and values. With these concerted efforts to provide intentional inclusive programming, campus recreation departments can really create a welcoming environment on their campus but all act as an example for other schools and program to mimic. For example, the practitioner from MC stated:

This department has been recognized in leadership for a long time. And whether it's with, you know, adaptive recreation, when no one was even really thinking about it, some of our stuff with unified sports and support a special Olympics that there's, from every of part of the department, it feels like it's in the DNA to think about who we're serving and, and to make sure that we start with, how we serve everyone.

These efforts to provide diverse programming create an environment within campus recreation to make it known that they are there to serve everyone.

Campus recreation practitioners utilize the idea of Unified Sports as a tool to get everyone on the same page with inclusion efforts. Providing specific programs which challenge individuals to compete on the same playing field with an individual different than themselves helps create a campus that is welcoming to everyone regardless of ability, gender, race, or religion. Unified Sports is an initiative to address the issues of inclusion for people with disabilities, but their other initiatives address the inclusion of other identities.

Another useful community partner for to provide a more inclusive campus recreation setting is the local medical industry. Many of the practitioners in this study discussed how they would partner with the medical industry to provide additional resources to people with disabilities. Many of the practitioners discussed how they purchased 
equipment specific to providing intramural events to people with disabilities. For example, the practitioner from CC stated:

We have a partnership with CC Medicine, and they've been able to obtain some grants and from different donors to purchase adaptive equipment. So, we are starting with Wheelchair basketball. So being able to, to offer those opportunities for those with disabilities to still be able to participate.

This partnership enables the campus recreation program to afford the adaptive equipment necessary to offer the inclusive offering of wheelchair basketball. These wheelchairs and other adaptive equipment can be expensive, so many of the practitioners discussed how they utilized these partnerships to gain access to equipment they otherwise would have been unable to purchase. The practitioner from AC said:

We work with a local organization which does adaptive recreation. Instead of us creating new programming and competing with them we usually work just with them. So, we'll do adaptive climbing clinics, wheelchair basketball, Special Olympics and unified basketball and we're looking to expand that and do more. Our limitations are honestly, we don't have a very large population of folks with physical disabilities on campus honestly. And so, we just don't have a large population on campus, and we wouldn't even have enough to have wheelchair basketball.

Many of the practitioners discussed how these partnership is integral to provide additional opportunities for people with disabilities that otherwise would not be feasible or practical. Many of these partnerships are needed to increase the perception of inclusion and diversity for the campus recreation departments. Another way campus recreation practitioners increase the inclusion perception is to provide opportunities for people of different identities. The next section will discuss the initiatives of campus recreation practitioners to create intentional programming and services to promote inclusion and equality across gender identities. 
Theme 3: Gender Inclusion

Gender inclusion and equality have been extremely important components of campus recreation since the passage of Title IX. Additionally, since the emergence of the 2017 Dear Colleague Letter, campus recreation practitioners have continued to advance their inclusive practices for transgender populations within campus recreation (NIRSA, 2017). The data from the interviews indicated that addressing gender equality was of the utmost concern in creating an inclusive campus recreation department. For example, the campus recreation practitioner from AC stated:

We have all the same policies and procedures that you expect that all of departments have. About inclusive practices and gender identities and things like that. So, all of those things exist to make sure that we're in compliance with Title IX.

Many of the efforts are guided by Title IX legislation so that all genders are treated equally. During the Obama Administration additional clarification extended the guidelines of Title IX to include people identifying as transgender (FindLaw, 2019). These additional protections of Title IX to the transgender population were later removed in 2017 by the Trump Administration (FindLaw, 2019). However, many campus recreation departments followed the 2014 guidelines to remove gender binaries from programming. This process is ongoing and is changing the way facilities have been built and programming has been run for years. Gender equality is constantly being assessed to ensure the equal treatment of every user. For example, the practitioner from Marshall College (MC) stated:

But you know, we're trying to reexamine gender leagues and intramurals and whether those are necessary. So, I just think that there's an ongoing analysis of, of effort, a real effort to make sure that the doors are, are wide open to everyone. 
This statement shows how much effort goes into ensuring inclusion for all gender identities in the current campus recreation climate.

Multiple institutions discussed how intramural leagues and facilities are no longer gender binary. The practitioner from AC stated:

I mean, we do open recreation and don't play Co Rec anymore. Intramural sports. We played men's, women's and open. If you don't prescribe to the gender binary, it doesn't matter. You can play open; you can use the locker room of your choosing based on your gender identity. All of our locker room and facilities have private showers and private changing areas.

This option means that individuals get to choose which league or locker room they want to participate in or utilize. Open recreation opportunities removed all gender identities from the participation requirements and rules. This practice has created an understanding among campus recreation professionals that in order to be truly inclusive, they cannot force individuals into specific gender roles. The practitioner from GC said, "we're acknowledging differences in gender and gender identity and being open to that, that continuum instead of forcing the binary on everyone." The practitioner from Adams explained how before they even develop programming the following question must be asked: "How do you participate if you do not prescribe to the gender binaries?" From there the campus recreation department can determine if any new programming or facility feature is inclusive for anyone on the gender continuum.

The campus recreation practitioners indicated how they are open to meeting the needs of any participants regardless of their identity, disability, color, creed, ethnicity, socioeconomic status, veteran status, or gender. Multiple campus recreation practitioners discussed a variety of ways in which their campus recreation departments provided inclusive facilities, services, and programming. However, a few unique initiatives 
discussed could be beneficial to other universities in this study to create a more inclusive campus recreation department. Many of the practitioners discussed how they developed their inclusive practices when answering research question two. This will be discussed in the following section since research question number two is how campus recreation professionals determine and create their inclusive practices.

RQ2: How do campus recreation professionals determine and create their inclusive practices?

The following section outlines the data collected from the campus recreation practitioners on how they determine and create inclusive practices for their campus recreation department. Data analysis elicited the three themes of policy source, assessment and surveys, and personnel involved. The following section will outline the thematic responses from the practitioners on how they determine their inclusive policies. Each theme will have multiple subthemes which will be outlined as well. Theme 1: Policy source

The campus recreation practitioners indicated how many of the policies were created from input from various sources around campus. This section will discuss the process by which inclusive policies were conceived and developed through the efforts of campus recreation staff, students, administrators, and the campus community. The subthemes of the policy source are from the top down and grassroots. Both of these subthemes are inherently opposite from each other on a leadership perspective. This finding is interesting as there was no one clear way in which these inclusive policies were conceived. Depending on the campus recreation department and the institutions, the 
inclusive policies were developed in an effort to create a more inclusive environment. From the top down was the most evident policy source and will be discussed first.

Subtheme 1: From the top down. The first subtheme of the policy source was how many policy decisions came from the top down. Campus recreation practitioners indicated how the focus to be inclusive came from their supervisors or was even mandated by the university. For example, the practitioner from EU said "The division of Student Affairs had asked departments to create goals surrounding diversity and inclusion. And so, our department, our senior staff originally created what those goals would look like for our department." This statement indicated that the need for inclusive practices was decided outside of the campus recreation department and specifically by the student affairs leadership on campus. Many of these inclusive practices were mandated by the law for institutions to be in compliance with the ADA. However, other initiatives were created to go above and beyond the legal mandates in order to increase the inclusive environment of the institution.

This statement was similarly represented at Hill Valley College (HV) where the campus recreation practitioner said, "I know that there's been a push, like all along more recently though we got a new vice president for student life and she has made it a push on campus to be inclusive." Western University (WU), also had a similar approach in creating their inclusive policies. The campus recreation practitioner stated: "I know my boss, as well as myself, have been involved in really putting the pressure on our programs to continue to have offerings that appeal to more people." Faber College indicated how the policy creation came from their campus leadership by saying "I think it started with 
our director wanting to make sure that we were focusing at that point on adaptive recreation."

This top down approach tends to have a trickle-down effect as the onus and responsibility to become inclusive falls specifically to the people in charge of the campus recreation facilities, programs, and services. This is evident in the following response by the campus recreation practitioner from SC:

I think it's been an evolved piece. I, I can tell you that the efforts that have been in place certainly preceded my time here and it's been something that has continued to grow over the years. And I think that it has been, first of all, at the expectation of our directors. I think it's at the very top is where it comes from is that we're going to be inclusive and welcoming for all people. And then from there, our staff has latched on to take that to varying degrees and programming levels to make sure that that has come available.

Campus leaders charge their subordinates with the responsibility to provide inclusive practices. Those subordinates push the responsibility down the line to their own subordinates until the inclusion resonates throughout the entire department. This technique allows the person directly in charge of the area to create an inclusive policy which works best for their program areas. For example, at AC, the campus recreation practitioner stated:

The senior leaders state this is the expectation and that we have final review, but we rely upon the people who actually have to operationalize the policies to write them because it's all well and good for me to think something's a good idea. But in practicality if it doesn't work. It's not a good policy. So, if it's a pool policy, then we let the aquatics person write it with supervision by their assistant director and then we review it.

The campus leadership often delegates responsibilities down the line of direct reports to ensure the policies work and meet the needs of their specific clientele. The campus recreation practitioner from $\mathrm{AC}$ discussed how each program is asked the following questions to ensure they are being as inclusive as possible: 
We need each area to be able to answer questions about how is it inclusive? How do you participate if you do not prescribe to the gender binaries? How are we serving people who may be a wheelchair user? Do we have any demand that we are not currently meeting?

The policies are spurred along as new administrators or ideas come from both the university level and at the national level. For example, the campus recreation practitioner from $\mathrm{HV}$ indicated momentum came from:

The Therapeutic Rec Department on campus because a part of their curriculum, they come into all of our facilities and evaluate the inclusiveness of them. So, like our main facility is way more inclusive than our older facility in terms of signage, in terms of like the strips on the stairs to notify, you know, that there's a barrier there. In terms of the gender inclusive restrooms, all that stuff. They come in and evaluate and then they actually provide us reports each year to tell us this is areas that you can improve on. So, one of the reports that we got last year was that in our older facility, the fieldhouse had horrible signage for Braille. And so, we redid all of our signage this past year, so that way students could actually find their way around the facility without asking.

That statement is interesting statement and unique to HV compared to the other campus recreation sites in this study. A program outside of their department comes into their facility and assesses their accessibility to help determine the next steps into becoming more inclusive.

Other programs indicated how they develop their ideas through other channels. For example, the practitioner from BC indicated they rely on the governing body of campus recreation to set the industry standard they need to follow. The campus recreation practitioner from BC said, "We act in accordance to the industry standards that we have, that are through NIRSA." This campus recreation program looks at the governing body to help determine their inclusive practices.

The leadership of the campus recreation department and instructions were shown to be the most evident source of inclusive policies. Many of these policies were 
developed due to efforts by the university's administration to create a more diverse campus community. With this charge, policies and practices were developed to create a more welcoming and diverse campus environment. These ideas were also developed from the leaders within the campus recreation department as they developed an expectation of the level of inclusion within every facility, program, and service provided. The final subtheme of policy source is grassroots which is the opposite of the first subtheme, from the top down. Grassroots policy creation will be discussed in the following section.

Subtheme 2: Grassroots. Swords (2019) defines grassroots efforts as mobilizing a group of passionate people willing to fight for a cause from the ground up. In the case of campus recreation departments, policies generating from the grassroots means the impetus for them comes from the facilities' patrons or entry level employees. The campus recreation practitioner from CC said it best stating "it's kind of started from the student life level." Many students at this university kept asking the same questions about how the campus recreation department decide how to meet their needs.

Understanding the needs of the clientele is important, so many of these campus recreation departments do their best to listen to their patrons' needs to best serve them. Sometimes these needs are identified based on specific populations on campus. As the campus recreation practitioner from SC discussed, many of their inclusive ideas are developed by determining the needs of groups of students. These needs are not simply "wants" but when a group of students continue to be underserved, it is up to the leadership to respond to those students. This is shown in the following statement by the SC practitioner:

I also think that it's growing based on the students' needs and student populations. There was a time three or four years ago that we had a heavier, a heavy number of 
students that had different types of mobility patterns that were different. So programming was geared specifically for that population. And then follow that up with, we had a year where we had a lot of numbers, a lot of students that were visually impaired. So, we changed some of our programming to meet that.

In this instance, the need grew from the student body but until the campus recreation department got behind addressing the need, no programming was developed. The needs of the student populations are not always evident, and it takes time to understand what their desires are. At times this can be from a push by a specific population or from the practitioners actually being able to identify those desires. Getting the support for a new idea is key, specifically when this support comes from the students.

The campus recreation practitioner from SC reiterated this in saying "So a lot of our direction and programs are dictated by what the students here want and what the population is like on campus and what their needs and desires are". Listening to the clientele the campus recreation department serves was a trend across all of the campus recreation programs in this study. Once the movement or desire for something is established from the students or entry level staff, the idea begins to build into something more tangible which the leadership begins to get behind and support. This is noted by the campus recreation practitioner from GC by saying "It started from mostly informal and passion based until a committee was established to direct it" Once there was enough of a ground swell of patrons asking for a specific need to be met, the leadership took note and began to meet the specific need through their policies and procedures. The GC practitioner reiterated this by saying an idea was "definitely grassroots when it started plus some awesome leadership role modeling in terms of how they designed the facility and staff." This illustrates how once a grassroots idea gets enough people behind it, the 
campus recreation department will support it. Many of programming needs and desires come from the patrons but until the ideas get support, they tend to just remain intangible.

This support works its way up the campus recreation program from the bottom until an employee gets behind the idea. For example, the campus recreation practitioner from GC stated:

I think it was mostly, like I said, small pockets of really passionate professionals who'd been worried and concerned about equity, diversity, inclusion issues at their past jobs or during Grad school. And then it was a total... What is the word for it? Grassroots - right is like having conversations with your peers and like, oh, we will both have this interest. Should we combine on an in-service and talk about this with all of our staff and, and then doing some assessments.

As they heard the desires of these individuals, the campus recreation administrators became more and more passionate about making sure they met the needs of all individuals within their campus recreation program. This passion developed into conversations at first and then grew into actual program assessments. From these assessments, practitioners developed tangible actions and practices in order to truly meet the needs of all of their patrons. This statement leads directly into the next identified theme of using assessments and surveys to develop inclusive policies and practices. Theme 2: Assessment and Surveys

As stated in the previous section, many of the practitioners were able to successfully develop inclusive practices through the use of assessments and surveys. These assessments identified areas of need in campus recreation programming and generated ideas to meet those needs. For example, the practitioner from HV discussed earlier how they frequently assess their facility in order to ensure they are in compliance with legal mandates and are being inclusive. 
Many of these assessments are physical in nature but there are also assessment techniques utilizing surveys. For example, the practitioner from GC Stated:

We are on our fourth large scale assessment that we've done in the past. It's been four or five years now since we started it. For each assessment we will look at a specific population and while no one experiences their identity like in isolation, we do take an identity and try to examine how we're doing from that lens. The campus recreation practitioner from GC indicated how they identify a

specific population of their clientele and develop an assessment to see how their campus recreation department meets their specific needs. It is integral for the specific population to be a part of this assessment because no one can speak to their needs without living in their shoes. The GC practitioner discussed how the assessment will help the campus recreation department develop a specific lens to truly meet the individual population's needs and desires. This action gives the population a voice in the determination of their own outcomes.

This process is shown to be similar at other campus recreation departments. The practitioner from EU discussed how to develop a specific survey to address the needs of the military veteran population at their institutions. The EU practitioner said "Our veteran needs assessment has identified that recreation is one of the top priorities that veteran have in their transition to campus. And so that's really helped us to have a good collaboration with veteran student life." The campus recreation staff was able to identify a specific population of their clientele and developed a survey to create a dialogue to understand their specific needs. Many practitioners discussed how it was integral to identify specific populations in order to ask for their direct input on how to best meet their needs. These assessments are not one size fits all, rather they specifically craft the surveys and assessments to align with each identified group of individuals. For example, 
the practitioner from GC said "So we have so far looked at LGBTQ, we've looked at disability, we've looked at race and ethnicity. and we're currently looking at socio economic status." This was reiterated by the practitioner from HV who said, "We've done our best to branch out and survey the different sub populations on campus to figure out why they may or may not be using our services." The goal of each of these departments is to continually assess how their department meets the needs of their clientele. As a new sub population is identified, it is imperative for the campus recreation practitioners to open up a line of communication to ensure the department is meeting the sub-population's needs.

Prior to each of these assessments, the campus recreation departments utilize university resources to ensure the success of the surveys. They will collaborate with assessment professionals and other campus programs developed to serve the needs of specific populations. For example, the practitioner from GC indicated they used the department on their campus responsible for providing resources to students with disabilities with the following statement:

The second ever assessment that we did, we looked at disability and recreation. That assessment, we did a survey through Resources for Disabled Students. They vetted our surveys, made it appropriate and taught us the correct language to utilize in the survey. Then they gave us access to their student listserv.

This not only ensured the surveys used the correct preferred language of the identified populations but also opened a direct line of communication specifically to specific population of interest. This is shown in the following statement by the campus recreation practitioner from FC:

There's still room for improvement. To me as far as improving, specifically because of our numbers it calls for it. I think a barrier that we all face because the students that signed up for the disability resource center, are students that need 
accommodations in the classroom. There's a lot of folks with disabilities out there that don't need a accommodations in the classroom, so it's hard for us to get that single identity because they might not have any need of the academic centers and so using the DRC is awesome But we also, how do we get some other folks out there that aren't necessarily registered with the DRC but still have disabilities. This will enable us to understand how adaptive sports would be a resource for them.

The amount of information garnered from these assessments not only helped identify the specific population and provide insights into their specific needs, but also how the department could potentially meet those needs.

These assessments generated a host of ideas on how to better serve the specific populations. For example, the practitioner from GC stated some of the ways their department was directly impacted through these surveys and assessments. The GC practitioner stated:

So out of the surveys a couple of things we did directly was identifying a lot of the issues were about communication actually, which has been fascinating to discover like making sure what we put on our website clearly articulates like what kinds of different equipment we have and you know, accessible equipment and even just like, the special harnesses that people can use at the climbing wall, right with, with people who are staff belaying them. so, some of it was just we need to communicate better. And then some of it was we did create new programming. So, the intramural staff took the survey feedback in one of the most popular suggestions of like, what are some new intramural sports we can offer that we're not offering was archery.

First off, communication proved to be a vital issue facing many of the campus populations surveyed. The practitioners were taking the right steps to be inclusive, but the patrons were not aware of the availability of those inclusive options. The campus recreation centers were able to identify new and innovative ways to elicit participation from these groups through creating new opportunities the people asked for. By giving a voice to specific individuals who do not usually have a say in the outcomes of their campus recreation department, the practitioners were able to directly meet those 
individuals' needs with solutions. This helped create a buy in from many of the surveyed populations. In the end, these surveys and assessments enabled the practitioners to identify ways to improve campus recreation experiences by communicating with the specific populations they served.

Another population the campus recreation departments surveyed was their own staffs including student staff or the full-time staff. These individuals were identified as people who worked in campus recreation and knew the ins and the out of the department as a whole. These assessments allowed for a critical self-examination of their own departments to identify levels of inclusion. The practitioner from EU discussed this technique in saying "We conducted a survey with the professional staff to determine the professional staff's perspective on our department's culture of inclusion.” This survey allowed the people within the department to identify ways in which they were or were not inclusive, to see where they could improve, and to see the progress the department has made since they started any inclusive initiatives. This staff assessment does not stop with the professional staff, as many of the programs surveyed their student staff as well to get another view on their departments' inclusive practices. For example, the practitioner from EU said:

We just did an assessment with our student staff to get their perspective on the campus recreation department's culture of inclusion and to look at what they say they need in terms of their development, but also what do they think the campus recreation department should be doing to better serve the campus community.

These surveys elicited many ways in which the campus recreation programs and services were inclusive but also identified areas where they needed improvement. For example, the practitioner from GC discussed how a student was able to identify how the campus 
recreation department was not being inclusive to the LGBTQ community. The practitioner stated:

The very first initiative got started because there was a student employee who was an undergrad during the design process for the renovation and he identifies as trans and he was working with our executive director at the time. And so that student got pretty involved and you know, in the advocacy for gender, gender neutral or gender inclusive spaces.

This student worker was able to identify an area of need within campus recreation and directly influenced a positive outcome and change to create a more inclusive environment.

Many of the inclusive policies were created from having open lines of communication to the entire campus community. The assessments and surveys were tools utilized by the campus recreation departments to foster communication from all the important stakeholders of their campus recreation program and university. The practitioner from EU reiterated this statement in saying "We are trying to hear from, you know, the important stakeholders, in order to best determine what we should be doing next." This process enabled their stakeholders to have input on the decision-making process within campus recreation. Allowing this type of open communication allows individuals being served to have an influence on the future goals and objectives of the campus recreation department. Enabling their input created a sense of belonging to ensure their voices had a direct influence on the future of the campus recreation department.

The inclusion efforts within campus recreation is a never-ending process. For example, the practitioner from EU stated, "The surveys and assessments enable us to understand what the next step for campus recreation is to create a more inclusive 
environment." Once the new inclusive opportunity was identified through the surveys, it was up to the campus recreation department to work toward and develop the new inclusive opportunity. Many of these surveys led to proactive steps geared to reach the inclusive goals and objectives. Once these goals and objectives were met the campus recreation department understood how inclusion is a continual and seamless process. For example, the practitioner from MC said, "We still desire to find an accommodation whenever necessary and communication is key to this assessment." This ongoing process is reiterated in the following comment by the GC practitioner: "Which then led us to understand, well we can't stop now. We found two really important things, but there's a lot more important stuff for us to look at." Seeking the feedback through the campus community via assessments is one of the ways campus recreation departments successfully continue the process of creating a truly inclusive environment. The practitioner from $\mathrm{MC}$ sums up this with the following statement:

We need to bring a voice of campus that it's, it's in all environments and frankly it's on campus and bleeding into our communities and blurring those lines because the lives of MC Students, faculty and staff don't end at the border of campus. How can we truly inspire, our key assets?

The individuals from the campus community who participate in these surveys and assessments are considered stakeholders of the campus recreation department. This leads to the next identified theme - the personnel involved in the inclusive efforts for the campus recreation departments.

Theme 3: Personnel Involved

One of the ways in which the campus recreation department ensured that they would achieve their goals was to attach a committee to the issue. For example, the practitioner from HV said "Once we identified an area of need a committee was 
developed to address the concern." This statement leads directly to the subtheme of the personnel involved in the decision-making process. Many of these initiatives were led by committees which are made up of professional staff, student, staff, and campus or community partners. The aspects of the diversity and inclusion committees were discussed earlier in this chapter. However, it is important to understand who is involved in the committees and how those involved helped determine the inclusive policies and practices.

Subtheme 1: Professional staff. The first subtheme of Personnel Involved is the professional staff. In many of the discussions with the campus recreation practitioners, they detailed how the professional staff would lead the committees on inclusion and diversity. For example, the practitioner from EU said "The professional staff originally created what those goals would look like for our department. And then that is when our department formed its diversity and inclusion committee." The original initiative was developed by the professional staff and then the committee was formed.

Some of the departments had individuals who actually had inclusion and diversity within their job titles. For example, the practitioner from FC is the Inclusive Recreation and Fitness Coordinator. This practitioner discussed how the initiative for providing services and programs for people with disabilities came from the campus recreation director and thus this position was created. The practitioner from FC stated:

Our director wanted to make sure to focus at that point on adaptive recreation. That was the turning point on that piece of it, and with my background and that's why I got hired. So that was my focus when I started, but like I said, I wanted to work myself out of a job.

The creation of a position focusing on creating adaptive recreation and fitness opportunities is a proactive step in creating a more inclusive campus recreation 
department. Proactive steps such as these need to include people directly involved in campus recreation who have a vested interest in the success of the program.

There are many ideas on how to become inclusive, but it is up to the campus recreation professionals to make those ideas operational. For example, the practitioner from $\mathrm{AC}$ stated:

There's a difference between what a policy is and whether that policy actually works. So, we try to do a little bit of both. And then internally we try to basically say at my level, that this is the expectation and that we have final review, but we rely upon the people who actually have to operationalize the policies to write them because it's all well and good for me to think something's a good idea. But in practicality if it doesn't work. It's not a good policy.

The leaders of the campus recreation program charge the professional staff working under them to create inclusive programming. However, it is up to the actual professional supervising the program areas to individually create initiatives and policies. This approach ensures the effectiveness of the initiatives and determines if the initiatives or policies are actually effective. The practitioner from AC discussed earlier how the process to develop a policy falls to the person directly responsible to enforce the policy.

From the data collected it was clear that these inclusive initiatives need direction from professional staff to ensure success. Not only is direction needed, but also passion to continue to advance the inclusive practices. The practitioner from GC discussed how they rely heavily on people who are passionate and have prior experience with similar initiatives. For example, the GC practitioner discussed how many of their employees have previously worked at other institutions which were inclusive, and how they could adapt those practices to their current program areas. 
A few of the practitioners in this study discussed bringing ideas and innovations from other institutions to implement in their program area. For example, the practitioner from BC stated:

Prior to myself getting here and a couple of others getting here, there historically weren't any individuals that were involved with NIRSA or a typical campus recreation program or had the knowledge the around the university settings. Here at Bayside College we were a little bit behind the game on offering services and programs to the campus community, with the premise of campus recreation and staying in accordance to the industry standards that we have through NIRSA.

This practitioner discussed how their institution's campus recreation department was not offering even some of the basic campus recreation programming much less inclusive programming. In this instance the entire staff worked to create inclusive programming throughout the entire department. The practitioner from BC discussed how they were able to go about this radical change in the following statement:

I was one of the individuals who worked with a group of members from our team. So, we would actually, oh, go, we went through and observed and monitored and went to and double checked and basically broke down every single program and offering we had in our department to see are we being as most inclusive as we possibly can. I was the one who spearheaded and worked and rewrote the mission, vision and goals and learning objectives and the inclusive vision and so forth that we have on our website. But we had a small team within our department here that, that had come from other college campus recreation departments around the country who had, who had been involved with it over the years. We have to sit down and visit every program area to see are we being as inclusive as we possibly can.

This initiative was led by the professional staff who were in charge of breaking down every offering to create the most inclusive programming possible.

Previously discussed was the effort by the practitioners to work within the realms of the campus recreation community to develop a standard for their inclusive initiatives. This practice of looking outside the campus at the governing body or at other campus recreation programs is an industry term called benchmarking. To identify areas of need, 
the practitioners used this benchmarking technique to compare their campus recreation program to successful campus recreation programs that they had knowledge of. This technique was discussed by other campus recreation practitioners involved in this study. For example, the practitioner from GC said they used benchmarking "To see what's out there already. We asked our peers what they're doing so that we can hopefully find things that we haven't thought of yet and implement them." Expanding on this topic the practitioner continued:

We have to be, you know, identify peers that we know are doing great work in that area. In terms of adaptive rec programming that UC Berkeley, I just saw a cool article about them as well. So, we need to do more of that here.

This practitioner is doing research to stay up to date on new innovative campus recreation offerings through reading articles, looking at websites, and talking to peers at other institutions. The sharing of ideas is commonplace within the campus recreation community. NIRSA promotes the sharing of ideas and innovations through conferences, research, newsletters, workshops, trainings, certifications, and networking opportunities. Other campus recreation programs are just one of the sources the campus recreation practitioners in this study identified for how they developed inclusive policies and programming. The other sources include a variety of networks established within their campus communities. The next section will discuss the final subtheme of campus and community partners.

Subtheme 2: Campus and community partners. Similar to the input received from peer institutions, many of the campus recreation departments in this study had established collaborations with campus and community partners to develop inclusive polices and programming. The partnerships discussed during the data collection phase of this study 
ranged from private programs to campus organizations. The most frequently discussed collaborations of multiple campus recreation practitioners were the partnership with the university's disability resource center.

The campus recreation practitioners involved in this study discussed many different ways in which the university's disability resource center collaborated with the campus recreation program. As discussed previously, many of the campus recreation departments utilized the disability resource center as an assessment service. The disability resource centers ensure the proper terminology is utilized thorough the department on their websites, manuals, signage, and facilities. Many of the campus recreation practitioners discussed how they collaborated with the disability resource center to make sure they stayed up to date with preferred and appropriate language. For example, the practitioner from GC said, "They vetted our surveys, made some of the language better for us since we were learning." This is a common use of the disability resource centers amongst the campus recreation practitioners. For example, the PR actioner from HV stated:

A lot of us developed PowerPoints without thinking about the adaptability of them for students who might have a physical, vison issue. And so, you know, we're working with the disability office on campus to teach us how to create power points that are inclusive for all individuals who might see them.

This statement shows how campus recreation practitioners utilized the disability resource center for not only ensuring the correct terminology is utilized but the correct communication resources are being utilized as well. Many times, the tools with which the campus recreation department communicates to the patrons is not accessible in and of itself. The disability resource centers vet all communication materials to make sure everyone has access to the information regardless of their disability status. 
The campus recreation practitioners frequently discussed how they relied on the expertise of the disability resource center to assist with not only ensuring the proper language is utilized in written materials but also trained the employees on the correct terminology to use when speaking. During the training periods of both professional and student staffs, many of the campus recreation departments indicated they relied heavily on the expertise of the campus disability resource centers to provide trainings on the proper language and how to interact with people with disabilities. For example, the practitioner from EU stated, "We're all at the same kind of starting level to support our students and then all of our employees go through an inclusive language training." This training is important for the employees to understand how through education, the campus recreation department can create a more welcoming environment for everyone.

These trainings by the experts within specific populations were not one size fits all. Each of these trainings is individualized to create a better understanding of specific identities utilizing the campus recreation department. For example, the practitioner from AU stated, "We get specialized training to our instructors on modifications and that necessarily is not modifications necessarily for disability, but modifications for anybody." These specialized trainings are ongoing as the need arises. The trainings are developed to increase the multicultural competency of all staff as they learn to deal with people different from themselves. As discussed previously, the campus recreation practitioner from EU described how they utilized experts to assist them in their staff training program. In these trainings, the campus recreation practitioners discussed how they worked to develop their staff's multicultural competency and capacity. These learning 
sessions require people with an expertise in the area of need to develop the competency

of the staff on providing a more welcoming space through competency.

Competency and understanding enable the campus recreation department to see potential areas of need within the department. This allows the campus recreation professionals to develop ideas on how to meet the desires of specific patrons in order to make them feel included. For example, the practitioner from CC stated:

We have worked with our services for students with disabilities office. With that office, we've worked with them a bit to kind of see where, where we may fit in and so it's getting different opinions and figuring out what we have the capacity for and figuring out where we go from there.

Working with experts in an area can determine the future direction how to meet the needs of specific clientele. Furthermore, the campus recreation practitioner from AU discussed how even the design of their building relied heavily on the expertise of professional in the following statement:

So, for the building of the building with the universal design that has to do with the disability resource center, there was a committee of people, the counseling department, the major health center, they all had a person on the committee. And then obviously the students were highly involved too by visiting all these different places of what would be inclusive.

Not only did the campus recreation professionals seek out experts in the area, they allowed the involved parties to gain expertise by visiting other inclusive spaces. This enabled the people involved in the design process to gain an expertise in how to build a truly inclusive campus recreation center.

The needs and desires of each individual utilizing the campus recreation department is not one size fits all. It is integral for campus recreation practitioners to understand that they must reach out to their community and campus partnerships to create a better understanding of each individual. The campus recreation department reached out 
to a variety of campus partners to create more inclusive campus recreation departments.

For example, the campus recreation practitioners involved in this study discussed seeking the help of disability resource centers, multicultural affairs departments, universal design specialists, the community, veterans' affairs, other inclusive campus recreation centers, governing bodies, the universities' general counsel, and even specific students themselves.

By involving vast groups of experts, the campus recreation department can tailor their facilities, programs, and services specifically to the needs of their patrons. This understanding and transparency enables campus recreation practitioners to be humble in the fact that they might not be the experts in every area. They can work with specific groups to create a better campus recreation department for everyone.

\section{Summary}

In summation, the data collected from the twelve campus recreation practitioners involved in this study elicited an understanding on the insights of how their campus recreation department creates and practice inclusion. This study generated multiple themes in which the campus recreation practitioners were able to directly answer the two research questions guiding this study. From this discussion, three themes became evident. The three themes were diversity and inclusion effort, disability inclusion, and gender inclusion Research question one examined how campus recreation practitioners perceived the inclusiveness of their campus recreation facilities, programs and services. The campus recreation practitioners provided an overview of the diversity and inclusion effort of their facilities, programs, and services. This data led to multiple subthemes on how they currently meet the needs and desires of their patrons. The first subtheme of 
Diversity and inclusion effort illustrated how the alignment to mission lead to an understanding of how the goals and objectives for the campus recreation departments must be inclusive and welcoming to everyone regardless of their specific identity.

The second subtheme illustrated how the campus recreation departments developed a specific committee to improve the inclusion and diversity efforts within the campus recreation setting. This committee provided insight and leadership in order to continually advance the inclusion process. The next subtheme under diversity and inclusion effort was the process by which the campus recreation departments hired their personnel. Many of the campus recreation practitioners discussed how they hired with a purpose to create a more diverse and inclusive staff.

This led to the final subtheme of staff training. In this study, the campus recreation practitioners discussed how they were able to increase the inclusiveness of their campus recreation department through the education of their staffs on multicultural competencies. Staff training created an awareness of interactions with people of diverse backgrounds and also established an understanding on how to best serve the patrons.

The next theme the campus recreation practitioners discussed was disability inclusion. The campus recreation practitioners indicated they were intimately familiar with the Americans with Disability Act and needed that knowledge base to keep their campus recreation departments in compliance at all times. Additionally, the campus recreation practitioners understood that the ADA provides guidelines for the basic efforts to provide accessible facilities, services, and programs. The campus recreation practitioners elaborated on how they continually went above and beyond ADA mandates 
to truly meet the needs and desires of everyone within their campus recreation department.

This led to the next subtheme of community partners to help inclusion. The campus recreation professionals identified a few partnerships which promoted inclusion and increase efforts to people with disabilities. Many of these relationships enabled the campus recreation departments to provide additional resources and opportunities to people with disabilities that they otherwise would not have been able to provide. The campus recreation practitioners utilized Unified Sports to integrate people of different abilities into the campus community by allowing them to compete in athletics at the same time. This program offering provided a great opportunity to get people with different identities to interact with each other in ways they never would have before.

The next theme identified in response to research question one was how the campus recreation department made efforts to be inclusive for all gender identities. Knowing and working to understand differences in gender identities created the awareness of the need to meet the individual needs of each gender. Through the purposeful efforts of the campus recreation practitioners, campus recreation departments were able to create initiatives which met the specific needs of any individual regardless of gender orientation. This created a more welcoming environment and set the example for other entities to follow.

Research question two was directly guided by Critical Disability Theory to create an understanding about the process by which practitioners developed and created their inclusive practices. Following Critical Disability Theory for framing, question two identified the amount of autonomy allowed to people with disabilities in determining the 
practices and policies directly influencing themselves (Rocco, 2005). This question was intended to determine if practitioners utilized people with disabilities to assist in establishing the organizations' inclusive practices and policies.

In response to research question two, the campus recreation practitioners provided three main themes. These themes were policy source, assessments and surveys, and personnel involved. Policy source has two main subthemes - from the top down and through grassroots efforts. From the top down discussed how many policies were created from initiatives charged by the campus leadership. These initiatives could emanate from university administration, leaders of the campus recreation department itself, or even NIRSA standards. The grassroots policy source rose from the bottom up. Facility users and entry level staff initiated these ideas to meet specific needs. These policies usually developed through a groundswell of growing belief that a policy needed to be created or changed. As the need arose from the users and staff, the campus recreation leadership was forced to act in order to meet these needs.

The next themes of assessments and surveys enabled the campus recreation practitioners to garner a true understanding of a specific population's needs and desires. This technique enabled the campus recreation practitioners to create a line of communication to their clientele and in order to best meet their needs. These surveys elicited ideas for initiatives which enabled the campus recreation departments to create a more welcoming campus recreation environment for everyone.

The last theme of personnel involved in policy creation was broken up into two subthemes. These were professional staff and campus and community partners. The professional staff were able to work amongst themselves in creating new policies and 
initiatives to meet the needs of their clientele. They operationalized their mission statements into inclusive programming and services to create a welcoming environment. This effort utilized the final subtheme of the role of campus and community partners. The campus recreation practitioners reached out to these partners in order to create the best policies and initiatives to establish an inclusive campus recreation department. These partners enabled the campus recreation departments to create meaningful policies and initiatives that specifically met the needs of people of any identity. Through this involvement the campus recreation practitioners improved the competency of their staff and programs and enabled the creation of a more welcoming and inclusive campus recreation department. The responses of the twelve campus recreation practitioners involved in this study created a greater understanding of the current inclusive culture within campus recreation. The next section of this document will review the findings and discuss how the findings from this study are connected to Critical Disability Theory and Universal Design. 


\section{CHAPTER V}

\section{SUMMARY OF FINDINGS AND IMPLICATIONS}

The purpose of the study was to investigate the current practices of campus recreation professionals to create inclusive campus recreation programs, services, and facilities. This study employed interviews with campus recreation practitioners in order to examine their campus recreation centers' inclusive practices for people with disabilities. Utilizing the framework of Critical Disability Theory and Universal Design, this investigation sought to identify how campus recreation practitioners perceive the inclusiveness of their campus recreation departments and how campus recreation practitioners develop their inclusive practices. Universal Design was utilized as a lens to understand how campus recreation practitioners, programs, facilities, and equipment serve to meet the needs of all users and specifically people with disabilities. Critical Disability Theory was utilized to help understand the methods through which the inclusive practices are created and operationalized within the campus recreation settings.

This study utilized two research questions to guide the investigation of the current inclusive climate of the campus recreation setting. Research question one examined the current inclusive practices and offerings from the perspective of a campus recreation professional. The campus recreation directors interviewed in this study were able to elaborate on their inclusive practices within their departments. This question led to an in- 
depth conversation of the entirety of the inclusive offerings of the campus recreation department and the perceptions of the practitioners and their knowledge and reasoning behind these offerings.

After interviewing the twelve campus recreation practitioners, the researcher was able to analyze how they perceived the inclusiveness of their campus recreation departments. The campus recreation practitioners discussed their perceptions of how their campus recreation departments provided inclusive facilities, services, and programming. This discussion generated the themes of (a) diversity and inclusion effort, (b) disability inclusion, and (c) gender inclusion in response to the perceived inclusiveness of their campus recreation department. In the campus recreation practitioners' responses to research question two, the participants discussed how they determined their inclusive practices and policies. The discussion led to the themes of (a) policy source, (b) assessments and surveys, and (c) personnel involved.

The following chapter will first discuss how these findings are tied to the theoretical frameworks of Critical Disability Theory and Universal Design and the existing literature. Next the author will discuss the practical implications of this study to practitioners striving to meet the needs of people with disabilities. Then the chapter will discuss the future research opportunities and directions to take this investigation further. A summary of the entirety of this study will conclude this chapter.

\section{Theoretical Frameworks}

The theoretical frameworks of Universal Design and Critical Disability Theory guided this study and provided a lens for the researcher to analyze the responses to the research questions. This section discusses how many of the themes identified in this study 
connect to the theories of Universal Design and Critical Disability. In order to better understand these connections, the following will detail a review of the theories utilized in this study and then discuss how the campus recreation practitioners' statements were informed or not informed by the theories. Review of Universal Design and Connections

Universal Design theory is the intentional design of an environment to be as accessible as possible for all people, regardless of age, size, ability, or disability (National Disability Authority, 2014a). The Universal Design concept is not regulated to benefit one specific group but to create the best design possible to benefit all potential users. Universal Design considers the diverse needs and abilities of all possible users to create an accessible environment which is both convenient and enjoyable to utilize (National Disability Authority, 2014a).

The conversations with the campus recreation practitioners in this study revealed how they continually worked to create the most inclusive campus recreation environment. To aid this task, the campus recreation practitioners discussed how the process had to be a holistic effort to create a welcoming atmosphere to all users. This practice goes hand in hand with the theory of Universal Design which has seven basic tenets: (a) equitable use, (b) flexibility in use, (c) simple and intuitive use, (d) perceptible information, (e) tolerance for error, (f), low physical effort, and (g) size and space for approach and use. The campus recreation practitioners discussed how they create an understanding within the campus recreation department to develop a campus recreation department that meets the needs and desires of all users. Many of the practitioners in this study had knowledge of what Universal Design is but did not specifically utilize the theory to increase the 
inclusiveness of their campus recreation departments. However, many of their practices aligned directly to Universal Design even without a specific desire to do so. The following will detail this practice.

Equitable use. The first tenet of Universal Design is equitable use. This principle insists all plans need to be useful, identical for everyone, avoid segregation, and provide the same safety and security to all users (National Disability Authority, 2014d). The campus recreation practitioners discussed how they strived to meet the needs of everyone within the campus recreation setting. This goes hand in hand with equitable use, as many of the campus recreation practitioners discussed how they purposely developed their mission statements around being inclusive to all users. The mission statements formed the backbone of their inclusive initiatives within campus recreation. The campus recreation practitioners discussed how their inclusive efforts were guided by creating opportunities for every user to encourage wellbeing through participation in campus recreation. Many campus recreation practitioners discussed how this effort of equitable use was at the very core of their campus recreation department and therefore was included in their mission statements. All actions of the campus recreation department were aimed at reaching the goals and objectives mandated through their mission, vision, and values. These mission statements were guidelines which the campus recreation departments utilized to ensure they reach their goals of creating an inclusive and diverse environment within campus recreation. These efforts were intentional to provide resources to individuals of any identity.

Flexibility in use. This holistic effort embraces the differences of all individual users. Creating the understanding that users have different needs and desires enables 
campus recreation practitioners to develop individualized practices to accommodate the needs of specific users. This understanding and effort is guided by the Theory of Universal Design's tenet of flexibility in use which discusses guidelines to accommodate the preferences and abilities of a broad range of individuals (National Disability Authority, 2014d). The principle of flexibility in use has four guidelines - offer a method of choice to the users, accommodate both left and right handed users, facilitate the users' accuracy and precision, and provide adaptability to all users' pace (National Disability Authority, 2014d).

The campus recreation practitioners' discussions indicated how their current practices aligned with the tenet of flexibility in use and the four guidelines. They developed multiple practices to give individuals a choice of how they would like to utilize campus recreation. This was done through individual programming, providing adaptable equipment, group programs, intramurals, club sports, unified sports, outdoor recreation, fitness, personal training, and wellness. The user has the ability to pick and choose what campus recreation opportunities they would like to be involved in. These programs are developed to enhance the users' abilities and personal wellness through a variety of activities. Many of these programs are geared toward people with very little prior experience with the activities. Through continued involvement in the activities, the campus recreation departments geared their programs to develop skills and abilities of the users to increase their lifelong wellness. Again, this effort goes back to the mission statement of the campus recreation program and how the program works to improve personal well-being through their offerings. However, during the learning process, it is 
understood that all participants learn at a different pace, hence campus recreation programming needs to be flexible in design.

The campus recreation department creates opportunities to reach a wide variety of skill levels. As individuals advance in skills, they can work into a more advanced programming opportunity. For example, Texas A\&M University offers recreational leagues and competitive leagues for all of their intramural sports (Recreational Sports, 2019a). As a user becomes more familiar with an activity, they have the opportunity to advance to the more competitive league or stay in the current recreational league. Additionally, the group exercise program at Texas A\&M University offers over 90 classes a week (Recreational Sports, 2019b). These classes meet the needs of a variety of skill ranges with some developed for beginners as introductions to the exercise routines and advanced classes geared toward more experienced users. This practice was utilized in all of the campus recreation departments within this study.

Simple and intuitive use. The campus recreation practitioners again discussed how their actions aligned directly with the theory of Universal Design in how they intentionally designed opportunities to be easily utilized. This follows the tenet of simple and intuitive use. Many campus recreation opportunities are created to be easily utilized by people without prior experience, language knowledge, or concentration level. Following the guidelines of this tenet of Universal Design, the campus recreation practitioners did their best to eliminate unnecessary complexity, stay consistent with the users' intuitions and expectations, accommodate various literacy or language skills of the users, arrange information in a consistent format by importance, and provide effective 
feedback both during the task and as the task is complete (National Disability Authority, 2014d). This guideline was accomplished in a variety of ways.

Many of the campus recreation practitioners discussed how they provided resources to individuals to enable use of their facilities, programs, and services. For example, every single piece of fitness equipment had directions on proper operation and how to adjust the machines to an individual's needs. Additional resources were available through signage, staff on site, and the training opportunities provided by the campus recreation programs. For example, the University of Kansas provides Recreational Assistants who monitor the campus recreation facilities and assist individuals in the proper use and adjustments of any equipment or of the facility generally (KU Recreation Services, 2019). The campus recreation practitioners discussed how they worked to make all recreational opportunities easily used. Another example of this is how the practitioner from SC discussed how they have chair lifts that can be operated easily without assistance from the lifeguard. These initiatives work to enable all users the ability to utilize any and all facilities, services, and programs at their own convenience.

Perceptible information. All of the programs, facilities, and services of the campus recreation programs were promoted and advertised across a variety of platforms and mediums. This enabled the campus recreation practitioners to inform users of offerings and how they can best meet their individual needs. This practice aligns with the Universal Design principle of perceptible information. This principle promotes the guidelines of utilizing different modes of communicating vital information, makes information stand out from the surroundings, makes the information as clear as possible, 
and states that directions must be clear and concise (National Disability Authority, 2014d).

The campus recreation practitioners discussed how they utilized all of the resources at their disposal to reach and educate their users including websites, signage, videos, lectures, trainings, and technology. Many of these efforts appear redundant but the campus recreation practitioners understood that people absorb information in a variety of ways. For example, the University of Arkansas has a website, a Facebook page, Twitter account, YouTube Channel, and an Instagram page (University Recreation, 2019a). Through these mediums the campus recreation department is able to advertise their offerings to users worldwide. Additionally, these mediums enable users to perceive information through pictures, signs, videos, and sounds. For example, the University Recreation YouTube channel promotes and advertises programming but is also used to educate users on proper workout techniques. This channel shows videos on how to properly utilize the facilities equipment and services to do individualized fitness routines without the help of anyone else. These videos provide verbal instruction but also show visual examples of the proper technique.

Tolerance for error. Campus recreation offerings were developed with the user in mind and with the knowledge that mistakes could be made. Campus recreation practitioners discussed how they acknowledged the potential risks to users. As discussed previously this was done through signage, instructional videos, and on-site staff. Again, these practices aligned directly with the Universal Design tenet of Tolerance for Error. The campus recreation practitioners discussed how their programs possessed inherent risks and they worked to provide a safe participation. The campus recreation practitioner 
from MC described how they provided any opportunity to a user unless it creates an unsafe environment for anyone involved in the activity. This was to mitigate any potential consequences before they occur. The campus recreation practitioners utilized their trained staffs to identify issues and work in a proper way to minimize any negative consequences that may occur such as improper use of equipment, malfunctioning equipment, or safety issues.

Low physical effort. The principle of low physical effort of Universal Design aligned with the practices of the campus recreation departments in the design of the facilities and utilization of equipment. All possible attempts were made to reduce/remove barriers to the facilities, equipment, programs, and services of campus recreation. This guideline aligns with the ADA to help the campus recreation practitioners better serve their users and specifically people with disabilities. Departments purchased accessible equipment any user could utilize. Titus et al. (2016) discussed how any barriers students faced in trying to engage in campus recreation led to stress and helplessness. Many of the practitioners indicated how they increased the number of accessible fitness machines within their facilities. These machines allow individuals the ability to adjust settings and features to match their individual needs. As indicated earlier, many campus recreation programs provided employees on site to assist in the machine adjustments.

Size and space of approach for use. Barriers to participation can come in various forms. The campus recreation practitioners discussed how their current practices also followed the Universal Design principle of size and space for approach and use. However, this principle was again influenced by the ADA where the facilities were mandated to have appropriate spaces that were accessible to everyone regardless of 
ability. The ADA stipulates the width of doorways, heights of counters, elevator access, accessible pathways, and a variety of other accessible features. The facilities were all designed to the specifications mandated by the ADA, but it is up to the campus recreation practitioners to ensure the specifications are met. For instance, the campus recreation practitioners detailed how they kept up to date with the standards mandated by the ADA and would routinely do facility checks to ensure they were in compliance. Many of these checks would be to identify appropriate space widths for individuals with disabilities to access equipment on the fitness floor. Hums et. al. (2016), suggested Universal Design and the ADA are essential components of facility design to promote diversity and inclusion. Furthermore, campus recreation practitioners who utilize Universal Design during the design process will find ADA compliance more easily attainable (Hums et al., 2016).

The application of both the mandates of the Americans with Disabilities Act and Universal Design is not a new process. In many ways both of these influence one another and previous literature has shown this to be true. Watchorn, Larkin, Hitch, and Ang (2014) investigated the use of Universal Design in promoting participation in social activities in Australia. These authors suggested incorporating a Universal Design approach to make buildings and communities usable by anyone results in increased social participation by everyone in a community (Watchorn, Larkin, Hitch, \& Ang, 2014). Campus recreation practitioners have identified the Universal Design approach as a way to increase their participation numbers by meeting the needs of all users. It is essential for practitioners to strive to create accessible facilities which meet all ADA standards and promote the Universal Design concept. The use of Universal Design will continue to 
grow and practitioners embracing the concepts of Universal Design will be considered leaders in inclusion.

The campus recreation programs participating in this study were considered by many of their peer institutions as leaders in inclusion and specifically for people with disabilities. This study elicited information about many of the ways in which the campus recreation practitioners were able to achieve an inclusive environment through their practices and initiatives to meet the needs and desires of all users and specifically people with disabilities. As discussed previously, many of these campus recreation departments had ties to the tenets of Universal Design. Additionally, these departments had many ties to the theoretical framework of Critical Disability Theory and to other research of inclusion for people with disabilities. The following will review and discuss the connection to Critical Disability Theory.

Review of Critical Disability Theory and Connections

Critical Disability Theory (CDT) examines the daily life of people with disabilities and compares their everyday experiences with the actualities of social norms and values (Hosking, 2008). CDT helps create an understanding of the realities people with physical and cognitive disabilities face on a daily basis (Procknow, et al., 2017; Rocco, 2005). According to Procknow, Rocco, and Munn (2017), CDT asserts the following six core concepts: the invisibility of ableism, the epistemic violence against the disabled, the binary view of disability instead of a continuum of human variation, disability as a social construct, the medical industry's commodification of people with disabilities, and the right of autonomy and self-determination for people with disabilities. 
Many of the core concepts of Critical Disability Theory could be identified within the responses of the campus recreation practitioners.

Ableism is invisible. This core concept is the belief that people with disabilities are under a constant threat of being discriminated against in everyday society (Mclean, 2011; Procknow, et al., 2017; Rocco, 2005). Since ableism is a natural state within today's society, it is invisible to offenders but is a constant threat to people with disabilities (Rocco, 2005). Ableism marginalizes and labels people with disabilities as incompetent, lazy, and dishonest about the extent or existence of their disability (Rocco \& Collins, 2017).

During the discussion with the campus recreation practitioners about their perceived inclusiveness, it was made clear that efforts to be more inclusive were intentional and designed to specifically meet the individual needs of people with disabilities. This intentional effort goes along with Critical Disability Theory's core concept of ableism is invisible. The majority of the population does not have a disability and therefore does not consciously think about how people with disabilities are being discriminated against in their everyday lives. The campus recreation practitioners in this study discussed how they made an effort to put inclusion in the forefront of their minds when thinking about how their facilities, services, and programs accommodated people with disabilities. Many of these accommodations for people with disabilities were not mandated and great consideration was put forth to make people with disabilities feel welcomed within the campus recreation setting.

The epistemic violence against the disabled. Epistemic violence is the understanding of ways the disqualification of groups within a society are legitimized 
(Liegghio, 2013; Procknow, et al., 2017). People with disabilities are under constant threat of being ignored, silenced, or rendered unintelligible (Procknow, et al., 2017). People with disabilities' personal identities are disregarded or discounted compared to the perceived "normal" populations (Procknow, et al., 2017). The views, knowledge, and understanding of people with disabilities are often overlooked or ignored due to their perceived disability (Procknow, et al., 2017).

The campus recreation practitioners discussed how this epistemic violence against people with disabilities was identified and initiatives were continually being made to curb these actions. For example, many of the campus recreation practitioners discussed their efforts to reach out to people with disabilities to ensure their needs and desires were not being ignored. It was evident from the interviews that the campus recreation practitioners went out of their way to figure out how to best meet the individual needs of each user and especially people with disabilities.

The campus recreation practitioners made an effort to reach out to specific users to identify how campus recreation can better accommodate their individual needs. No personal identities were disregarded and if the campus recreation practitioners could make specific modifications to meet the individual needs of a user they did so. The only times these modifications were not met by the campus recreation practitioners were if the modifications created an unsafe environment for all users. Understanding the individual needs of every user is integral for the campus recreation department to fulfill their specified mission statement of providing recreational activities for all users. This process forced the campus recreation practitioners to create an understanding of the fact that all users are important regardless of their identity. 
The binary view of disability instead of a continuum of human variation. Human variations are naturally occurring phenomena which manifest differently in different individuals. Disability has the possibility to transcend other human variations and an individual can become disabled at any point in their life (Procknow, et al., 2017). However, when a variation is identified as a disability it is often considered a problem. Society sees disability as a black and white concept of either having a disability or not.

As discussed previously, the campus recreation practitioners at these inclusive institutions created an understanding that regardless of an individual's identity they are still a person and a user of the campus recreation department. The campus recreation practitioners recognized that disability is a continuum (ex - not all visually impaired people are "blind") and therefore worked within their power to meet the specific needs and desires of every individual. The campus recreation practitioners discussed how they supported all their users to get the most of their educational experience and used campus recreation as a tool to give the individuals a holistic education. This helps the user to develop lifelong healthy habits which will enable them to live better healthier lives even after they graduate.

Campus recreation creates a supportive environment to encourage individuals to meet their individual goals. These goals may be health related, activity related, recreationally related, or socially related. Whatever the goal, the campus recreation practitioners worked to create an environment to support the individual in reaching their specified goals. This support came through creating new opportunities, accommodating existing opportunities, mentorship, participation, and social networking. Whatever the 
need, campus recreation practitioners at these institutions worked within their means to help a user in any capacity.

Disability as a social construct. Disability is viewed by society as a deficiency. Objectification of disabilities is determined by the political, social, economic, and cultural norms of the "in-group", that is, able-bodied individuals. Ableism creates obstacles for people with disabilities by labeling such individuals as disadvantaged (Procknow, et al., 2017). This view allows society to isolate people with disabilities by creating attitudes that prohibit achieving success (Procknow, et al. 2017). Barriers are created to uphold these beliefs, reinforcing inequalities for people with disabilities.

The campus recreation practitioners routinely discussed how they assessed their programming to specifically remove any potential barriers to participation. Obviously, many physical barriers have been removed due to the mandates of the ADA, but the practitioners believe they went beyond the ADA to provide access to people with disabilities. To break down the societal construct of disability as a deficiency, campus recreation practitioners created programming to include people of all abilities. For example, the practitioners discussed how they utilized Unified Sports as a tool to get people of different disabilities and identities to interact with each other. Through the power of sport, individuals of different abilities are now competing with one another to promote social inclusion.

In the same sense, campus recreation practitioners developed intramural sports to include people of all abilities. Intramural sports are being designed to incorporate inclusive sports into the competition calendar. Sports such as goalball, sitting volleyball, beep ball, and wheelchair basketball now have active intramural competitions among all 
students, not just students with disabilities. Unified Sports are a continued effort to remove the social stigma surrounding disabilities and promote social integration of all identities. No longer are people with disabilities isolated to their own specific programs but they are now able to socialize and participate in almost any activity.

The medical industry's commodification of people with disabilities. Historically, the medical profession and society have treated people with disabilities as a commodity (Rocco, 2005). Taking away the identity of self, medical professionals long sequestered people with disabilities in treatment facilities, asylums, or group homes (Finkler \& Grant 2011; Procknow, et al., 2017). The medical profession can actually make the decision if a person with a disability is going to be a successful contributor to society or not. This determination fosters a stigmatization which may result in permanent dependence and lack of responsibility (Malhotra \& Rowe, 2014; Procknow, et al., 2017).

Since this study related to campus recreation, this tenet of Critical Disability Theory does not really connect. However, campus recreation works to help all individuals learn habits which will help them live longer lives through independent and autonomous choices to be healthier. Campus recreation does not care or decide if an individual is going to be a contributor to society. Instead the campus recreation practitioners work with individuals to meet their own specific needs and desires. If an individual wants to learn how to swim, campus recreation will provide the opportunity and the means to help the individual develop this skill. Being able to swim does not determine if a person is a contributor to society. Campus recreation provides the tools and support to assist individuals in accomplishing their own goals. The responsibility of reaching their individual goals is all on the specific user and not the responsibility of campus recreation. 
The right of autonomy and self-determination for people with disabilities. People with disabilities should have the same rights as all individuals for their autonomy and self-determination (Rocco, 2005). Oftentimes, disabilities are viewed as monolithic instead of being viewed as individual variations (Procknow, et al., 2017). It is important to remember that the needs of one do not represent the needs of all. Self-determination is the ability to make one's own choice to determine the outcomes of one's individual actions (Rocco, 2005). People with disabilities do not need to rely on others to make decisions for them, but instead should be able and free to make decisions on their own behalf. Being able to exercise one's right to autonomy is true equality.

The campus recreation practitioners indicated they worked to ensure people with disabilities have a voice in the direction of the campus recreation department. This effort to allow people with disabilities to have a voice and a say in the direction of the campus recreation department was discussed by many of the campus recreation practitioners in this study. The practitioners discussed how they utilized people with disabilities to help determine the inclusion efforts of the campus recreation department. This strategy follows the core concept that people with disabilities should have the right of autonomy and self-determination. The campus recreation practitioners discussed how they empowered people with disabilities and sought input in the planning of campus recreation facilities, programs, and services. This practice allowed people with disabilities to have the freedom to decide the future direction of the campus recreation department.

The campus recreation practitioners indicated they did this through a variety of processes such as focus groups, surveys, assessments, and asking for direct input. For example, the campus recreation practitioners discussed how they identified specific 
populations and utilized them to examine their campus recreation department. The campus recreation practitioners empowered their patrons to help develop practices which suited their individual needs and desires. The individuals were charged with the responsibility to look at the campus recreation department with the critical lens of their identity to see where the campus recreation department was lacking and could be improved. The campus recreation practitioners understood that no one knows the needs of a specific person more so than themselves. The practitioners discussed how they empowered people with various disabilities to assess their programs and facilities by experiencing the campus recreation department firsthand. They would then work with the campus recreation department to create campus recreation department programs and offerings that meet their needs and desires.

This autonomy and responsibility show how the campus recreation departments continually advanced their inclusive efforts. These findings show how the inclusion initiatives of campus recreation have connections to both Universal Design and Critical Disability Theory. The next section will discuss additional connections of the findings from the campus recreation practitioners to literature on inclusion.

Connections to Literature

The discussion of the campus recreation practitioners indicated numerous connections to previously covered literature and research regarding inclusion. The most evident connections to the literature from the practitioners' responses was their knowledge of the needs for recreation for people with disabilities and the need to eliminate and overcome participation barriers. Another connection was the unexpected theme of gender inclusion. This theme was derived from the practitioners' responses to 
the interview questions on the practitioners' perception of inclusion within their campus recreation department. The following section will discuss each of these connections to previously established literature on inclusion.

Need for recreation for people with disabilities. Previously discussed in chapter two, there is an evident need for people with disabilities to participate in recreation and leisure activities. Recreation plays a large role in and strongly impacts social inclusion, health, and wellness for individuals with disabilities (Wright \& Titus, 2013). Compared to the general population, people with disabilities have a greater risk of living with secondary health conditions and physical activity can reduce the likelihood and severity of these secondary conditions (Calder, Sole, \& Mulligan, 2018; Rimmer, Padalabalanarayanan, Malone, \& Mehta, 2015). Even with the known benefits of recreation and leisure activities, people with disabilities routinely engage in physical activity less frequently than people without disabilities (Altman \& Bernstein, 2008; Lezzoni, 2011; Rimmer, et al., 2015).

The campus recreation practitioners in this study routinely discussed how important campus recreation was for people with disabilities. Not only did the campus recreation practitioners address this but they also addressed the importance of campus recreation for everyone through, for example, the creation of the Unified Sports and accessible intramural sports. These efforts were designed to provide social opportunities for all users as indicated previously. Additional modifications to programming and services allowed and encouraged participation by individuals with disabilities.

This action provides opportunities for people with and without disabilities to engage with each other's in a manner otherwise not afforded to them. Furthermore, many 
of these accommodations, modifications, and programs created opportunities to show individuals the similarities between people with and without disabilities. At times this could be a modification to allow people with disabilities to participate or a modification for people without disabilities to compete on an equal level. For instance, goal ball is a sport designed to remove the sight of all participants. This sport allows people with and without visual impairments to compete against each other and interact in ways they previously would not. During these types of activities, people with disabilities engaged with and assisted the people without disabilities on sport techniques to be successful. This social engagement dispelled any preconceived notion of superiority or differences between the participants. Providing the opportunities for people previously isolated from society serves to increase their psychosocial health and wellness.

Participating in recreation not only improves psychosocial health through social interaction but will also improve personal health levels. The campus recreation practitioners routinely discussed how important their recreation and leisure opportunities were to the health of the entire campus community and not just people with disabilities. However, there was knowledge among the practitioners of the increased risk people with disabilities have to developing secondary health conditions due to sedentary behavior. Therefore, the practitioners discussed initiatives specifically designed to meet the individualized needs of people with disabilities. This effort was made to encourage participation by people with disabilities in order to avoid any possible secondary health conditions from developing.

The campus recreation practitioners discussed how they developed inclusive programming to provide access to people with disabilities in intramurals, group fitness, 
outdoor recreation, and club sports. These activities included goal ball, unified sports, beep ball, wheelchair basketball, sitting volleyball, water aerobics, personal training, adapted climbing, adapted group exercise classes, and adapted outdoor recreation excursions.

The campus recreation practitioners discussed how their departments were striving to meet the recreational, health, and wellness needs of every user. Many of the programs, facilities, and services were designed for any student to participate in order to gain the benefits from participation. Sedentary lifestyle is not just an issue for people with disabilities but the entire campus community. The campus recreation practitioners continually updated their opportunities in order to elicit greater participation numbers, while knowing many barriers must be overcome to garner this participation. The next section will discuss these barriers in regard to participation by people with disabilities and how the campus recreation practitioners overcame the barriers. Many of these barriers are the same for all individuals not just the ones with disabilities.

Overcoming barriers. People with disabilities face numerous obstacles when trying to participate in recreation, sport, and leisure opportunities. These obstacles can range from physical environments (inaccessible sidewalks, trails, and facilities) to social environments (non-inclusive groups, practices, and lack of education). These barriers actively exacerbate low participation rates (Rimmer et al., 2016). Studies have shown the most prevalent barriers to recreation for people with disabilities were inadequate facilities, lack of knowledge/education, lack of resources, lack of preferences, and fear/intimidation (Calder, Sole, \& Mulligan, 2018; French \& Hainsworth, 2001; MartinGinis, Latimer-Cheung, \& Rimmer, 2016; Mulligan, Hales, Whitehead, \& Baxter, 2012; 
Rimmer, Chen, \& Hsieh, 2011; Rimmer \& Rowland, 2008; Rolfe, Yoshida, Renwick, Bailey, 2007).

Many barriers to participation deal with physical access to opportunities. The campus recreation departments follow the mandates of the Americans with Disabilities Act to remove many of these barriers. However, a variety of physical barriers still persist that are not governed by the laws. For instance, the campus recreation practitioners discussed how they go above and beyond the mandates of the ADA to remove barriers by providing zero entry pools, adding lifts throughout the facility, providing additional equipment, and bringing opportunities directly to people with disabilities.

The campus recreation practitioners discussed how they routinely worked to identify potential barriers to participation. Assessments, surveys, focus groups, experts, and interviews were utilized in determining barriers to participation. Additionally, the campus recreation practitioners discussed how they utilized these tools to determine how to overcome barriers. The suggestions provided enabled the practitioners to directly address barriers unique to their program. For example, a few individuals with disabilities indicated a barrier of how far their accessible residence hall was to the campus recreation center. Therefore, the practitioners developed specific programming that is easily transported or can be provided in-house in the accessible residence hall. Another example was when students with vision impairments utilizing personal trainers needed a space to keep their guide dogs. The campus recreation practitioner went out and purchased kennels to address this barrier directly.

Modifications and adapting current programs are tools many of the practitioners indicated they used to remove barriers to participation. Again, this process was not 
unique to people with disabilities but to all people. The campus recreation practitioners constantly sought ways to improve their departments in order to elicit more participation by the campus community. To ensure they met the needs of the entire campus community, the campus recreation practitioners discussed how they needed to first identify the underserved populations of their campus. The campus recreation practitioners indicated one of these highly identified underserved populations were all other gender identities other than male participants.

Gender Inclusion. An unexpected result of this study was the amount of discussion from the campus recreation practitioners on providing inclusion to people of all gender identities. This could be due to the recent trend stemming from the Dear Colleague Letter and the impact of Title IX on the whole campus community. In this instance, many of the campus recreation practitioners indicated how they reviewed the policies and procedures of their campus recreation department to ensure that all gender identities were being treated equally.

From this review, many practitioners identified how many of their practices were not inclusive of all gender identities and did not specifically follow the 2014 Obama Administration mandates of Title IX for treating all gender identities equally including the transgender population. As discussed earlier, these extended protections to include the transgender population were removed by the Trump Administration (FindLaw, 2019). However, many of the campus recreation programs changed their policies in accordance to the 2014 guidelines and did not reverse the changes after the repeal. There could be a few reasons for this. First, making major changes and going back and forth between rules and policies could cause confusion for patrons. Second, the rules created a better sense of 
inclusion and the practitioners decided that the 2014 guidelines better aligned with their departments' missions.

McDowell et al. (2016) indicated the OCR found no cases of Title IX violations in intramural sports, club sports, and campus recreation departments from 2000 to 2014 . However, many of the policies to increase participation for gender identities other than males might be inherently unequal such as the simple practice of awarding more points to a female-made basket in Co Rec basketball than a male made basket. This practice was instituted in an effort to create more opportunities and increase participation for the female gender but also treated males unfairly.

Many institutions had similar policies regarding multiple sport and opportunities. To address and fix this issue of organizational oppression of a specific gender, many of the institutions in this study removed the rule modifications and even removed the gender binary requirements for many of their intramural sports. In order to provide truly equal and inclusive offerings, many of the campus recreation departments redesigned the titles of their programs and even removed any inherently gender oppressive rule changes.

This new awareness has sparked numerous investigations and research into the current state of the campus recreation community's effort to include all gender identities. NIRSA recently published articles discussing how only $1 \%$ of the campus recreation community utilizes specific programming open to meet the needs of the transgender population of college campuses (NIRSA, 2017). This current dissertation research study took place about two years after this NIRSA study was published and many of the practitioners in this study discussed how they have developed practices to include the 
transgender community. The practices in this dissertation suggest how there is constant effort to continually meet the changing needs of any and all campus populations.

This study created a conversation around the current inclusive practices within the campus recreation setting to meet the needs of people with disabilities. From this conversation, it is evident that many of the institutions involved in this study have created programs which accommodate people with disabilities. However, it is integral for practitioners to continually advance these practices to continue efforts to be inclusive to every user. Many of the theories, research, and legal guidelines influence these practices but it is up to the practitioner to facilitate the correct methods to maximize the inclusive potential of their campus recreation department. In discussing these practices and inclusion efforts, many of the practitioners just recognized this as best practices and did not attribute their actions to theories or literature. Most of these ideas were generated through the shared experiences of the individuals involved and the professional campus recreation community. Therefore, it is integral for campus recreation practitioners to become familiar with the theoretical literature and research to continue the advancement of inclusive practices for people with disabilities.

\section{Practical Implications}

Campus recreation practitioners will be able to utilize this study to create more inclusive recreation departments for all patrons, especially people with disabilities. Much of the data provided by the campus recreation practitioners involved in this study illustrated ways in which campus recreation practitioners could enhance the inclusive aspects of their facilities, services, and programs. This section will outline the takeaways on how to create a more inclusive campus recreation environment for people with 
disabilities. These implications could be transferable to other recreation programs as well as practitioners hoping to be more inclusive in their own industries.

The campus recreation practitioners discussed how their inclusive efforts derived from the very core purpose of serving and meeting the needs of all users. This practice was regarded by the practitioner from MC as being in the DNA of campus recreation. The practitioner from SC discussed how their entire campus recreation lives and breathes inclusion throughout their facilities, programs, and services. This thought process is integral in creating a truly welcoming environment for everyone.

Creating a successful inclusive and welcoming environment requires many different techniques and initiatives. The first initiative to discuss is increasing the campus recreation department's understanding and awareness of the needs and desires of people with disabilities or other underserved populations. For example, the practitioners indicated how their facilities, programs, and services met ADA standards and routinely performed checks to ensure these practices were maintained. This process of ensuring access and inclusion did not stop with the legal mandates. The practitioners understood that these mandates were minimal steps in providing inclusion to the campus recreation setting. Many ADA mandates discuss removal of physical access issues which create barriers to opportunities. This knowledge enabled the practitioners to ensure their compliance with the laws in every facet of their departments.

However, the campus recreation practitioners indicated that to go beyond the ADA to meet the needs of people with disabilities they must first identify ways they are not currently meeting the demand. This process employed a variety of different techniques but is predicated on giving people with expertise or passion in the area a voice 
in the process. The practitioners discussed how they utilized people with disabilities, campus partners, staff, students, experts, and community partners to help assess their current inclusive practices and develop initiatives to increase their inclusion efforts. This also allowed interested people to have a voice in the decision making process. Not only did the campus recreation practitioners seek out experts but they specifically asked for input from users who identified as having a disability. The process ensured campus recreation departments would meet their specific needs and enable those individuals to be involved in determining the inclusive practices for themselves. These involvement practices allowing people with disabilities the autonomy to make decisions directly tied to meeting their individual needs and desires in line with Critical Disability Theory. The campus recreation practitioners expressed how transparency and open communication were integral in creating a welcoming campus recreation environment. This voice established a line of communication to show how the campus recreation departments in this study were willing to be inclusive in every way possible. This practice also speaks directly to how many of the campus recreation departments incorporated Critical Disability Theory into the decision making process by giving people with disabilities the autonomy to make decision for their own needs. This involvement by people with disabilities created a sense of belonging as staff and program participants worked together to develop a more inclusive campus recreation environment. From this line of communication, the campus recreation practitioners were able to go above and beyond the mandates of the ADA to be even more inclusive and cognizant of the needs of people with disabilities. This practice could be used in a variety of ways to create a more inclusive environment across many different service areas. 
For example, the practitioners discussed how they purchased additional equipment to enable people with disabilities access to specific activities. These purchases included additional fitness equipment, chair lifts, kayak launches, software, outdoor equipment, sports equipment, accessible vehicles, technology, and even dog kennels. Some of these items like chair lifts and accessible fitness equipment are ADA requirements, but the ADA provides only limited mandates on equipment style and operation. For example, a chair lift for a pool is an ADA requirement but in order to create a more inclusive campus recreation environment, the practitioner from SC indicated how they bought a chair that an individual with disabilities could operate on their own. At many aquatic centers, an individual must ask the lifeguard for assistance in operating the chair lift. The very action of asking for help is in and of itself a barrier to participation. The campus recreation practitioners were able to identify and remove this barrier by purchasing a chair one person can easily operate without the assistance of others. Another practitioner identified how the needs of individuals with vision impairments were not being met. The ADA mandates that programs should be available to all users regardless of abilities and one of these programs was personal training. During training sessions, a personal trainer accompanied the individuals with vision impairments around the facility. This action eliminated the need to have a Seeing Eye dog with the individual during the sessions. The campus recreation practitioner from AU saw this as an opportunity to go above and beyond the ADA and so they purchased dog kennels to meet the needs of this individual. Therefore, when the individual with a vision impairment utilized the service of a personal training session, they were able to kennel their dog in a safe location. Identifying these non-inclusive features of a campus 
recreation environment is easier said than done. Many barriers to inclusion are not physical yet still create an appearance of a campus recreation program that is not inclusive. Many of the practitioners in this study suggested how they utilized these conversations with people with disabilities and experts to extend their own knowledge about the populations they are trying to include.

The next step to creating a more inclusive environment is increasing the competencies and knowledge of the campus recreation staff on disabilities. This practice enables experts or people with disabilities to create educational or training seminars which will develop the multicultural and inclusive competencies of the campus recreation employees. This is particularly germane for people with disabilities, since the staff might not have any personal knowledge about the experiences people with disabilities face on a daily basis. This staff training strategy helped increase the knowledge of the campus recreation personnel on the needs of people with disabilities and empowered them to identify where the campus recreation program was not meeting those needs. This firsthand knowledge can help develop practices and initiatives to remove potential barriers before any patrons even encounter the obstacle.

The campus recreation practitioners in this study discussed how they routinely utilized trainings and seminars to improve their staffs' multicultural and inclusive competencies. These education initiatives helped train their campus recreation staff on how to better meet the programmatic needs and desires of people with disabilities. These efforts to educate the campus recreation staff are integral to creating a welcoming campus recreation environment. The campus recreation practitioners discussed how they implemented trainings and education courses to ensure the staff was knowledgeable 
about inclusion and diversity. The goal for each of these programs was to sufficiently educate the staff so that inclusion and diversity were embedded in the very core of their department. Inclusive language, accessibility, and diversity should constantly be on the mind of any staff working the facility, services, and/or programs. This mindset enabled campus recreation employees to be cognizant of the needs and desires of people with disabilities. This understanding encouraged campus recreation employees to continually develop their inclusive strategies through the shared knowledge of the experiences from people with disabilities. The involvement of people with disabilities is integral to creating a more inclusive environment because the individuals with disabilities are the experts in knowing their own needs and desires.

However, it is important to note that the campus recreation practitioners in this study discussed how they created inclusive environments, but they did not include a discussion about the challenges that arose from incorporating these inclusive initiatives. This oversight could be due to the culture of inclusion within each of these campus recreation settings. The inclusive environment was so established that the practitioners understood that their inclusive initiatives had the full support of their campus recreation departments and universities. This support could include additional resources such as time, money, personnel and equipment in order to accomplish their inclusive goals. This just goes to show how creating a welcoming and inclusive campus recreation environment for everyone was really a full campus community effort. Sharing resources, ideas, and initiatives is integral to creating a campus environment that is welcoming for any identity regardless of gender, color, creed, socioeconomic status, and disability. 
Future Research

The year 2015 marked the 25th anniversary of the Americans with Disabilities Act. While these laws have created a more inclusive environment and society in the United States, continued efforts to increase inclusive practices are still needed. A review of the literature about inclusive practices within campus recreation indicated campus recreation practices are not fully meeting the needs and desires of people with disabilities (Petersen \& Piletic, 2012; Piletic et al., 2014; Rimmer , 2005; Rimmer, et al., 2004; Rimmer \& Riley, 2006; Rimmer et al., 2005; Rimmer, et al., 2017; Ross \& Phillips, 1995; Roth \& Hudson, ,1994; Staeger-Wilson et al., 2012; Yoh et al., 2008; Young et al., 2016). However, many of the practitioners were able to dispel this notion. The campus recreation practitioners discussed how they were currently meeting the needs of people with disabilities and how many other campus recreation departments were able to do the same. Sharing information about inclusive practices and knowledge across the landscape of campus recreation is evident and research needs to show how this industry is working to be more inclusive. This research project is in an effort to do just that by exploring the current successful practices of inclusion used by campus recreation practitioners. This study provides insights on how campus recreation facilities and programs can improve on meeting the needs and desires of the underserved population of people with disabilities.

Many campus recreation programs comply with inclusive laws, but these programs do not necessarily meet the needs and desires of people with disabilities (Young et al., 2016). This study brings the issue of not meeting the needs of people with disabilities to the forefront and creates a better understanding on how to become more inclusive. This study utilized relatively larger institutions, and therefore the results are 
potentially transferable to any campus recreation program investigating their current inclusion efforts for people with disabilities.

Originally this study sought to investigate the current lived experiences of people with disabilities within the campus recreation setting. However, the researcher was unable to enlist enough people with disabilities to complete the intended study. The next step for the research will be to utilize the same institutions from this study but to instead investigate the lived experiences of the people with disabilities who use (or choose not to use) campus recreation programs and facilities. This will enable future researchers to create an understanding of the experiences from both the practitioner and the user perspectives. From this current and future study, a framework could be created to include people with disabilities in the decision-making processes, in keeping with CDT. This framework could easily translate into improving best practices for recreation facilities and programming in the campus setting and the private sector.

Additional research on best practices could lead to a systematic assessment process of the inclusive offerings of recreation centers. This study serves as the foundation to establish a necessary line to increase inclusive practices in the campus, sport, and social communities. Future research possibilities are countless as society becomes more and more accepting of differences. As society become more knowledgeable of different identities and variations of the human form, it is integral to design practices to be inclusive of every specific user. Therefore, this study can help develop practices for practitioners to create a more inclusive and welcoming environment for every variation of the human form. 


\section{Summary}

In summation, this study investigated the current practices of campus recreation professionals to create inclusive campus recreation programs, services, and facilities. This study was able to identify twelve campus recreation programs known by their peers and the industry to be at the forefront of providing inclusion efforts for people with disabilities. Through in depth discussions and interviews, many of the practitioners indicated how they utilized aspects of both Critical Disability Theory and Universal Design within their campus recreation facilities, services, and programs, Moreover, both of these theories are utilized in providing or creating new inclusive policies and initiatives for people with disabilities. In this sense, the practitioners are utilizing both Critical Disability Theory and Universal Design without fully knowing they are practicing these theories in their everyday lives.

The practitioners indicated a limited understanding of the concept of Universal Design, but few had an understanding of Critical Disability Theory. Many of the practitioners just understood the connection of their actions to these theories as best practices. Creating a campus recreation department to meet the needs and desires of all users starts from the mission statements with the goals of achieving the greatest amount of participation and to provide services to the entire campus community. Many programming initiatives are set up to meet the needs of all users and utilized the theory of Universal Design.

The involvement of people with disabilities in the decision-making process is integral in creating a truly inclusive campus recreation department. This process is being utilized by the campus recreation practitioners in order to identify what needs and desires 
are not currently being met. By involving people with disabilities in the decision-making process the campus recreation practitioners are following the Critical Disability Theory tenet of right of autonomy and self-determinacy. The campus recreation practitioners indicated how they utilized people with disabilities in the decision-making process because no one knows their needs better than themselves. This process also elicited buy in by the people with disabilities as they are now an integral part of the future of campus recreation on their campus. As new ideas were developed, many of the practitioners routinely asked people with disabilities if the ideas would be inclusive of them and if not, how can we make programming and services more accessible.

This flexibility and desire to cater to personal needs of individual users is the crux of how the campus recreation departments continue to provide an inclusive environment. All of the campus recreation practitioners in this study indicated how they did their best to accommodate any and all individual needs that are communicated. This spoke to both Critical Disability Theory and Universal Design but was truly intended to create a welcoming aspect to all users. This practice of accommodations can be utilized by any user whose needs are not currently being met. The campus recreation practitioners understand accommodation is integral in meeting their department's goals and objectives. Furthermore, accommodation actions advance the campus recreation department in meeting their mission statement of meeting the needs and desires of all users.

In conclusion, this study elicited a great conversation on the current inclusive environment of the campus recreation industry. The sites indicated in this study are considered some of the most inclusive programs in the United States. However, many of these inclusive initiatives are being practiced at a large number of campus recreation 
departments. The continued advancement of the inclusive practices in the campus recreation setting is integral in meeting the needs of the growing population of people with disabilities in the higher education setting. Furthermore, this study and the campus recreation industry as a whole, can set the example for other industries and settings to increase their inclusion efforts to create a more inclusive world. 


\section{REFERENCES}

A Policy Interpretation: Title IX and Intercollegiate Athletics, 44 C.F.R. § 239 (1979).

Access Equestrian. (n.d.) Adapted riding and horsemanship program. Retrieved from http://www.accessequestrian.org/index.html

ADA National Network. (2015). ADA: Findings, purpose, history. Retrieved from https://www.adaanniversary.org/2015/ada_findings_history_2015_adatoolkit.pdf

ADA National Network. (n.d.). An overview of the Americans with Disabilities Act. Retrieved from http://adata.org/factsheet/ADA-overview

Adapted Physical Education National Standards. (2008). What is adapted physical education. Retrieved from https://www.apens.org/whatisape.html

AE Networks. (2018). The U.S. Constitution. Retrieved from https://www.history.com/topics/constitution

American Therapeutic Recreation Association Certification. (2018). About recreational therapy. Retrieved from https://nctrc.org/about-ncrtc/about-recreational-therapy/.

Americans with Disabilities Act of 1990, 42 U.S.C. $§ 12181$, et seq., 2015. Arizona ex rel. Goddard v. Harkins Amusement Enterprises, 603 F.3d 666 (9th Cir. 2010).

Americans with Disabilities Act, 42 U.S. Code $§ 12132$ (1990).

Annells, M. (2006). Triangulation of qualitative approaches; Hermeneutical phenomenology and grounded theory. Journal of Advanced Nursing, 56(1), 5561.

Benhabib, S. (1992). Situating the self: Gender, community, and postmodernism in contemporary ethics. New York: Routledge.

Bill of Rights Institute. (2018). Bill of Rights of the United States of America (1791). Retrieved from https://www.billofrightsinstitute.org/founding-documents/bill-ofrights/ 
Blauwet, C., \& Willick, S.E. (2012) The Paralympic Movement: Using sports to promote health, disability rights, and social integration for athletes with disabilities. Academy of Physical Medicine and Rehabilitation, 4, 851-856.

Blick, R., Saad, A., Goreczny, A., Roman, K., \& Sorensen, C. (2015). Effects of declared levels of physical activity on quality of life of individuals with intellectual disabilities. Research in Developmental Disabilities, 37, 223-229.

Bloemen, M., Van Wely, L., Mollema, J., Dallmeijer, A., \& De Groot, J. (2017). Evidence for increasing physical activity in children with physical disabilities: A systematic review. Developmental Medicine \& Child Neurology, 59, 1004-1010.

Bodin, M., \& Hartig, T. (2003). Does the outdoor environment matter for psychological restoration gained through running? Psychology of Sport and Exercise, 4, 141153.

Bogdan, R., \& Taylor, S. J. (1994). The social meaning of mental retardation: Two life stories. New York: Teachers College

Bohlig, M. A. (1991). Recreational programming for women. Recreational Sports Journal, 16(1), 8-10.

Broadhag, K. (2012, May). New ADA requirements affect fitness facilities. Club Industry. Retrieved from http://clubindustry.com/design/new-ada-requirementsaffect-fitness- facilities

Burghardt, M. (2011). The human bottom of non-human things: On critical theory and its contributions to critical disability studies. Critical Disability Discourse, 7, 1-16.

Calder A.M., \& Mulligan H.F. (2014). Measurement properties of instruments that assess inclusive access to fitness and recreational sports centers: A systematic review. Disability Health Journal, 7(1), 26-35.

Calder, A., Sole, G., \& Mulligan, H. (2018). The accessibility of fitness centers for people with disabilities people with disabilities: A systematic review. Disability Health Journal, 11(4), 1-12.

Canha, L., Simoes, C., Gaspar Matos, M., \& Owens, L. (2016). Well-being and health in adolescents with disabilities. Psicologia: Reflexao e Critica, 29(32), 1-8.

Carroll, D., Courtney-Long, E. A., Stevens, A. C., Sloan, M. L., Lullo, C., Visser, S. N., $\&$ Centers for Disease Control and Prevention. (2014). Vital signs: Disability and physical activity - United States, 2009-2012. Morbidity and Mortality Weekly Report, 63(11), 407-413. 
Center for Universal Design. (2008). About UD: Universal Design history. Retrieved from http://www.ncsu.edu/ncsu/design/cud/about ud/udhistory.htm

Charlton, J. I. (1998). Nothing about us without us: Disability oppression and empowerment. Los Angeles, CA: University of California Press.

Chekola, M.G. (1975). The concept of happiness (Doctoral Dissertation, University of Michigan, 1974). Dissertation Abstracts International, 35, 4609A.

Cho, K. J. (2009). Relationship among participation types of sports for all, loneliness, and life satisfaction in physically handicapped people. Journal of Adapted Physical Activity, 17(3), 213-232.

ColoradoUniversity of Colorado. (2019). CU student rec center intramurals flag football rules. Retrieved from https://www.colorado.edu/recreation/sites/default/files/attached-files/football.pdf

Cottingham, M., Gearity, B., Goldsmith, A., Kim, W., \& Walker, M. (2015). A comparative analysis of factors influencing spectatorship of disability sport. Journal of Applied Sport Management, 7(1), 20-39.

Crenshaw, K. (1988). Race, reform, and retrenchment: Transformation and legitimation in anti- discrimination law. Harvard Law Review, 101 (7), 1331-1387.

Creswell, J. W. (2007). Qualitative inquiry and research design: Choosing among five approaches. Thousand Oaks, CA: Sage Publications.

Creswell, J. W. (2014). Research design: Qualitative, quantitative, and mixed methods approaches. Thousand Oaks, CA: Sage Publications.

Crockett, L. (2003). Adaptive snowsport instruction. Retrieved from http://www.thesnowpros.org/portals/0/News\%20and\%20Information/PSIAAdaptiveManual_2003_as_PDF.pdf

Culberson, C.E. (1977). A holistic view of joy in relation to psychotherapy derived from Lowen, Maslow, and Asagioli. (Doctoral Dissertation., California School of Professional Psychology, 1977). Dissertation Abstracts International, 28. 2853B.

Da Gama, G. (2000). Recreation and leisure as a content area of transition planning for students with disabilities: A review of five transition programs. Doctoral Dissertation. Minnesota: University of Minnesota. Retrieved from http://proquest.umi.com

Davis, L. J. (2001). Identity politics, disability, and culture. In G. L. Albrecht, K. D. Seelman, \& M. Bury (Eds.), Handbook of disability studies (pp. 535-545). Thousand Oaks, CA: Sage. 
Denzin, N. K. (1978). The research act: A theoretical introduction to sociological methods. New York: McGraw-Hill.

DePauw, K., \& Gavron, S. (1995). Disability and sport. Champaign, IL: Human Kinetics.

Diener, E., \& Seligman, M. E. P. (2004). Beyond money: Toward an economy of wellbeing. Psychological Science in the Public Interest, 5, $1-31$.

Diener, E., Ng, W., Harter, J. , \& Arora , R. ( 2010 ). Wealth and happiness across the world: Material prosperity predicts life evaluation, whereas psychosocial prosperity predicts positive feeling. Journal of Personality and Social Psychology, 99, $52-61$.

Disabled Sports USA. (n.d). Our Mission. Retrieved from https://www.disabledsportsusa.org/about/our-mission/

Douglas, P. (2005). Higher education: A complex microcosm of a complex society. Retrieved from http://conference.herdsa.org.au/2005/pdf/non_refereed/111.pdf

Dream adaptive. (2018). Dream adaptive recreation: History. Retrieved from http://www.dreamadaptive.org/outdoor-activities-for-the-disabled/

Dvorak, K. (2018, February 27). SMHS Office of Diversity and Inclusion holds educational session on Title IX. Retrieved from https://smhs.gwu.edu/diversity/news/smhs-office-diversity-and-inclusion-holdseducational-session-title-ix

Eastern Kentucky University. (2016, September 22). Campus rec launces adaptive climbing program. Retrieved from http://stories.eku.edu/people/campus-reclaunches-adaptive-climbing-program

Eckes, S.E. \& Ochoa, T.A. (2005). Students with disabilities: Transitioning from high school to higher education. American Secondary Education, 33(3), 6-20.

Edwards T.C., Patrick D.L., \& Topolski T.D. (2003). Quality of life of adolescents with perceived disabilities. Journal of Pediatric Psychology, 28(4), 233-241.

Faber College. (2018a). About us. Retrieved from https://www.pdx.edu/recreation/aboutus

Faber College. (2018b). Inclusive rec. Retrieved from https://www.pdx.edu/recreation/inclusive-rec

Fields, S. K. (2006). Intramural and club sports: The impact of Title IX. Journal of College and University Law, 33(3), 521-546. 
FindLaw. (2019). Title IX protections for transgender students. FindLaw. Retrieved from https://education.findlaw.com/discrimination-harassment-at-school/title-ixprotections-for-transgender-students.html

Finkler, L., \& Grant, J. (2011). Minimum separation distance bylaws for group homes: The negative side of planning regulation. Canadian Journal of Urban Research, 20, 33-56.

Fontaine, K. R. (2000). Physical activity improves mental health. The Physician and Sport Medicine, 28(10).

Forrester, S. (2014). The benefits of campus recreation. Corvallis, OR: NIRSA.

Frank, M.A., \& Gustafson, S. (2001). The reciprocal influence of self-esteem and exercise. Retrieved from http://www.behavioralconsultants.com/exercise_\&_selfesteem.htm.

French, D., \& Hainsworth, J. (2001). There aren't any buses and the swimming pool is always cold!': obstacles and opportunities in the provision of sport for disabled people. Manage Leisure, 6, 35-49.

Fried, G. (2015). Managing sport facilities. ( $3^{\text {rd }}$ ed) Champaign, IL: Human Kinetics: Champaign, IL.

Gleeson, B. (1999). Geographies of disability. London, England: Routledge.

Glesne, C. (2016). Becoming qualitative researchers: An introduction (5th ed.). Boston, MA: Pearson.

Gordon, R. (1990). New developments in legal theory. In D. Kairys (Ed.), The politics of law: A progressive critique (pp. 413-425). New York: Pantheon Books.

Greendale College (2018a). Inclusivity. Retrieved from https://rec.colostate.edu/inclusivity/

Greendale College (2018b). Inclusive facilities. Retrieved from https://rec.colostate.edu/inclusivity/inclusive-facilities/

Grigsby, K. (2008). Committee, taskforce, team: What's the difference? Why does it matter? Academic Physician \& Scientist. Retrieved from https://www.aamc.org/download/164730/data/grigsby_committee_task_force_tea m.pdf

Harbourne, E. (2016, June 26). Creating a new path for recreation at Arlen University. Retrieved from https://campusrecmag.com/creating-a-successful-new-path-forrecreation-at-missouri-state-university/ 
Hayman, R. L., \& Levit, N. (2002). Un-natural things: Constructions of race, gender, and disability. In F. Valdes, J. McCristal Culp, A. P. Harris (Eds.), Crossroads, directions, and a new critical race theory (pp. 157-186). Philadelphia: Temple University Press.

Higher Education Compliance Alliance. (n.d.). Compliance matrix. Retrieved from http://www.higheredcompliance.org/matrix/

Horkheimer, M. (1972 [1937]) Traditional and critical theory. In M. Horkheimer Critical theory: Selected essays. Translated from the German by MJ O'Connell et al. New York, NY: Herder.

Hosking, D.L. (2008). Critical disability theory. Proceedings of the $4^{\text {th }}$ Biennial Disability Studies Conference (pp. 1-17). United Kingdom: Lancaster University

Howard, T.C., \& Navarro, O. (2016). Critical race theory 20 years later: Where do we go from here? Urban Education, 51(3), 253-273.

Hums, M.A., Schmidt, S.H., Novak, A., \& Wolf, E.A. (2016). Universal Design: Moving the Americans with Disabilities Act from access to inclusion. Journal of Legal Aspects of Sport, 26, 36-51.

Institute for Human Centered Design. (2011). Museum of science: The user expert perspective; Universal Design consultation. Boston, MA: Author.

Institute for Human Centered Design. (2015a). History of Universal Design. Retrieved from http://www.humancentereddesign.org/universal-design/history-universaldesign

Institute for Human Centered Design. (2015b). Universal Design. Retrieved from http:// www.humancentereddesign.org/universal-design

International Paralympic Committee. (n.d.). Paralympics - History of the movement. Retrieved from https://www.paralympic.org/the-ipc/history-of-the-movement

Intramural Sport Rules. (2017). Retrieved from http://nirsa.net/nirsa/sport-rules/

Job Accommodation Network. (2017, September 1). Workplace accommodations: Low cost, high impact. Retrieved from https://askjan.org/media/downloads/LowCostHighImpact.pdf

Jones, H.M. (1953). The pursuit of happiness. Cambridge, MA: Harvard University Press. 
Judge, L.W. (2013). Designing strength and conditioning facilities. In T. H. Sawyer (Ed.), Facility planning and design for health, fitness, physical activity, recreation, and sport (13th ed.). Urbana, IL: Sagamore Publishing.

Kehn, M., \& Kroll, T. (2009). Staying physically active after spinal cord injury: A qualitative 8 exploration of barriers and facilitators to exercise participation. $B M C$ Pub Health, 9(9), 168-179.

Kesebir, P., \& Diener, E. (2008). In pursuit of happiness: Empirical answers to philosophical questions. Perspectives on Psychological Science, 3, $117-125$.

Kim, B. D., \& Kim, C. J. (2009). The effects of participation of people with disabilities in daily life sports on their confidence and daily life satisfaction. Journal of Adapted Physical Activity \& Exercise, 13(3), 161- 176.

Kim, B. D., \& Kim, C. J. (2009). The effects of participation of people with disabilities in daily life sports on their confidence and daily life satisfaction. Journal of Adapted Physical Activity \& Exercise, 13(3), 161- 176.

Kudlick, C. J. (2005). Disability history, power, and rethinking the idea of "the other". Modern Language Association, 120, 557-561.

Ladson-Billings, G. (1998). Just what is critical race theory and what's it doing in a nice field like education? International Journal of Qualitative Studies in Education, $11(1), 7-24$.

Ladson-Billings, G., \& Tate, W. F. (1995). Toward a critical race theory of education. Teachers College Record, 97, 47-68.

Landers, D.M. (1997). The influence of exercise on mental health. President's Council on Physical Fitness and Sports Research Digest, 2(12).

Legg, D., Fay, T., Hums, M.A, \& Wolff, E.A. (2009). Examining the inclusion of wheelchair exhibition events within the Olympic Games 1984-2004. European Sport Management Quarterly, 9, 243-258.

Leuchovius, D. (2003). ADA Q \& A... The ADA, Section 504 \& postsecondary education. Pacer Center action information sheets, PHP-c51g. Retrieved from http://www.pacer.org/publications/adaqa/504.asp

Leung, L., \& Lee, P. (2005). Multiple determinants of life quality: The roles of Internet activities use of new media, social support, and leisure activities. Telematics and Informatics, 22,161-180.

Liasidou, A. (2014). Critical disability studies and socially just change in higher education. Social Justice in Higher Education, 41(2), 120-135. 
Liegghio, M. (2013). A denial of being: Psychiatrization as epistemic violence. In B. LeFrancois, R. Menzies, \& G. Reaume (Eds.), Mad matters: A critical reader in Canadian mad studies (pp. 122-129). Toronto, Ontario: Canadian Scholars' Press.

Linton, S. (1998). Claiming disability: Knowledge and identity. New York: New York University Press.

Lyubomirsky, S., King, L., \& Diener, E. (2005). The benefits of frequent positive affect: Does happiness lead to success? Psychological Bulletin, 131, $803-855$.

Mahar, A. L., Cobigo, V., \& Stuart, H. (2013). Conceptualizing belonging. Disability \& Rehabilitation, 35, 1026-1032.

Make a Hero. (2014). World of adaptive sports. Retrieved from https://www.makeahero.org/adaptive-sports/world-of-adaptive-sports/

Malhotra, R. (2006). Justice as fairness in accommodating workers with disabilities and critical theory: The limitations of a Rawlsian framework for empowering people with disabilities in Canada. In D. Pothier, \& R. Devlin (Eds.). Critical disability theory: Essays in philosophy, politics, policy and law (pp. 70-86). Vancouver: UBC Press.

Malhotra, R., \& Rowe, M. (2014). Exploring disability identity and disability rights through narratives: Finding a voice of their own. London, England: Routledge.

Malone, H., Nicholl, H., \& Tracey, C. (2014). Awareness and minimization of systemic bias in research. British Journal of Nursing, 23(5), 279-282.

Marshall, M. N. (1996). Sampling for qualitative research. Family Practice, 12(6), 522525.

Martin Ginis, K. A., Ma, J. K., Latimer-Cheung, A. E., \& Rimmer J. H. (2016). A systematic review of review articles addressing factors related to physical activity participation among children and adults with physical disabilities. Health Psychology Review, 5, 1-31.

Maurer, B. L. (Eds.). (2015). 2015 \& 2016 NIRSA flag \& touch football rules book \& officials' manual (17th ed.). Champaign, IL: Human Kinetics

McCarron, J. (2000, May 1). The repercussion of reparations. Chicago Tribune. Retrieved from http://articles.chicagotribune.com/2000-0501/news/0005010113_1_reparations-movement-affirmative-action-africanamericans 
McDonnell, A. (2006, November). Cardio equipment for special populations: Fitness management. Athletic Business. Retrieved from

http://www.athleticbusiness.com/articles/article. aspx?articleid=3094\&zoneid=42

McDowell, J., Deterding, R., Elmore, T., Morford, E., \& Morris, E. (2016). Title IX and campus recreation: Guidelines to increase gender equity in club and intramural sports programs. Recreational Sports Journal, 40(2), 133-151.

Merriam, S. B. (2009). Qualitative research: A guide to design and implementation. San Francisco, CA: Jossey-Bass.

Mgulwa, N.N., \& Young, M. E. M. (2014). University sports administrators' perceptions on campus recreation services for students with physical disabilities. Journal of Community \& Health Sciences, 9(1), 9-20.

Mid-Atlantic ADA Center. (2018). History of the ADA. Retrieved from http://www.adainfo.org/content/history-ada

Miller, D. (January 14, 2018). University of Alabama Adapted Athletics opens StranHardin Arena. Retrieved from http://alabamanewscenter.com/2018/01/14/uaadapted-athletics-opens-stran-hardin-arena/

Mull, R.F., Forrester, S.A., \& Barnes, M.L. (2013). Recreational sport programming (5th ed.). Urbana, IL: Sagamore Publishing.

Mulligan, H., Hale, L., Whitehead, L., \& Baxter, G. (2012). Barriers to physical activity for people with long-term neurological conditions: a review study. Adaptive Physical Activity Quarterly, 29, 243-265.

National Center for Education Statistics (2016). Students with disabilities. Retrieved from https://nces.ed.gov/fastfacts/display.asp?id=60

National Disability Authority. (2014a). What is Universal Design. Retrieved from http://universaldesign.ie/What-is-Universal-Design/

National Disability Authority. (2014b). History of UD. Retrieved from http:// http://universaldesign.ie/What-is-Universal-Design/History-of-UD/

National Disability Authority. (2014c). The seven principles of Universal Design. Retrieved from http:// www.universaldesign.com/universal-design/1761-theseven-principles-of-universal- design.html

National Intramural-Recreational Sports Association. (n.d.) Core beliefs. Retrieved from http://nirsa.net/nirsa/about/strategic-plan/ 
Nemcek, D. (2016). Quality of life of people with disabilities: Differences in satisfaction with indicators and domains between active and inactive individuals. Physical Activity Review, 4, 62-71.

Nemček, D., Labudová, J. \& Oršulová, N. (2014). Self-Esteem in people with disabilities. Acta Facultatis Educationis physicae Universitatis Comenianae, 54(2), 33-42.

NIRSA Championship Series. (2017). It's more than competition. Retrieved from http://play.nirsa.net/nirsa-championship-series/

NIRSA. (2013). Campus recreational sports: Managing employees, programs, facilities, and service. Champaign, IL; Human Kinetics.

NIRSA. (2019a). NIRSA history. Retrieved from https://nirsa.net/nirsa/about/history/

NIRSA. (2019b). NIRSA mission. Retrieved from https://nirsa.net/nirsa/about/missionvision/

NIRSA. (July 10, 2017). RSJ highlights: Transgender policies in recreation. Retrieved from https://nirsa.net/nirsa/2017/07/10/whats-new-in-the-rsj/

O’Neill, J. (1976). Critique and Remembrance. In J. O’Neill (Ed.), On critical theory (pp. 1-11). New York: Continuum.

O’Neill, J. (2004). Five bodies: Refiguring relationships. London: Sage.

Oishi, S., \& Schimmack, U. (2010). Culture and well-being: A new inquiry into the psychological wealth of nations. Perspectives on Psychological Science, 5, $463-$ 471.

Oliver, M. (1996). Understanding disability: From theory to practice. New York, NY: St. Martin's Press.

Pagan, R. (2015). How do leisure activities impact on life satisfaction? Evidence for German people with disabilities. Applied Research Quality Life, 10, 557-572.

Parks, A.C. \& Smith, B. (2014). Qualitative research methods in sport, exercise and health. From process to product. London: Routledge.

Pavot, W. \& Diener, E. (1993). Review of the satisfaction with life scale. Psychological Assessment, 5, 164-72.

Pavot, W. \& Diener, E. (1993). Review of the satisfaction with life scale. Psychological Assessment, 5, 164-72. 
Petersen, J., \& Piletic, C. (2012). University fitness center accessibility: An assessment via the AIMFREE instrument. Research Quarterly for Exercise and Sport, 83(1).

Piletic, C., Judge, L.W., \& Petersen, J.C. (2014). Creating ADA accessible strength and conditioning facilities: The impact of the new 2010 standards. Journal of Facility Planning, Design, and Management, 1(1), 35-46.

Pollio, H. R., Henley, T. B., \& Thompson, C. J. (1997). The phenomenology of everyday lift. Cambridge: University Press.

Procknow, G., Rocco, T.S., \& Munn, S.L. (2017) (Dis)Abling notions of authentic leadership through the lens of critical disability theory. Advances in Developing Human Resources, 19(4), 362-377.

Pufahl, A. E. (1987). Title IX: Boon or bust to intramural programs. NIRSA Journal, $11(2), 48-56$.

Richardson, E.V., Smith, B.M., \& Papathomas, A. (2016). Disability and the gym: Experiences, barriers and facilitators of gym use for individuals with physical disabilities. Disability and Rehabilitation, 39(19), 1950-1957.

Rimmer, J, Chen, M., \& Hsieh, K. (2011). A conceptual model for identifying, preventing, and managing secondary conditions in people with disabilities. Physical Therapy. 91(12), 1728-1739.

Rimmer, J. (2005a). Exercise and physical activity in persons aging with a physical disability. Physical Medicine and Rehabilitation Clinics of North America, 16, $41-56$.

Rimmer, J. (2005b). The conspicuous absence of people with disabilities in public fitness and recreation facilities: lack of interest or lack of access? American Journal of Health Promotion, 19(5), 327-329.

Rimmer, J. H., Riley, B., Wang, E., \& Rauworth, A. (2004). Development and validation of AIMFREE: Accessibility instruments measuring fitness and recreation environments. Disability and Rehabilitation, 26(18), 1087-1095

Rimmer, J., \& Riley, B. (2006). Accessibility instruments measuring fitness and recreation environments: Professional version. Chicago, IL: RECTECH

Rimmer, J., \& Rowland, J. (2008). Physical activity for youth with disabilities: A critical need in an underserved population. Dev Neurorehabil, 11(2), 141-148.

Rimmer, J., Chen, M., \& Hsieh, K. (2011). A conceptual model for identifying, preventing, and managing secondary conditions in people with disabilities. Physical Therapy. 91(12), 1728-1739. 
Rimmer, J., Padalabalanarayanan, S., \& Malone, L.A. (2017). Fitness facilities still lack accessibility for people with disabilities. Disability and Health Journal, 10, 214221.

Rimmer, J., Riley, B., Wang, E., \& Rauworth, A. (2005) Accessibility of health clubs for people with mobility disabilities and visual impairments. American Journal of Public Health, 95(11), 2022-2028.

Rocco, T. S. (2005). From disability studies to critical race theory: Working towards critical disability theory. In R. J. Hill \& R. Kiely (Eds.), Proceedings of the 46th Annual Adult Education Conference (pp. 369-374). Athens, GA: The University of Georgia.

Rocco, T. S. (2006). Disability as an issue of marginalization. In S. Merriam, B. Courtenay, \& R. Cervero (Eds.), Global issues in adult education: Perspectives from Latin America, Southern Africa, and the United States (pp. 169-181). San Francisco, CA: Jossey-Bass.

Rocco, T. S., \& West, G. W. (1998). Deconstructing privilege: An examination of privilege in adult education. Adult Education Quarterly, 48, 171-184.

Rolfe, D., Yoshida, K., Renwick, R., \& Bailey, C. (2007). Beyond barriers: Women living with disabilities and their participation in community exercise programs. Retrieved from: http://stargate.uwaterloo.ca/ jzelek/teaching/ syde361/ficcdat2007/Full\%20Papers/GOWD/G0052.pdf.

Ross, C.M., \& Phillips, R. (1995). The Americans with Disabilities Act (ADA) and its impact on recreational sports facilities. NIRSA Journal, 19(3), 38-43.

Roth, D., \& Hudson, S.D. (1994). The impact of the Americans with Disabilities Act on recreational sports programs. NIRSA Journal, 18(3), 22-25.

Rush, F. (2004). Conceptual foundations of early critical theory. In F. Rush (Ed.), The Cambridge companion to critical theory (pp. 6-39). Cambridge: Cambridge University Press.

Sacks, G., \& Kern L. (2008). A comparison of quality of life variables for students with emotional and behavioral disorders and students without disabilities. Journal of Behavioral Education, 17, 111-27.

Sandvik, E., Diener, E., \& Seidlitz, L. (1993). Subjective well-being: The convergence and stability of self-report and non-self-report measures. Journal of Personality, $61,317-342$. 
Schneider, R. C., Stier, W. F., \& Kampf, S. (2014). Gender equity perceptions related to college and university campus recreation programs. Recreational Sports Journal, $38(1), 2-13$.

Sex, 20 U. S. C. $\$ 1681$ (1972).

Sheared, V. (1999). Giving voice: Inclusion of African American students' polyrhythmic realities in adult basic education. In T. C. Guy (Ed.), New directions for adult and continuing education: No. 82: Providing culturally relevant adult education: A challenge for the twenty-first century (pp. 33-48). San Francisco, CA: JosseyBass.

Sheldon, K. M., Cheng, C., \& Hilpert, J. (2011). Understanding well-being and optimal functioning: Applying the Multilevel Personality in Context (MPIC) model. Psychological Inquiry, 22, 1 - 16.

Shields, N., \& Synnot, A. (2016). Perceived barriers and facilitators to participation in physical activity for children with disability: A qualitative study. BMC Pediatrics, 16(9), 1-10.

Simons, J. (2002). Immanuel Kant (1724-1804). In J. Simons (Ed.), From Kant to Levi Strauss: The background to contemporary critical theory (pp. 17-32). Edinburgh: Edinburgh University Press.

Simons, J. (2004). Introduction. In J. Simons (Ed.), Contemporary critical theorists: From Lacan to Said (pp. 1-17). Edinburgh: Edinburgh University Press.

Smeddema, S.M., Cardoso, E.D., Chan, F., Dutta, A., Muller,V., Keegan, J., Ebener, D.J., \& Yaghmaian, R.A. (2015). The relationship of core self-evaluations and life satisfaction in college students with disabilities: Evaluation of a mediator model. Journal of Postsecondary Education and Disability, 28(3), 341-358.

Smith, B., and A. C. Sparkes. (2016). Routledge handbook of qualitative research in sport and exercise. London: Routledge.

Smith, P.B., Ahmad, A.H., Owe, E., Celikkol, G.C., Ping, H., Gavreliuc, A., Chobthamkit, P., Rizwan, M., Chen, S.X., Teh, H.B., \& Vignoles, V.L. (2016). Nation-level moderators of the extent to which self-efficacy and relationship harmony predict students' depression and life satisfaction: Evidence from 10 cultures. Journal of Cross-Cultural Psychology, 47(6), 818-834.

Soffer, M., \& Almog-Bar, M.. (2016). Therapy or human right? The meaning of recreation for children and youth with disabilities in the "Krembo Wings" youth movement. Disability and Health Journal, 9, 399-405. 
Special Olympics. (2016). Equestrian sport rules. Retrieved from https://media.specialolympics.org/resources/sports-essentials/sportrules/Equestrian-Sports-Rules.pdf

Special Olympics. (2019). Unified sports. Retrieved from https://www.specialolympics.org/our-work/sports-and-games/unifiedsportshttps://www.specialolympics.org/our-work/sports-and-games/unified-sports

Staeger-Wilson, K., Barnett, C., Mahoney, S., \& Sampson, D.H. (2012). Planning for an inclusive campus recreation facility and program. Recreational Sports Journal, $36,37-44$.

Stewart, R. E. (1993). A brief history of the intramural movement. Recreational Sports Journal, 17(1), 12-14.

Stier, W.F., Schneider, R.C., Kampf, S., Wilding, G.E., \& Haines, S.G. (2006). Current hiring practices of campus recreation directors of NIRSA institutions. Recreational Sport Journal, 30, 100-115.

Strunk, B. (March 7, 2019). Hiring the best in any position. Campus Rec Magazine. Retrieved from https://campusrecmag.com/hiring-the-best-in-any-position/

Swords, J. (2019). Grassroots activism: Make that change. ThoughtWorks. Retrieved from https://www.thoughtworks.com/insights/blog/grassroots-activism-makechange

Tatarkiewicz, W. (1976). Analysis of happiness. The Hague, Netherlands: Martinus Nijhoff.

Tay, L., \& Diener, E. (2011). Needs and subjective well-being around the world. Journal of Personality and Social Psychology, 101, 354-365.

Texas A\&M. (n.d). Mission. Retrieved from http://recsports.tamu.edu/about-us-2/

Tharp, L. R. (1994). The effect Title IX has had on intramural sports. NIRSA Journal, 19(1), 29-31.

Toepoel,V. (2013). Aging, leisure and social connectedness: How could leisure help reduce social isolation of older people? Social Indicators Research, 113, 355372.

Tov, W., \& Diener, E. (2013). Subjective well-being. Research Collection School of Social Sciences. Paper 1395. Retrieved from http://ink.library.smu.edu.sg/soss_research/1395

Tov, W., \& Diener, E. (2013). Subjective well-being. The Encyclopedia of CrossCultural Psychology, 1, 1-7. 
United States Access Board. (2004). Americans with Disabilities Act and Architectural Barriers Act accessibility guidelines. Retrieved from http://www.wbdg.org/ccb/ASTAND/ ada aba.pdf

United States Access Board. (n.d.). Guide on sports facilities. Retrieved from http://www. access-board.gov/guidelines-and-standards/recreation-facilities/guides/sportsfacilities

United States Department of Justice. (2010). Fact sheet: Adoption of the 2010 Standards for Accessible Design. Retrieved from https://www.ada.gov/regs2010/factsheets/2010_Standards_factsheet.html

United States Department of Justice. (n.d.) 1991 ADA Standards for Accessible Design. Retrieved from http://www.ada.gov/1991ADAstandards_index.htm.

University of Kansas. (2018). Inclusive Recreation Extravaganza. Retrieved from https://recreation.ku.edu/inclusive-recreation-extravaganza

US Census Bureau. North American Industry Classification System Code (NAICS) 713940. [cited 201210 May]. Available from: http:// www.census.gov/epcd/ec97/def/713940.HTM; 2012.

US Department of Justice. (2009). A guide to disability rights laws. Retrieved from https://www.ada.gov/cguide.htm\#anchor65610

US Department of Justice. (2010). 2010 ADA standards for accessible design. Retrieved from https://www.ada.gov/regs2010/2010ADAStandards/2010ADAstandards.htm

Veselinova, C. (2013). Understanding physical disability. Nursing \& Residential Care, 15(3), 161-164.

Watchorn, V., Larkin, H., Hitch, D., \& Ang, S. (2014). Promoting participation through the universal design of built environments: Making it happen. Journal of Social Inclusion, 5(2), 65-88.

Watson, S.M.R., \& Keith, K.D. (2002). Comparing the quality of life of school-age children with and without disabilities. Mental Retardation, 40, 304-12.

Wegner, J.W. (1984). The antidiscrimination model reconsidered: Ensuring equal opportunity without respect to handicap under section 504 of The Rehabilitation Act of 1973. Cornell Law Review, 69(3).

Willhite, B. \& Shank, J. (2009). In praise of sport: Promoting sport participation as a mechanism of health among persons with a disability. Disability and Health Journal, 2, 116-127. 
Wimpenny, P. \& Gass, J. (2000). Interviewing in phenomenology and grounded theory: Is there a difference? Journal of Advanced Nursing, 31(6), 1485-1492.

Wood, Z. (2014). Administrator perceptions of intramural coed flag football modifications: A qualitative analysis (Doctoral dissertation). Retrieved from WorldCat. (898281079)

Wood, Z. C. \& Garn, A. C. (2016). Leveling the playing field? Perspectives and observations of coed intramural flag football modifications. Sociology of Sport Journal, 33(3), 240-249.

World Health Organization. (2006). Diet and physical activity: A public health priority Retrieved from http://www.who.int/dietphysicalactivity/en/.

World Health Organization. (2018ab). WHO definition of health. Retrieved from http://www.who.int/suggestions/faq/en/

World Health Organization. (2018ba). WHOQOL: Measuring quality of life. Retrieved from http://www.who.int/healthinfo/survey/whoqol-qualityoflife/en/

Wright, S.A., \& Titus, S. (2013). Experiences and perceptions of students with disabilities concerning factors influencing participation in recreation sport at a university in the Western Cape Province, South Africa. African Journal for Physical, Health Education, Recreation and Dance, 19(4 Part2): 1146-1157.

Yin, R. K. (2009). Case study research: Deign and method (4th ed.). Thousand Oaks, CA: Sage.

Yoh, T., Mohr, M., \& Gordon, B. (2008). Assessing satisfaction with campus recreation facilities among college students with physical disabilities. Recreational Sports Journal, 32 .

Young, S.J., Ramos, W. D., York, S.L., \& Fletcher, A.L. (2016). On the $25^{\text {th }}$ anniversary of the ADA: How inclusive are campus recreation programs? Journal of Legal Aspects of Sport, 26, 22-25.

Zwinkels, M., Verschuren, O., Balemans, A., Lankhorst, K., te Velde, S., van Gaalen, L., de Groot, J., Visser-Meily, A., \& Takken, T. (2018). Effects of a school-based sports program on physical fitness, physical activity, and cardiometabolic health in youth with physical disability: Data from the Sport-2-Stay-Fit study. Frontiers in Pediatrics, 6(75), 1-11. 


\section{Appendix A - Interview Guide}

\section{Campus Recreation Practitioners Questions.}

1. Tell me about how your campus recreation department promotes an inclusive and diverse campus climate? (Rocco, 2002; Schelly, Davies \& Spooner, 2009?)

2. How do your campus recreation department programs and services meet the needs of people of all abilities? Patrons with disabilities? (UD and CDT)

3. How did your campus recreation program develop your inclusive practices? (Rocco, 2002)

a. Who was involved in the decision making for your inclusive practices?

4. How would you improve the inclusive practices of your campus recreation program? 
Appendix B - Question Grid

Research Questions/Interview Questions Grid

\begin{tabular}{|l|c|c|c|c|c|}
\hline & Q & Q & Q & Q & Q \\
\hline $\begin{array}{l}\text { RQ 1: How do campus } \\
\text { recreational practitioners } \\
\text { perceive the } \\
\text { inclusiveness of their } \\
\text { facilities, programs, and } \\
\text { services? }\end{array}$ & X & X & X & X & X \\
\hline $\begin{array}{l}\text { RQ 2: How do campus } \\
\text { recreation professionals } \\
\text { determine and create } \\
\text { their inclusive practices? }\end{array}$ & $\mathrm{X}$ & $\mathrm{X}$ & $\mathrm{X}$ & $\mathrm{X}$ & $\mathrm{X}$ \\
\hline
\end{tabular}




\title{
CURRICULUM VITAE
}

\section{EDUCATION}

\author{
Tyler C. Spencer
}

Ph.D. University of Louisville

Educational Leadership, Evaluation and

Organizational Development

Specialization: Sport Administration

Dissertation: Campus recreation inclusion for people with disabilities: A case study investigation of current inclusive practices (Chair: Dr. Mary A. Hums

M.Ed. University of South Florida

College Student Affairs

B.S. Western Kentucky University

Recreation Administration Major

Facility and Event Management Minor

Outdoor Leadership Minor

Academic Positions

St. Ambrose University, Kinesiology Department

Assistant Professor

Courses: KIN 307 Sport Facilities and Event Management

August 2019 to present

KIN 335 Sport and Society

KIN 408 Capstone in Sport Management

Advise undergraduates students

Develop and market the Capstone Event-Sport Industry Insider

University of Louisville, Sport Administration Program

Graduate Teaching Assistant

August 2016 to present

Courses: SPAD 605 Graduate Sport Facility Management

SPAD 605.50 Graduate Sport Facility Management (Online)

SPAD 405 Sport Facility Management

SPAD 360 Campus Recreation and Intramural Activities

HHS 138, Basketball

HHS 114, Fitness Walking 
Primary research assistant for Dr. Evan Frederick

Assisted Dr. Mary Hums on Sport Governance book

Assisted Dr. Chris Greenwell on Event Management book

Provided assistance to Faculty as needed with additional research and duties

Lead student trips and assist with SPAD Association

Western Kentucky University, Kinesiology, Recreation and Sport Dept.

Adjunct Faculty

May 2011 to October 2011

Courses: REC 235 Outdoor Skills

PE 300 Introduction to Outdoor Skills

Graduate Teaching Assistant

Summer 2008, 2009

Course: PE 300 Introduction to Outdoor Skills

University of South Florida, P.E. Dept.

Teaching Assistant

Fall 2009

Course: PE CPR and First Aid

\section{RESEARCH}

\section{$\underline{\text { Refereed Publications }}$}

Pond, A., Cocco, A. \& Spencer, T.C. (in review). Road back to glory: How the NCAA Football video game franchise could make a comeback. Sage Business Cases.

Spencer, T.C., \& Greenwell, T.C. (in review). Fan reaction to franchise relocation: An analysis of the St. Louis Rams relocation to Los Angeles. Submitted to Sport Marketing Quarterly.

Lee, S., Spencer, T.C., Hums, M.A., \& Alagaraja, M. (in review). Qualitatively exploring international graduate students' experiences with campus recreation services. Submitted to Recreational Sports Journal.

Spencer, T.C., \& Hambrick, M.E. (in press). The decision by Western Kentucky University to transition to NCAA Division I athletics and the Football Bowl Subdivision. Sage Business Cases.

Cocco, A. \& Spencer, T.C. (in press). Path to the Pros: How Major League Soccer is revolutionizing youth player development in the United States. Sage Business Cases.

Schmidt, S. H., Frederick, E. L., Pegoraro, A., \& Spencer, T. C. (in press). An analysis of Kaepernick, Rapinoe, and the National Anthem protests. Communication and Sport.

\section{$\underline{\text { Book Chapters }}$}


Hums, M.A. \& Maclean, J. (in press). Governance and policy in sport organizations. $\left(4^{\text {th }}\right.$ ed.). Assisted with Chapter 7 Campus Recreation

Research in Progress

Spencer, T.C. (in preparation). Campus recreation inclusion for people with disabilities: A case study investigation of current inclusive practices. Dissertation. Gathering Data anticipated defense date November 2019.

Shreffler, M., Greenwell, C., \& Spencer, T.C. (in preparation). Understanding quality attributes that predict service value and word of mouth for two minor-league sports.

\section{Scholarly Presentations}

Spencer, T.C. \& Jones, C. (2020). Campus recreation inclusion for people with disabilities: A case study investigation of current inclusive practices. Applied NIRSA National Conference, Phoenix, AZ.

Lee, S., Spencer, T.C., Hums, M.A., \& Alagaraja, M. (2019). Qualitatively exploring international graduate students' experiences with campus recreation services. North American Society for Sport Management Conference, New Orleans, LA.

Cocco, A., Spencer, T.C., \& Police, C. (2019). The Neymar effect: How soccer's biggest transfer has impacted player valuation in England's Premier League. Applied Sport Management Association Conference, Nashville, TN.

Spencer, T.C. (2018). Fan identity after relocation: An analysis of the fan reaction to the Rams and the National Football League after the organization relocated to Los Angeles. Sport Marketing Association Conference, Frisco, TX.

Spencer, T.C. (2018). Intramural Rules Modifications for Co-Ed Sports: Legal Implication under Title IX. Sport Recreation and Law Association Conference, San Antonio, TX.

Cocco, A. \& Spencer, T.C. (2018). Path to the Pros: How Major League Soccer is revolutionizing youth player development in the United States. Spring Research Conference, Louisville, KY

Schmidt, S. \& Spencer, T.C. (2017). An analysis of Colin Kaepernick, Megan Rapinoe and the national anthem protest. NASSM Conference, Denver, CO

Spencer, D. \& Spencer, T.C. (2017). WV, VA, \& KY: Capitalizing on Trail Systems to Create Economic Growth. International Trail Symposium, Dayton, $\mathrm{OH}$

Spencer, S., Spencer, T.C., \& Bartlett, L. (2008, February) ACA Canoe Instructor Workshop. National Wilderness Education Association Conference, San Diego, CA 
Guest Lectures

SPAD 390 Sport Governance, Title - Campus Rec Governance, University of Louisville, Fall 2016, Spring 2017

SPAD 382 Organizational Behavior in Sport, Title - Team Development, University of Louisville, Fall 2016, Spring 2017

REC 200 Introduction to Recreation, Title - Careers in Campus Recreation, Western Kentucky University, Fall 2013

\section{$\underline{\text { SERVICE }}$}

University Service

Title IX Hearing Board, University Representative and Case Chair 2014-2016

Western Carolina University Programming Committee 2015-2016

Student Affairs Leadership Committee 2014-2016

Student Leadership Banquet Planning Team 2014-2015

Member of The KU Hazing Prevention and Task Force 2011-2014

Department Service

Faculty lead for Capstone Sport Industry Insider Networking Event 2019-Present

Search Committee for Sport Management Faculty Member 2019-Present

Perspective Sport Management Student Meetings 2019-Present

Co-Coordinator, COSMA Accreditation, University of Louisville Spring 2018-2019

HSS Student Engagement Committee Fall 2016-2019

Master of Sport Administration Applicant Interviews Fall 2016-2019

Search Committee Chair for Associate Director of Outdoor Programs Spring 2016

Departmental Chair for Campus Recreation Advisory Board 2015-2016

Search Committee Chair for Facilities Operations Coordinator Summer 2012

Search Committee for Assistant Director of Facilities Spring 2011

Planning Committee for Campus Recreation Center Expansion 2010-2011

Search Committee for Intramural Coordinator Summer 2008

Planning Committee for Preston Center Expansion 2008

Professional Service

2018 NFL Draft Volunteer on Red Carpet/Guest Services 2018

NFL Sustainability Green Team for Super Bowl LII 2018

NCCS Flag Football National Championships Operation committee 2010-2018

NIRSA Annual Conference Career Opportunities Center Volunteer and Resume

Reviewer 2011-2014

WKU Flag Football Regional Host Committee 2005-2014

Community Service 
Volunteer (Shuttle and Logistics) Tuck River Clean Up 2015, 2016

Coached Youth Football Team, Lawrence Hurricanes to 27-3 record 2012-2014

Volunteered for Annual 400 Mile Yard sale 2011

\section{PROFESSIONAL DEVELOPMENT WORKSHOPS}

Attended workshops presented by the Delphi Center for Teaching and Learning:

- Building your Teaching Philosophy

- Dissertation Boot camp

- Literature search for a literature review: Using the library and other resources to find literature for a literature review

- Delphi U Principles of Online Course Design

- Mental Health First Aid Certification Workshop November,

\section{$\underline{\text { SPORT INDUSTRY EXPERIENCE }}$}

Western Carolina University, Campus Recreation

Associate Director

2014-2016

- Served as a member of the CRW Senior Leadership Team and acted on behalf of the Director in her absence

- Supervised 3 full-time Building and Environmental Service Technicians and 2 Graduate Coordinators, as well as 60 student staff

- Recruited, hired, trained, evaluated, and managed the day-to-day staffing operations of the Campus Recreation Center and Reid Pool

- Developed and managed a comprehensive student development plan for CRW student staff.

- Managed both informal and scheduled activity supervision of the Campus Recreation Center and Reid Pool

- Developed and manage a comprehensive risk management plan and standardized safety practices for the department

- Scheduled, supervised, and instructed departmental and campus/community Health and Safety classes

- Oversaw the Aquatics program, including community and campus partnerships as well as formal and informal programming

- Oversaw the Informal Recreation program, including equipment and locker checkout

- Assisted in the planning, implementation and evaluation of strategic initiatives and activities related to the department

- Organized departmental marketing efforts by coordinating efforts with the student graphic designer and managed marketing for department-wide efforts

- Served as Co-Race Director for Valley of the Lilies Half Marathon and 5k

University of Kansas, Recreation Services 
Sport Clubs and Special Events Coordinator

2011-2014

- Oversaw the management of the Rec Services Special Events, scheduling, Sport Club Program, 34 clubs, 1,100 student athletes, 6-person staff, and special event staff

- Managed $\$ 180,000$ operating budget

- Acted as University representative with community groups, marketing firms, and local government to provide facilities for revenue generating events

- Collaborated with Facility Services, Custodial Services, Student Judicial, Athletics, and Physical Education to provide excellent services to the KU community

- Oversaw administrative paperwork, record keeping, and budget

- Enforced all policies, procedures, and conducted disciplinary meetings

- Taught monthly CPR/AED classes for student staff

- Advised the student run Sport Club Council

- Generated \$237,551 for Sport Club fundraising

- Served as hiring chair for the Facility Operations Coordinator position

University of South Florida, Campus Recreation

Sport Clubs Graduate Assistant/Facilities Intern

2009-2011

- Recruited, hired, trained, supervised, evaluated, and mentored the undergraduate student staff

- Created, revised, implemented, and enforced all policies of the Sport Clubs program

- Scheduled campus recreation facilities for club practices and events

- Promoted student development by teaching managerial and leadership skills to student staff

- Met with advisors and coaches/instructors

- Advised the student run Sport Club Council

- Reviewed daily facility reports and identified reoccurring issues that needed addressing

- Scheduled the maintenance and supervision of the Campus Recreation Center

- Collaborated with Associate Directors to develop new forms and procedures

- Assisted in the development of a facility expansion phasing plan

- Supported the day to day operations of the Campus Recreation Center

- Oversaw schedule and payroll of student staff

Seattle University, Recreational Sports

Intern

2010-2010

- Scheduled 2010-11 Calendar for Intramural, Sport Club, and Varsity Athletics 
- Received in depth training using Event Management Systems

- Assisted with planning and design for building expansion

- Developed new forms and signs for Campus Recreation use

- Supervised the Connolly Center and day to day operations

- Shadowed Campus Recreation Director and his responsibilities

The Pennsylvanian State University, Athletics

Intern

2009-2009

- Assisted with the management of 70 club sports

- Oversaw and planned club events, meetings, and trainings

- Manned the club sport informational desk and assisted clubs with operations

- Prepared Multi-Sport building for NCAA Fencing National Championship

- Assisted with the basic operation of NCAA Fencing National

Championship

\section{HONORS AND AWARDS}

William N. Wasson Student Leadership and Academic Award 2008

NIRSA Region II Excellence Grant Award 2008

\section{PROFESSIONAL AFFILIATIONS}

National Intramural Recreational Sports Association

North American Society for Sports Management

Sport Recreation Law Association

CERTIFICATIONS

Delphi U: Principles of Online Course Design

CITI Program IRB Certification

American Red Cross CPR/AED/First Aid Instructor

American Red Cross Lifeguard

American Red Cross Lifeguard Instructor

CPR/First Aid/AED

NIMS National Incident Management

Mental Health First Aid

Leave No Trace Master Educator

American Canoe Association Instructor 